Florida International University FIU Digital Commons

6-20-2011

\title{
Predicting Hurricane Evacuation Decisions: When, How Many, and How Far
}

Lixin Huang

Florida International University, lixin_huang@hotmail.com

DOI: $10.25148 /$ etd.FI1 1081005

Follow this and additional works at: https://digitalcommons.fiu.edu/etd

\section{Recommended Citation}

Huang, Lixin, "Predicting Hurricane Evacuation Decisions: When, How Many, and How Far" (2011). FIU Electronic Theses and Dissertations. 461.

https://digitalcommons.fiu.edu/etd/461 


\section{FLORIDA INTERNATIONAL UNIVERSITY}

Miami, Florida

\section{PREDICTING HURRICANE EVACUATION DECISIONS: \\ WHEN, HOW MANY, AND HOW FAR}

A dissertation submitted in partial fulfillment of the

requirements for the degree of

DOCTOR OF PHILOSOPHY

in

CIVIL ENGINEERING

by

Lixin Huang 


\section{To: Dean Amir Mirmiran}

\section{College of Engineering and Computing}

This dissertation, written by Lixin Huang, and entitled Predicting Hurricane Evacuation Decisions: When, How Many, and How Far, having been approved in respect to style and intellectual content, is referred to you for judgment.

We have read this dissertation and recommend that it be approved.

Mohammed Hadi

Zhenmin Chen

L. David Shen, Co-Major Professor

Albert Gan, Co-Major Professor

Date of Defense: June 20, 2011

The dissertation of Lixin Huang is approved.

Dean Amir Mirmiran

College of Engineering and Computing

Interim Dean Kevin O'Shea

University Graduate School

Florida International University, 2011 


\section{DEDICATION}

I dedicate this dissertation to my dear wife, Shanghong Ding, for her love, understanding, and constant support; to my lovely son, Yuliang Huang; and to my father, Wenxuan Huang, and my mother, Yinghua Zhang, for their love and encouragement. 


\section{ACKNOWLEDGMENTS}

I would like to express my deepest gratitude and sincere appreciation to Dr. Albert Gan for his valuable guidance and encouragement throughout my doctoral study. His invaluable advice made the dissertation process go smoothly when I had difficulties in developing the models. I feel privileged in expressing my sincere thanks for devoting his precious time to the direction and review of the research papers and dissertation. His vast experience and in-depth knowledge of transportation engineering has provided critical success in the dissertation.

I would like to convey my deepest appreciation and thanks to Dr. L. David Shen for his assistance and guidance in getting my graduate career started on the right foot. $\mathrm{He}$ guided me in choosing the topic of the dissertation, and encouraged me during the preparation of the dissertation. His inestimable support and advice on literature review and data collection was a great help in starting the doctoral study. He is a very generous professor in terms of helping his students.

I am also greatly indebted to the rest of my dissertation committee members and other professors for their guidance, comments, suggestions, and interests in my research. I particularly wish to express my sense of gratitude to Dr. Mohammed Hadi for providing me with comments and suggestions on the dissertation. A very special thank you is extended to Dr. Fang Zhao for her enlightenment in building a model in the research, and for her comments and suggestions on the dissertation. I would like to thank Dr. Zhenmin Chen for his help with statistical analyses. I also want to express thanks to Dr. Hugh Gladwin for his generous help with providing data for the dissertation. 
I want to extend my thanks to Ms. Natalie Defraene for her help with the proofreading of the dissertation. I am also grateful to Dr. Kaiyu Liu and Dr. Rax Jung for their comments and suggestions for the dissertation.

Finally, I would like to thank numerous people in the Department of Civil and Environmental Engineering at Florida International University for their help and assistance during my doctoral study. I thank all of my friends in China and in the USA for their care and support. 


\author{
ABSTRACT OF THE DISSERTATION \\ PREDICTING HURRICANE EVACUATION DECISIONS: \\ WHEN, HOW MANY, AND HOW FAR \\ by \\ Lixin Huang \\ Florida International University, 2011 \\ Miami, Florida \\ Professor Albert Gan, Co-Major Professor \\ Professor L. David Shen, Co-Major Professor
}

Traffic from major hurricane evacuations is known to cause severe gridlocks on evacuation routes. Better prediction of the expected amount of evacuation traffic is needed to improve the decision-making process for the required evacuation routes and possible deployment of special traffic operations, such as contraflow. The objective of this dissertation is to develop prediction models to predict the number of daily trips and the evacuation distance during a hurricane evacuation.

Two data sets from the surveys of the evacuees from Hurricanes Katrina and Ivan were used in the models' development. The data sets included detailed information on the evacuees, including their evacuation days, evacuation distance, distance to the hurricane location, and their associated socioeconomic characteristics, including gender, age, race, household size, rental status, income, and education level.

Three prediction models were developed. The evacuation trip and rate models were developed using logistic regression. Together, they were used to predict the number of daily trips generated before hurricane landfall. These daily predictions allowed for 
more detailed planning over the traditional models, which predicted the total number of trips generated from an entire evacuation. A third model developed attempted to predict the evacuation distance using Geographically Weighted Regression (GWR), which was able to account for the spatial variations found among the different evacuation areas, in terms of impacts from the model predictors. All three models were developed using the survey data set from Hurricane Katrina and then evaluated using the survey data set from Hurricane Ivan.

All of the models developed provided logical results. The logistic models showed that larger households with people under age six were more likely to evacuate than smaller households. The GWR-based evacuation distance model showed that the household with children under age six, income, and proximity of household to hurricane path, all had an impact on the evacuation distances. While the models were found to provide logical results, it was recognized that they were calibrated and evaluated with relatively limited survey data. The models can be refined with additional data from future hurricane surveys, including additional variables, such as the time of day of the evacuation. 


\section{TABLE OF CONTENTS}

CHAPTER

PAGE

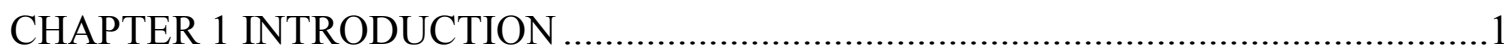

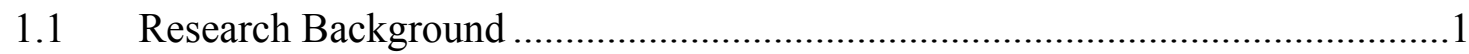

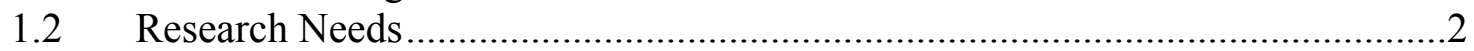

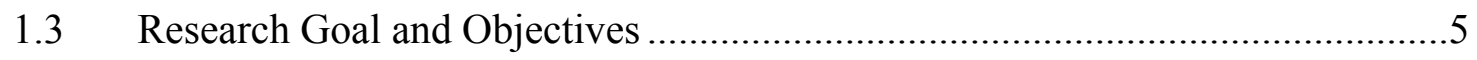

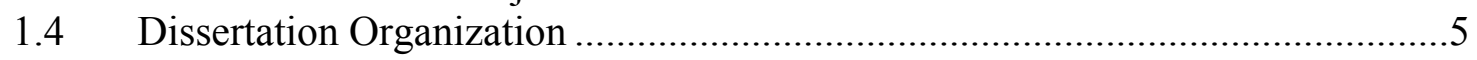

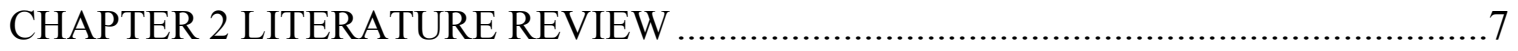

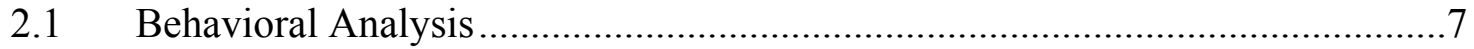

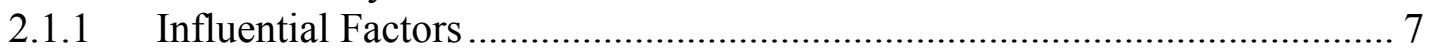

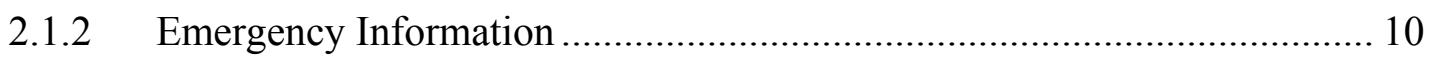

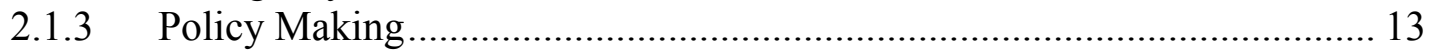

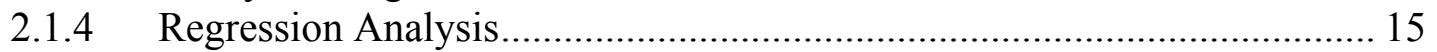

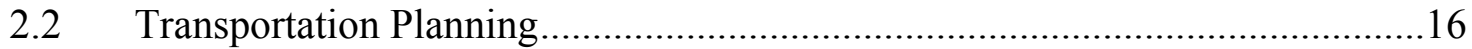

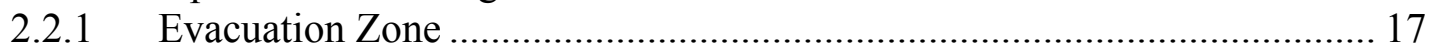

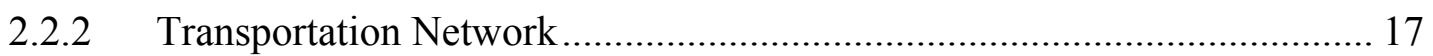

2.2.3 Multi-agency Cooperation ..................................................................... 19

2.2.4 Policy Making .................................................................................. 21

2.2.5 Restricted and Special Needs Population ................................................ 22

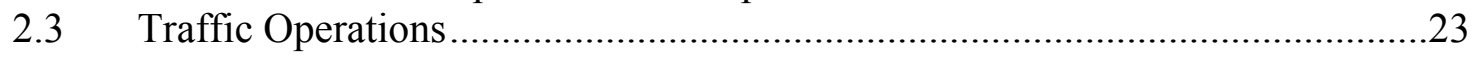

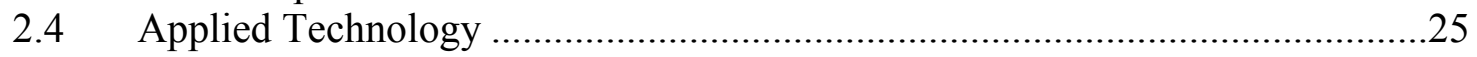

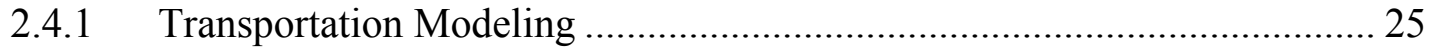

2.4.2 Computer Simulation ............................................................................ 35

2.4.3 Intelligent Transportation Systems ……………........................................ 37

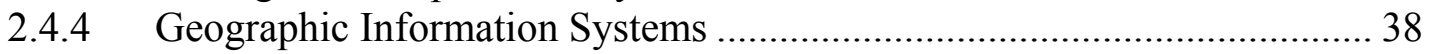

2.4.5 Geographically Weighted Regression ...................................................... 40

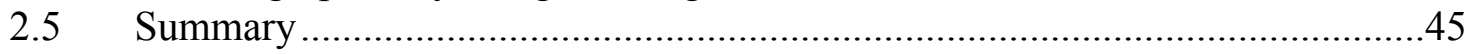

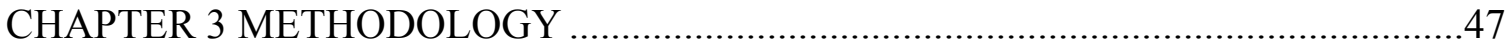

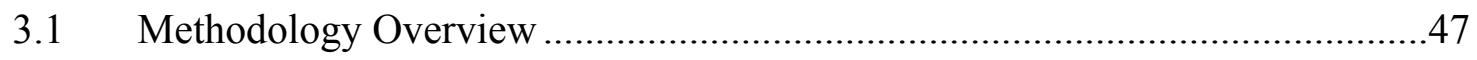

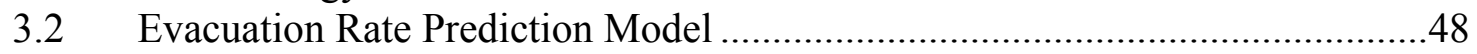

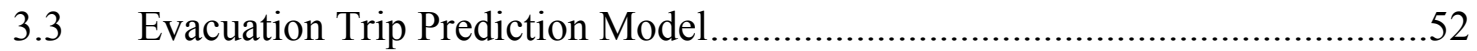

3.4 Evacuation Trip Distance Prediction Model....................................................55

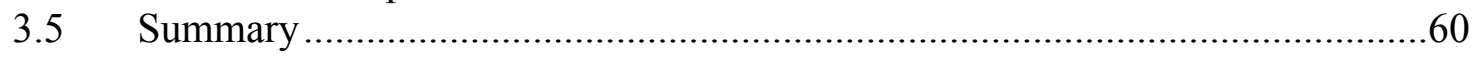

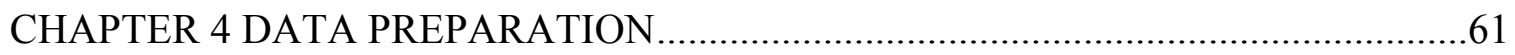

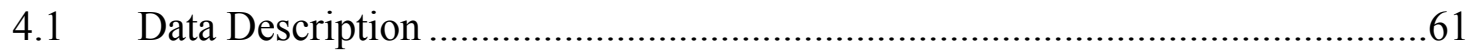

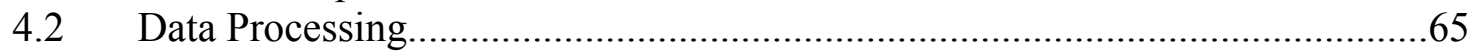

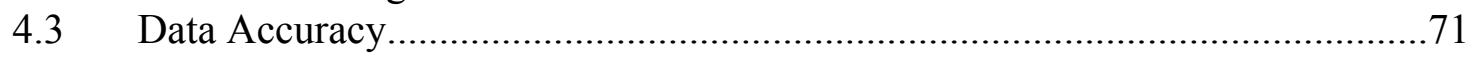

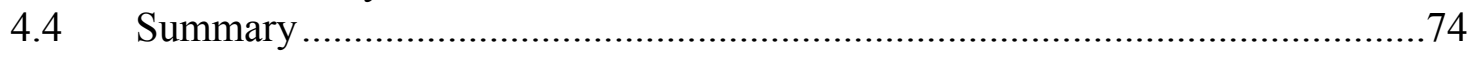


CHAPTER 5 MODEL DEVELOPMENT .................................................................

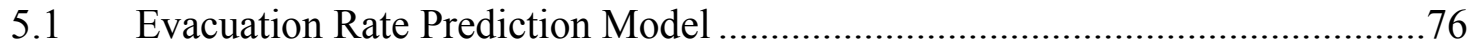

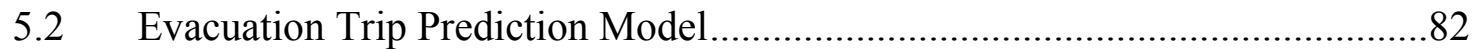

5.3 Evacuation Trip Distance Prediction Model........................................................8

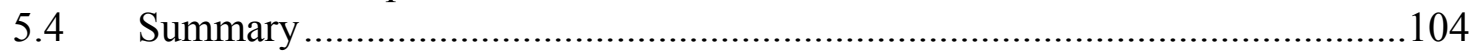

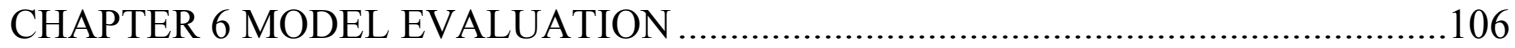

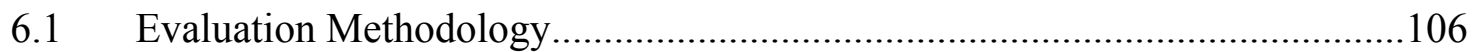

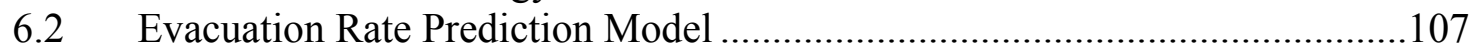

6.3 Evacuation Trip Prediction Model..................................................................109

6.4 Evacuation Trip Distance Prediction Model...................................................111

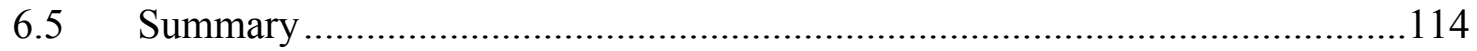

CHAPTER 7 CONCLUSIONS, LIMITATIONS AND RECOMMENDATIONS ........116

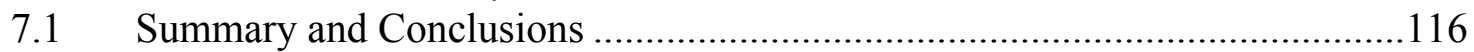

7.2 Limitations and Recommendations …………...........................................119

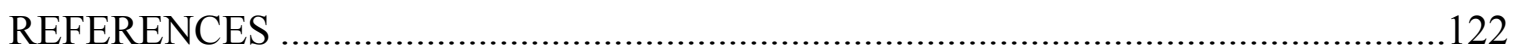

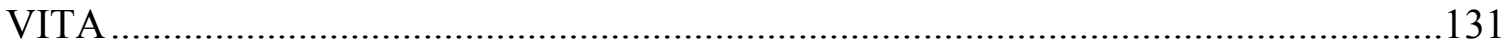




\section{LIST OF FIGURES}

Figure 1-1: Cumulative Percentage of Evacuees in Hurricane Frances in 2005 .............. 3

Figure 3-1: Methodology Applied to Develop the Hurricane Evacuation Models......... 49

Figure 4-1: Hurricane Katrina Evacuation Survey Data Locations ............................... 64

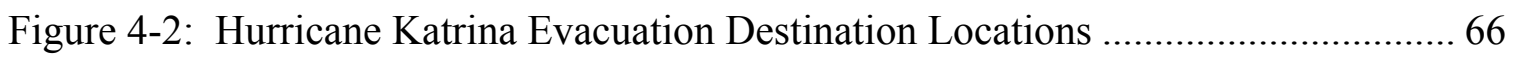

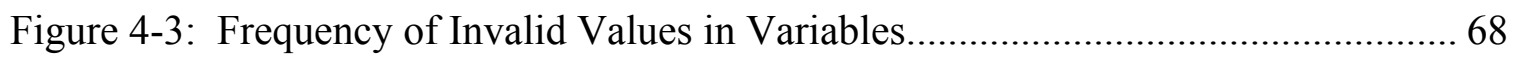

Figure 4-4: Cumulative Distribution of Five-Year Official Atlantic Basin Tropical Cyclone Track Forecast Errors ............................................................. 72

Figure 4-5: Different Forecast Tracks of Hurricane Katrina ..................................... 73

Figure 4-6: Forecast Locations of Hurricane Katrina at 11:00 AM, 8/28/2005 ............ 74

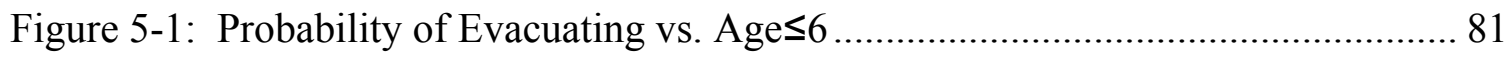

Figure 5-2: Age Distribution of Evacuees for Homeowner and Renter ....................... 81

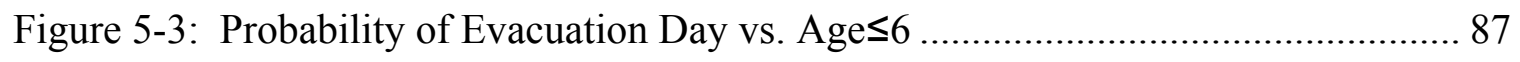

Figure 5-4: Frequency Distribution of Evacuation Distance without Education Variable

Figure 5-5: Cumulative Distribution of Evacuation Distance without Education Variable 90

Figure 5-6: GWR Standard Residual Distribution................................................. 95

Figure 5-7: Distribution Map of GWR Standard Residual ........................................ 95

Figure 5-8: Distribution Map of GWR Local R-Squared .......................................... 96

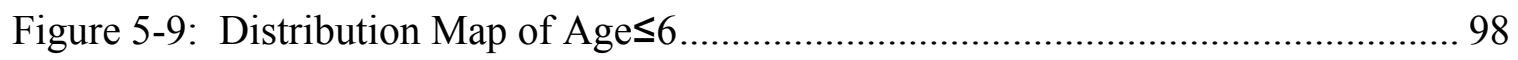

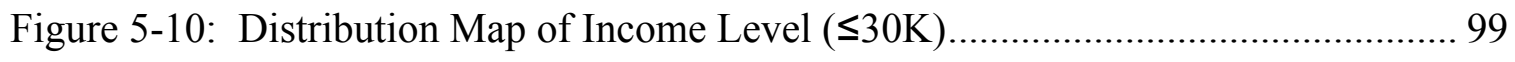

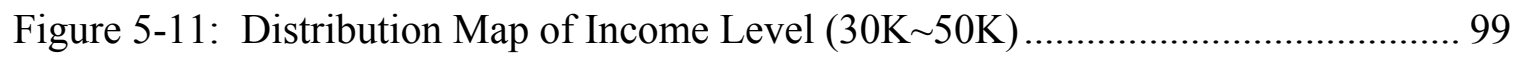

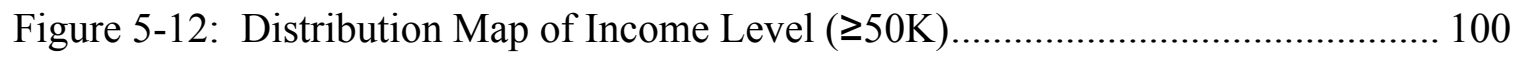




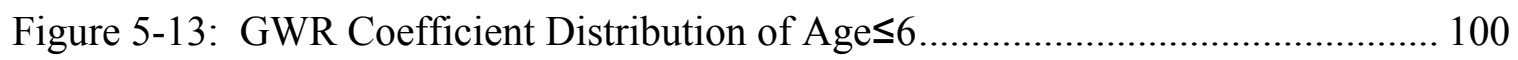

Figure 5-14: GWR Coefficient Map of Income Level (10K 20K) …………………... 101

Figure 5-15: GWR Coefficient Map of Income Level (20K 30K) .............................. 101

Figure 5-16: GWR Coefficient Map of Income Level between (30K 50K)…............ 102

Figure 5-17: GWR Coefficient Map of Income Level (50K 80K) …......................... 102

Figure 5-18: GWR Coefficient Map of Income Level ( $\geq 80 \mathrm{~K})$.................................... 103

Figure 5-19: GWR Coefficient Map of Hurricane Distance............................................ 103

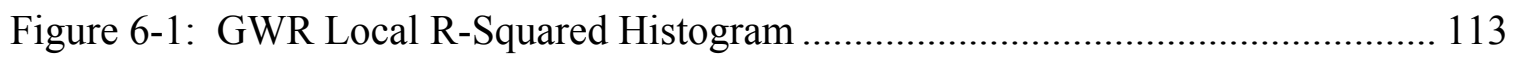

Figure 6-2: GWR Standard Residual Histogram ..................................................... 114 


\section{LIST OF TABLES}

Table 3-1: Methodology Applied to Develop the Prediction Models............................. 48

Table 4-1: Evacuation Survey Data Selected for Developing Prediction Models........... 62

Table 4-2: Sample Size of Hurricane Katrina Evacuation Survey Data .......................... 64

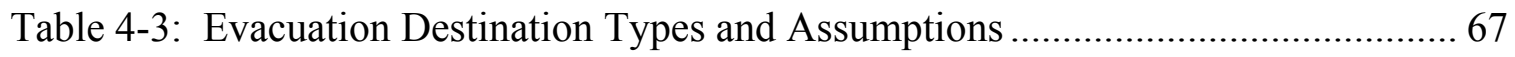

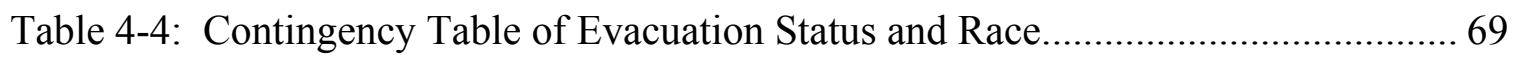

Table 4-5: Processed Hurricane Katrina Evacuation Survey Data ............................... 69

Table 4-6: Sample Size of Hurricane Katrina Evacuation Survey Data ......................... 71

Table 4-7: Forecast Locations of Hurricane Katrina at 11:00 AM 8/28/2005............... 73

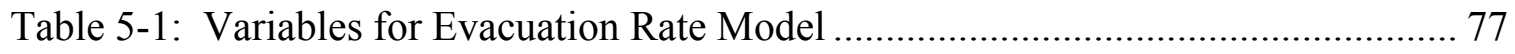

Table 5-2: Result of Evacuation Rate Model Developed from Data with Education

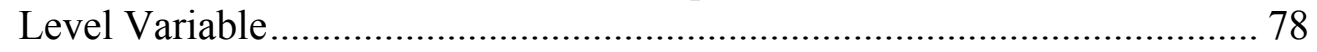

Table 5-3: Result of Evacuation Rate Model Developed from Data without Education

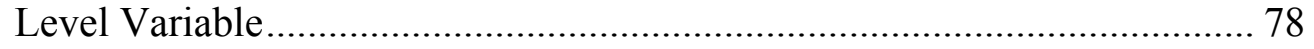

Table 5-4: Variables for Evacuation Trip Model................................................... 83

Table 5-5: Result of Evacuation Trip Model Developed from Data with Education Level Variable ........................................................................................ 84

Table 5-6: Result of Evacuation Trip Model Developed from Data without Education Level Variable.............................................................................. 84

Table 5-7: Result of Redeveloped Evacuation Trip Model Developed from Data with Education Level Variable ................................................................ 85

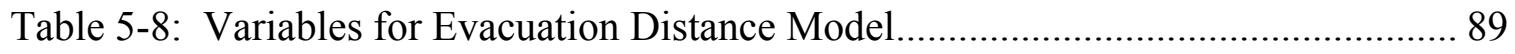

Table 5-9: Result of Evacuation Distance Model Developed by OLS from Data with Education Level Variable ........................................................................ 91

Table 5-10: Result of Evacuation Distance Model Developed by OLS from Data without Education Level Variable .............................................................. 91

Table 5-11: Comparison of Two Models Developed by OLS .................................... 93 
Table 5-12: Result of Evacuation Distance Model Developed by GWR from Data without Education Level Variable

Table 6-1: Evaluation Result of Evacuation Rate Model .......................................... 108

Table 6-2: Evaluation Result of the Evacuation Trip Model ....................................... 110 


\section{CHAPTER 1 INTRODUCTION}

\subsection{Research Background}

The population along the coastal areas of the United States is increasing rapidly. This population growth will result in an increase in the vulnerability of property and a consequent increase in economic losses and loss of life during hurricane strikes. For example, the total economic loss caused by Hurricane Katrina in 2005 is estimated at over $\$ 100$ billion (RMS, 2005), and the official death toll for Hurricane Katrina is at least 1,500 (Blake et al., 2007). Clearly, evacuations are needed to help move the population living in dangerous areas, such as storm surge and low-lying areas, to safe places during the approach of a hurricane.

The nature of traffic generated by a hurricane evacuation is usually high volume over a short period of time, typically within one to three days of the landfall of a hurricane. This kind of traffic usually creates gridlocks on the evacuation routes. For example, in the case of Hurricane Floyd in 1999, more than three million residents of Florida, Georgia, South Carolina, and North Carolina evacuated, making it the largest hurricane evacuation in history. As a result, people were trapped inside their vehicles for as long as 24 hours without access to restrooms, gas stations, and food. Similarly, the evacuation generated by Hurricane Rita in 2005 in the Houston, Texas area resulted in 100-mile freeway backups, and most evacuees were stuck on the freeways for more than 10 hours.

Transportation planning plays an important role in hurricane evacuation, as it

determines the effectiveness and swiftness of the evacuation. It is very important for 
transportation planners to estimate the number of trips that will be generated during a hurricane evacuation. An estimated number of trips enables transportation planners to create a hurricane evacuation plan that accommodates the evacuees' needs, including making decisions on the number of evacuation routes, number of traffic operation staff, number of shelters, whether to deploy contraflow traffic operations, etc.

Predicting the number of trips generated by a hurricane evacuation is a complex and difficult task. There are many factors affecting it. These factors include people's socioeconomic status, their residential locations, past hurricane evacuation experiences, and the uncertainty of hurricane forecasting. Most evacuees will leave within three days of the landfall of a hurricane. The number of evacuees varies from day to day. It is important to predict the number of evacuees for each day so that transportation planners can develop a viable hurricane evacuation plan.

\subsection{Research Needs}

The transportation planning process can be used in the planning of hurricane evacuations. Traditional four-step transportation planning includes trip generation, trip distribution, mode choice, and traffic assignment. Trip generation is the first step and plays an important role in the entire process. This is especially true in the planning of hurricane evacuations. Traditional trip generation is based on zones. The number of trips generated from each zone may be determined by the social and economic characteristics of households in each zone. Traditional trip generation is not time-based and can only be used to determine the number of trips generated from each zone over a certain period of time, such as a weekday. Understandably, most hurricane evacuation trips are, in fact, 
generated over the two to three days before hurricane landfall. The number of trips generated during this period is usually much larger than during a regular weekday. The number of evacuation trips also varies from day to day. Error! Reference source not found. (COE, 2005b) shows the cumulative percentage of evacuees of Hurricane Frances in 2004. The horizontal axis indicates specific days in September 2004 leading up to landfall. Hurricane Frances made landfall at 12:30 AM on September 5, 2004. It can be seen from the figure that nearly 70 to 80 percent of people evacuated two days (September 3) before the landfall of Hurricane Frances for all study areas. The evacuation percentage varies from day to day and area to area. It can also be seen that most people tend to evacuate during the daytime. Accordingly, it would be better for trip generation measures during hurricane evacuations to be time-based to better reflect an actual condition.

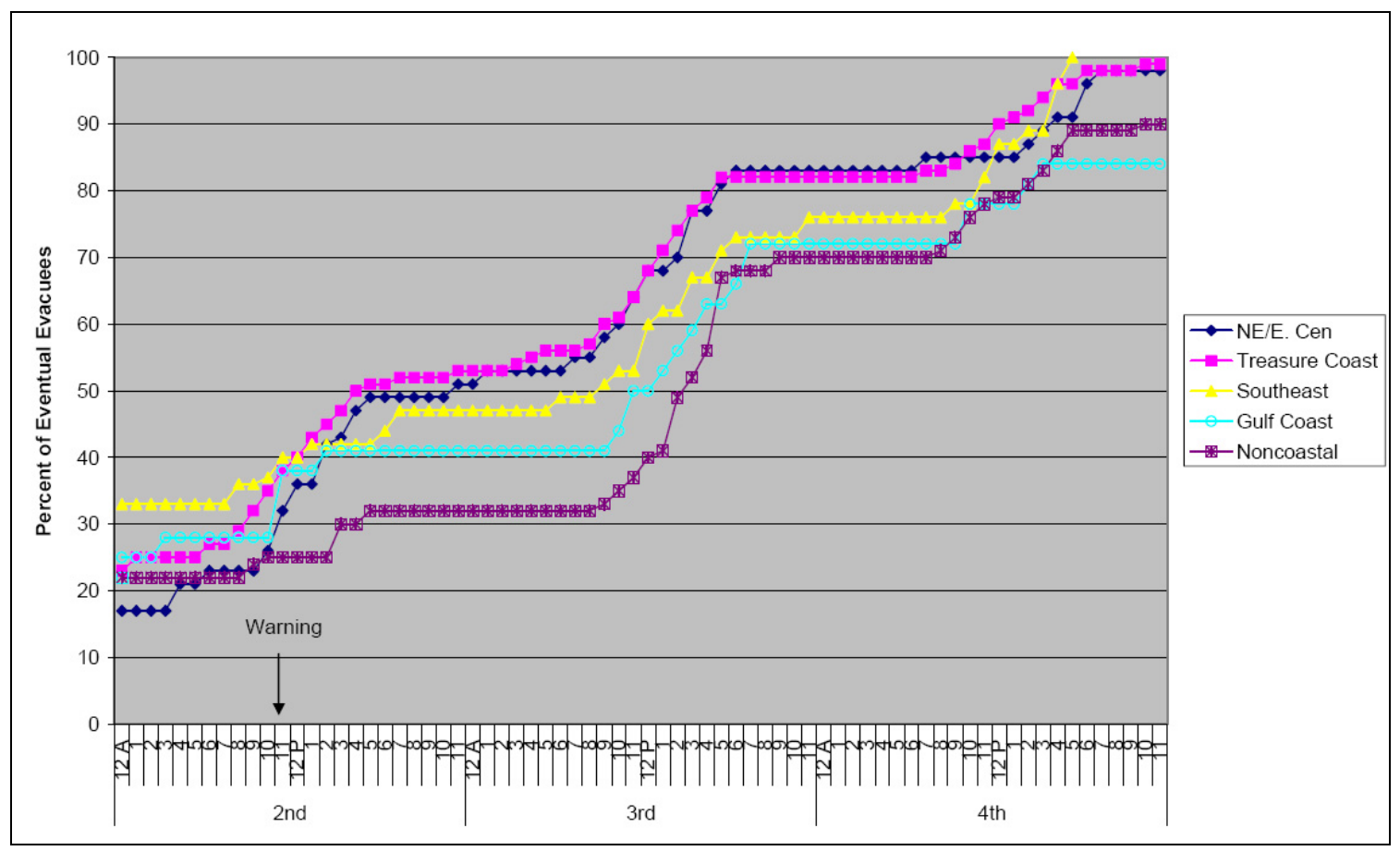

Figure 1-1: Cumulative Percentage of Evacuees in Hurricane Frances in 2005 
Many factors could affect whether people will evacuate three days, two days, or even one day before hurricane landfall. These factors include people's socioeconomic status, their residential location, the intensity of the incoming hurricane, past hurricane evacuation experiences, and so on. These factors may also interact with each other, which make predicting trip generation for hurricane evacuations a more challenging and difficult task.

The evacuation rate is usually used to calculate the number of trips generated during a hurricane evacuation and is usually used as a constant throughout the hurricane evacuation period. This does not reflect an actual scenario because the number of trips generated varies from day to day before hurricane landfall. For example, the number of evacuees who leave their homes varies in relation to the number of days before hurricane landfall. Most evacuees tend to leave two or three days before the landfall of a hurricane, and fewer evacuees leave four days before hurricane landfall. Thus, the evacuation rate should be used in conjunction with the percentage of people who will evacuate one to three days before hurricane landfall. It would be appropriate to use varied evacuation rates for different time periods in order to accurately calculate the number of trips generated by hurricane evacuation. It is vital that emergency agencies make evacuation plans that are in accordance with real evacuation needs.

The evacuation distance is the distance an evacuee traveled during a hurricane evacuation. It may be used as one of the criteria to evaluate how the evacuation trips impact on the roadway network involved. The farther the evacuation distance, the more impact the roadway network will experience. Therefore, it is helpful for emergency 
agencies to obtain some knowledge of the evacuation distance in advance so that the evacuation routes can be planned in an efficient manner.

\subsection{Research Goal and Objectives}

The goal of this dissertation is to develop prediction models that can be used to better predict the number of daily trips generated and the evacuation trip distance during a hurricane evacuation. The specific objectives of this dissertation are:

1. Study the feasibility of hurricane evacuation survey data as a potential source for developing the models for hurricane evacuation.

2. Develop a model to predict the number of trips generated on a given day before hurricane landfall.

3. Develop a model to predict the evacuation trip distance during hurricane evacuation.

\subsection{Dissertation Organization}

This dissertation consists of seven chapters. Chapter 1 introduces the background of the research, describes the research needs, and sets the goals and objectives of the dissertation.

Chapter 2 presents an extensive literature review covering behavioral analysis, transportation planning, traffic operation, and applied technology as they relate to hurricane evacuation. The purpose of the literature review is to identify the problems pending to be solved, determine research objectives, and form the research framework and tasks for this dissertation. 
Chapter 3 proposes a complete methodology to develop the prediction models. In response to the problems stated in Chapter 1, this chapter puts forth four methods to develop the prediction models. They are Binomial Logistic Regression, Multinomial Logistic Regression, Ordinary Least Square, and Geographically Weighted Regression.

Chapter 4 discusses the data acquisition and how the data acquired was processed in order to be used in developing the prediction models.

Chapter 5 applies the proposed methodology in Chapter 3 to the development of the hurricane evacuation models. The models developed include the evacuation rate prediction model, evacuation trip prediction model, and evacuation trip distance prediction model. The findings from these models were presented.

Chapter 6 evaluates the prediction models developed and presents the evaluation results.

Chapter 7 summarizes the major research results, draws conclusions, and makes recommendations for future research. 


\section{CHAPTER 2}

\section{LITERATURE REVIEW}

Many studies have been conducted on hurricane evacuation. These studies involved behavioral analysis, transportation planning, traffic operation, and applied technology. Sections 2.1 to 2.4 describe each part in detail, respectively.

\subsection{Behavioral Analysis}

Behavioral analysis deals with peoples' responses to the threat of an oncoming hurricane. In an evacuation, there are two possible responses from people who live in a threatened area. One is to leave their homes, and the other is to stay. There are many factors affecting peoples' responses, such as socioeconomic status, demographic information, evacuation distance, risk perception, hurricane forecasting accuracy, and hurricane information dissemination. A behavioral analysis will provide information on

how these factors affect peoples' responses to a hurricane. Sections 2.1.1 to 2.1.4 describe the behavioral analysis in detail.

\subsubsection{Influential Factors}

Many factors affect peoples' behaviors during hurricane evacuation. Two behavioral analyses based on data from Hurricanes Andrew and Floyd, respectively, were conducted to study hurricane evacuation utilization and information dissemination (PBS\&J 1993 and 2000). Both analyses focused on the evacuation rates, evacuation timing, use of public shelters, evacuation destinations, and vehicle use. 
Whitehead et al. (2000a) conducted a study that involved a preliminary comparison of the evacuation behaviors among Hurricanes Bonnie, Dennis, and Floyd. The comparison was based on three aspects: evacuation behavior and cost, factors affecting evacuation behavior, and actual and hypothetical behavior. Several differences in behavior and household cost of evacuation between hurricanes were found. The major determinants of evacuation behavior were similar among the three hurricanes. The hypothetical and actual behaviors were not different for the evacuation and distance traveled decision. However, they were different for the destination mode decision.

Whitehead et al. (2000b) evaluated the determinants of hurricane evacuation behavior of North Carolina coastal households during Hurricane Bonnie, and a future hypothetical hurricane, by using data from a telephone survey of North Carolina coastal residents. It was found that households were more likely to go to a safer place when given evacuation orders due to an oncoming hurricane. It was also found that objective and subjective risk factors also played an important role in making evacuation decisions, and social and economic factors were the primary determinants of the destination decision.

The Corps of Engineers (COE 2001 and 2002) performed two behavioral analysis studies on hurricane evacuation for the states of Alabama and Mississippi, respectively. The analysis for the state of Alabama was performed based on two hurricanes in 1995. The analysis for the state of Mississippi was performed based on one hurricane in 1998. The evacuation participation rate, peoples' responses to the evacuation notice, and peoples' perceptions of vulnerability were derived from both analyses. In the study, the methods of evacuation response rate and evacuation destination analyses provided 
estimates of public response to a variety of hurricane threat. These estimates are the base of developing evacuation models.

The Corps of Engineers (COE 2005a, 2005b, 2005c, and 2005d) also performed a behavioral analysis study based on four hurricanes in 2004. The analysis was based on 29 Floridian counties. These counties were then aggregated into seven areas for sampling and reporting purposes. The analysis involved more detailed content compared to the previous behavioral analyses. The socioeconomic status, demographic information, hurricane forecast information, potential evacuation constraints, and preparations by evacuees and non-evacuees were included in the analysis. The study provided the detailed analyses of evacuation participation rate, evacuation timing, and evacuation destination and travel, which were used as guidance in the further study of hurricane evacuation.

Howell and Bonner (2005) conducted the citizen hurricane evacuation behavior surveys in twelve parishes in southeastern Louisiana. The survey included risk perception, willingness to evacuate when recommended, actual evacuation during the last recommended evacuation, citizen focus on storm category, types of people being most or least likely to evacuate, the role of income, the Hurricane Ivan effect, the role of family and friends, evacuation planning, and sources of information and advice. The survey results revealed that the most significant finding was the low perception of risk of a Category 3 or higher hurricane felt by most residents in southeastern Louisiana. It indicated that educating citizens of the risk of a Category 3 or higher hurricane was very important. 
Li et al. (2010) studied the evacuation and return of African Americans and Vietnamese Americans in one racially mixed eastern New Orleans neighborhood, where African Americans and Vietnamese Americans accounted for a majority of 93.4 percent of pre-Katrina residents. The study examined the spatial morphology of routes, volumes, frequencies of evacuees, the return rates, experiences, and rationales and motivations to return or stay, based on the disaster migration, place attachment, and social network literature. It was found that the evacuation and return experiences of each minority group were significantly different.

\subsubsection{Emergency Information}

Emergency information is one of the factors that influence peoples' responses during hurricane evacuation. Dowab and Cutter (1998) examined the evacuation behavior of residents in two South Carolina communities during the 1996 hurricane season, which involved two hurricanes that approached South Carolina, but instead, hit North Carolina. It was found that evacuation decisions were based on multiple sources of risk information rather than from the emergency management officials. Emergency managers seemed to have little effect on the evacuation decisions of local residents. It suggested that coastal residents in South Carolina were becoming more independent in their assessments, relying on widely available technology such as cable television, weather radios, the Internet, and so forth.

Dow et al. (1999) conducted a study in South Carolina that included a survey on hurricane evacuation behavior based on three past hurricanes. The contents of the survey involved peoples' responses to hurricane evacuation warnings. The evacuation decisions 
made by residents were affected by the hurricane evacuation warnings. It can be concluded from the survey that hurricane evacuation warnings should be timely, personoriented, and provided by reliable sources.

Lindell et al. (2005) conducted a study to collect data on the evacuation process during Hurricane Lili in order to answer questions about households' reliance on information sources, the factors affecting the decision to evacuate, the timing of hurricane evacuation decisions, and the time it took to prepare to evacuate. It was found that the study's results were consistent with the findings from previous studies on the sources of hazard information, evacuation concerns, and the timing of evacuation decisions. However, no correlation between household characteristics and evacuation decision times or evacuation preparation times were found.

Arlikatti et al. (2006) conducted a study to examine the accuracy with which Texas coastal residents were able to locate their residences on hurricane risk area maps provided to them. It was found that the risk area accuracy showed minimal correlation with respondents' demographic characteristics, but was negatively correlated with the respondents' previous hurricane exposure and evacuation experience. It was concluded that risk area accuracy appeared to have little significance because it was uncorrelated with evacuation expectations that were related to respondents' previous hazard experiences and expected evacuation contexts.

Rosenkoetter et al. (2007) conducted a descriptive survey on the lower socioeconomic participants at congregate meal sites in order to investigate the evacuation needs and beliefs of older adults in two counties in Georgia, to identify health risk factors, and to provide public health and emergency management officials with planning 
information. It was found that trust and belief in county officials and the media were the best predictors of willingness to evacuate, and participants in this study would need assistance with transportation, preparation, and support for serious health problems in order to evacuate.

Burnside et al. (2007) discussed how information sources and risk perceptions affected residents living in vulnerable areas who were making the decision to evacuate when they were threatened by an approaching hurricane. It was found that individuals used a variety of sources when they decided to evacuate, as follows: by examining the role of information from authorities, family, and friends; visual imagery; and the media. It was also found that viewing visual images of hurricane damage had a significant effect on the likelihood of evacuating, and the effectiveness of information sources could enhance an individual's sense of risk and make them more likely to evacuate.

Kang et al. (2007) compared the respondents' hurricane evacuation expectations with their actual behavior two years later, during Hurricane Lili. It was found that the respondents had accurate expectations about their information sources, evacuation transportation modes, number of vehicles taken, and evacuation shelter types, as well as generally accurate expectations about the time it would take them to implement some evacuation preparation tasks. The study's results showed that the respondents' behaviors corresponded well with their actual evacuation behaviors. It was suggested that emergency planners use many aspects of coastal residents' evacuation expectations as a reasonable basis for evacuation planning.

Boyd et al. (2009) presented the results of an effort to examine how the storm's development and movement, the announcement of warnings and evacuation orders by 
government officials, and the highly visible media reports, impacted the temporal and spatial movement of evacuation traffic in southeastern Louisiana during the 48 hours prior to Hurricane Katrina's landfall. It was important for emergency agents to understand the relationship between emergency communication and response. The Louisiana Katrina data revealed that despite the ferocity and movement of the storm, the overwhelming media coverage, and the urgency of the evacuation orders, most pre-storm evacuees waited until the day before Hurricane Katrina's landfall, when government officials and the media began using extremely urgent and dire pronouncements.

Stein et al. (2010) conducted a survey in 2005 for the residents in the eight-county Houston metropolitan area after Hurricane Rita made landfall on September 24, 2005. This study focused on finding out determinants of individual evacuation decisions. It was found that the evacuation decisions were affected by a heterogeneous set of parameters, including perceived risk from wind, influence of media and neighbors, and awareness of evacuation zone. It was also found that the perceived risk and its influence on evacuation behavior was a local phenomenon more easily communicated by and among individuals who share the same geography.

\subsubsection{Policy Making}

Policies related to hurricane evacuation plans can also affect peoples' responses during hurricane evacuation. Peacock et al. (2005) examined factors contributing to hurricane risk perceptions of single-family homeowners in Florida by using data from a statewide survey. The contributing factors included knowledge of hurricanes, previous hurricane experience, and socio-economic and demographic characteristics. It was found 
that there was a good deal of consistency between residing in locations identified by experts as being high hurricane wind risk areas and homeowner risk perceptions. It was also found that there was inconsistency between the implementation of the statewide building code and risk perceptions.

Dombroski et al. (2006) started with a formal risk assessment of an anticipated emergency, whose parameters include factors potentially affecting and affected by behavior, as identified by social science research. The standard procedures were then used to elicit scientific experts' judgments regarding these behaviors and dependencies, in the context of an emergency scenario. Finally, the judgments elicited were used to refine the model and scenario, enabling local emergency coordinators to predict the behavior of citizens in their area. A case study was used to illustrate this approach. It was found, to some extent, that the preparatory policies could improve the public compliance of evacuation order.

Dash and Gladwin (2007) reviewed the literature that focused on three broad areas of research that often overlap: warning, risk perception, and evacuation research to highlight important dimensions of evacuation decision making. It was critical to understand how emergency officials better motivated the public to evacuate, why individuals decided to evacuate or to stay, and how individuals and their households arrived at a decision to evacuate or not. It was recommended that the prediction of evacuation rates be more accurate and geographically focused, that better prediction of evacuation rates enable better estimation of potential hurricane consequences, and that there should be more research focused on understanding shadow or spontaneous evacuators. 
Lindell et al. (2007) reviewed research and the theory of the processes by which emergency-relevant organizations communicate with each other and with the population at risk from hurricanes. It was found that social science research was needed to expand the existing knowledge, based on the responses of households, businesses, and special facilities for hurricane warnings. It was suggested by available research that local officials need better information about evacuation time estimates, evacuation costs, and the potential loss of life in a late evacuation, as well as improved decision support systems.

\subsubsection{Regression Analysis}

Regression analysis has been used to analyze peoples' responses during a hurricane evacuation. Dixit et al. (2008) proposed a methodology that could be used to understand the factors associated with the mobilization time during a subsequent hurricane, while accounting for the effects of the preceding hurricane. The effects of the preceding hurricane were accounted for by modeling mobilization times simultaneously with an ordinal variable representing evacuation participation levels during Hurricane Charley. The data from a survey conducted with the evacuees of Hurricane Frances, which made landfall three weeks after Hurricane Charley, were used in this study. It was found that homeownership, the number of individuals in the household, income levels, and the level or the risk of a surge were significant in the model, and explained the mobilization times for households.

Smith and McCarty (2009) surveyed households throughout the state of Florida and in the local areas that experienced the greatest damage from the four hurricanes in 
2004 to collect information on demographic impact. Logistic regression was used to analyze the survey data. It was found that the strength of the hurricane and the vulnerability of the housing unit had the greatest impact on evacuation behavior. It was also found that several demographic variables, such as gender, households with children younger than age 18, and homeownership, had significant effects on the probability of evacuating and the choice of evacuation lodging.

Petrolia and Bhattacharjee (2010) used a multinomial choice framework to analyze data from hypothetical storm forecast scenarios, implemented by a mail survey to a random sample of U.S. Gulf Coast residents. It was found that the issuance of a mandatory evacuation notice and the presence of higher wind speeds had the largest influence on increasing the likelihood of evacuation. It was also found that age, race, disability, distance, and education were significant factors explaining one's decision to wait, relative to choosing to evacuate. The study's results revealed that residents who lived in mobile homes and had their evacuation destinations identified were more likely to evacuate.

\subsection{Transportation Planning}

Transportation planning for a hurricane evacuation usually involves evacuation zone designation, transportation network planning, regional planning, and policy making for hurricane evacuations. Transportation planning is a crucial part of the process in creating a hurricane evacuation plan since it determines the effectiveness of transporting people from vulnerable places to safe ones. Sections 2.2.1 to 2.2.5 describe the transportation planning in detail. 


\subsubsection{Evacuation Zone}

Transportation planning is based on zones. Hurricane evacuation zones are very important in estimating evacuation demand (i.e., how many people will evacuate when a hurricane strike is imminent). A given emergency management agency will determine which areas should be evacuated based on the hurricane evacuation zones, in case of a hurricane strike. Wilmot and Meduri (2005) discussed a methodology to establish hurricane evacuation zones. A methodology was developed based on current practices in the establishment of hurricane evacuation zones. An example was also given to illustrate how to use the methodology to establish hurricane evacuation zones, as well as how to use these zones. It was found that there had not been a clear description of principles or criteria that were essential in establishing hurricane evacuation zones. The study involved developing a criteria-based methodology to determine the hurricane evacuation zones.

\subsubsection{Transportation Network}

Hurricane evacuation planning involves transportation network planning. Wolshon (2002) discussed how the comprehensive regional evacuation plan was created to evacuate the city of New Orleans. First, the limitations of the New Orleans highway network for evacuation were analyzed. Then the evacuation routes were selected, and the contraflow plan was implemented along some highway segments, based on the aforementioned analysis. Some critical issues regarding the evacuation plan were also discussed, such as the interstate movement of evacuees, roadway safety, construction zones, unpredictability of hurricane forecasting, and the time required to evacuate the city. 
It was necessary to actively involve transportation professionals in the evacuation planning and preparedness process.

Wolshon et al. (2006) described and evaluated the Louisiana highway evacuation plan. Due to the difficulties experienced during the Hurricane Ivan evacuation, the Louisiana Hurricane Evacuation Task Force was created to develop a viable hurricane evacuation plan to more effectively evacuate vulnerable populations of the state of Louisiana. The task force analyzed the regional traffic pattern, focusing on New Orleans and Baton Rouge, and finally created a hurricane evacuation plan. The plan includes three major components: a staged evacuation plan, an improved contraflow plan, and forced movement. This plan was then used successfully during the Hurricane Katrina evacuation. It was found that active involvement of highway agencies, public awareness of roadway congestion during hurricane evacuation, and regional hurricane evacuation plans were necessary to make the hurricane evacuation successful.

Wolshon (2006) discussed the evacuation management plan for Hurricane Katrina 2005 from the perspective of a transportation engineer and focused mainly on the highway-based aspects of the evacuation, including demand, capacity, and issues related to the non-evacuees. This plan was developed based on the previous one by incorporating the lessons learned from the evacuation for Hurricane George 1998 and Hurricane Ivan 2004. Evacuees suffered congestion and delays during both evacuations, due to the deficiencies in the evacuation plan. It was concluded that the evacuation of New Orleans for Hurricane Katrina was successful.

Wolshon (2008) used the collected traffic data from two recent evacuations in Louisiana to assess how well various roadway classifications in different geographic 
areas were able to carry traffic during emergencies under both normal-flow and contraflow operations. The objectives were to characterize the general conditions of traffic flow during an evacuation, and to examine how the traffic flows compared with those suggested in the Highway Capacity Manual (HCM). It was found that during the evacuation, the traffic flows carried by most roadways were well below the maximum that the HCM predicted, and the maximum traffic flows on urban roadways typically did not even reach those of average daily commuter periods.

Litman (2006) discussed the lessons learned from evacuations during Hurricanes Katrina and Rita. For Hurricane Katrina, the evacuation plan worked well for people with automobiles. However, it failed for people without automobiles due to the lack of a plan for using public transportation during the evacuation period. For Hurricane Rita, an estimated three million people evacuated the Texas coast, creating 100-mile traffic jams. Evacuees were stranded on the highway without food or gas. The evacuation plan failed because it did not anticipate the traffic volume created by the evacuation. The author also discussed some methods to improve hurricane evacuation plans, such as overcoming resistance to evacuation, caring for the most vulnerable, and planning for resilience. Finally, the author addressed what the best evacuation plan should include. It came to a conclusion that a good evacuation plan is the one that considers both automobile and nonautomobile evacuees, and both of their needs.

\subsubsection{Multi-agency Cooperation}

It is important for the transportation agency to work with other agencies so that the transportation planning for hurricane evacuations can meet the needs of the agencies 
involved. Wegmann and Fink (2006) described how Houston's Transtar aided in the evacuation preceding Hurricane Rita. Houston's Transtar is the Great Houston Transportation and Emergency Management Center. It was created via the combination of transportation and emergency management from four agencies: the city of Houston, Harris County, the Metropolitan Transit Authority of Harris County, and the Texas Department of Transportation. The Houston Transtar could leverage all of the community's resources from all of the participating agencies. Hence, it could provide decision-makers with real-time regional traffic information during a hurricane evacuation. Although the implementation of the Houston Transtar during the evacuation preceding Hurricane Rita was not very successful, it provided a new way to implement hurricane evacuations.

Carpender et al. (2006) discussed the evacuation for Hurricane Rita 2005 from the public health point of view. Problems that were identified during the evacuation included traffic congestion, failure of shelter hubs and evacuation information centers, communications, inefficient patient evacuations, and hazardous evacuations of nursing homes. It was recommended that the planning include a multi-state effort to assure the evacuation effectiveness of major metropolitan areas, public officials learn about the whole evacuation process, emergency management officials involve public health officials in the whole evacuation process, and emergency management and public health staff work with all agencies involved in the hurricane evacuation process.

Kiefer and Montjoy (2006) revealed a lack of preparedness in the disaster management network in the New Orleans area. Disaster management was a special case of collaborative public management. It was found that the evacuation of populations with 
private transportation was a success due to the successful implementation of a contraflow plan. The contraflow plan involved the collaboration of multiple agencies and was improved based on the lessons learned from the previous application of a contraflow plan in the New Orleans area.

\subsubsection{Policy Making}

Some research has been done to analyze how policies influenced hurricane evacuation planning. Wolshon et al. (2005a) reviewed transportation engineering aspects of hurricane evacuations, addressing policies and practices for transportation system planning, preparedness, and response. Evacuation modeling methods were reviewed, and recent transportation community initiatives were discussed. The study results showed that the hurricane evacuations were improved in the United States. The study also showed that highway and transportation professionals have become more involved in evacuation planning and operations since 1998. The involvement of transportation planners and engineers brought expertise and experience in dealing with transportationrelated issues, including forecasting evacuation travel demand, evacuation traffic analysis and modeling, and the application of ITS technologies.

Baker et al. (2008) studied five coastal counties in Florida to assess the effects of state-mandated local comprehensive plan policies on hurricane evacuation clearance times and public shelter demand operations. Abbreviated transportation models were utilized to calculate 2002 evacuation times and shelter demand, and to ascertain the impacts of post-plan residential growth within hurricane hazard areas. It was found that the calculated increases in clearance times and shelter demand were not consistent with 
the state's mandate to maintain or reduce clearance times. It was recommended that a concurrency management strategy that parallels the state's mandate be implemented to provide enough transportation facilities to accommodate the impacts of future residential growth.

\subsubsection{Restricted and Special Needs Population}

The restricted and special needs population should be taken into account during hurricane evacuation planning since they need help from others to evacuate. Renne (2006) discussed the evacuation of New Orleans during Hurricane Katrina. The evacuation of people with cars was successful, with the help of a highway contraflow plan. However, the evacuation failed for people without cars, due to inadequate planning. With this in mind, evacuation plans for people without cars were also reviewed at the national level. It was found that only a few cities had specific, detailed plans. It was recommended that planners at every level of government start a dialog about how to create a more efficient and resilient transportation system that takes into account residents who do not have cars.

Renne et al. (2008) performed a literature review on how state departments of transportation, metropolitan planning organizations, transit agencies, and local governments were considering the unique needs of minority, low-income, elderly, disabled, and limited English-proficient persons, especially for households without vehicles. It was found that there were some problems with evacuating the mobilityrestricted population by reviewing the evacuations of Hurricanes Katrina and Rita in 
2005. It was recommended that actions be taken to take into account the mobilityrestricted population in the evacuation planning.

Wolshon (2009) collected and documented information on the transportation's role in emergency evacuations and reentry by summarizing aspects of its planning, control, and research, as well as highlighting effective and innovative practices. It was shown that transportation plays an active role in supporting and assisting in evacuations, and was included in evacuation planning and preparedness exercises. It was also found that some transportation agencies lacked planning for the evacuation of dependent and special needs populations and the post-event, reentry of evacuees and mass repopulation of impacted areas.

\subsection{Traffic Operations}

Traffic operation usually involves the operation of the transportation network during a hurricane evacuation. Contraflow is considered a potential remedy to reduce congestion and is typically used during hurricane evacuation. Contraflow freeway operation uses the in-bound freeway lanes as out-bound lanes. The benefit of the contraflow operation is that it can increase the capacity of a freeway, compared to the one-way operation.

Wolshon and Lambert (2004) documented the historical development of reversible lanes, applications for various needs, lessons learned from previous implementations, costs and benefits associated with their uses, and various techniques and successful practices that have been developed. The report was based on previous research and evaluation studies, a survey of known and potential users of reversible lanes, 
and informal interviews with representatives of highway agencies that currently use them. Four main findings of reversible lane and roadway use included the commonness of usage; a general agreement on the conditions that warrant reversible operations and the basic requirements for their effective use; a wide variety in the design, control, and management methods; and the extent to which the benefits and costs of reversible roadway operations were not well understood.

Wolshon et al. (2005b) summarized the state of current practice from the perspective of evacuation traffic operations, management, and control. Results of a survey of state evacuation practices were presented, focusing on the design and operational aspects of contraflow evacuations and the use of intelligent transportation systems for evacuation management. The study showed most states were adopting contraflow freeway operations and were working to form partnerships between emergency management and transportation agencies within and across states, as well as with their counterparts at federal agencies.

Wolshon (2001) discussed various aspects of contraflow freeway operation during a hurricane evacuation. First, the author explained what contraflow is and how it works. Then, the plans for contraflow operation from nearly every coastal state were discussed. Finally, the critical issues related to contraflow evacuation were discussed, such as safety, regional and interstate traffic, accessibility, and cost. Recent studies showed that contraflow operation could increase the flow rates of evacuating traffic by nearly $70 \%$. Contraflow operation, however, had the inherent safety problems, in terms of traffic control devices and safety appurtenances. 
Wolshon and Lambert (2006) discussed the planning and operational practices for reversible roadways. They concluded that reversible operation might not be as complicated, controversial, or dangerous as many agencies thought. However, they also recognized some other problems related to multi-agency cooperation, enforcement, and incident management.

Shekhar and Kim (2006) presented the first macroscopic approaches for the solution of contraflow network reconfiguration incorporating road capacity constraints, multiple sources, congestion factor, and scalability. The contraflow problems were defined based on graph theory and provided a framework of computational structure to classify the contraflow approaches. The proposed contraflow approaches were evaluated both analytically and experimentally, using real-world datasets. Experimental results showed that the contraflow approaches could reduce evacuation time by $40 \%$ or more.

\subsection{Applied Technology}

Various technologies have been used in hurricane evacuation-related studies, such as transportation modeling, computer simulation, Intelligent Transportation System (ITS), Geographic Information Systems (GIS), and Geographically Weighted Regression (GWR). Sections 2.4.1 to 2.4.5 describe the applied technology in detail.

\subsubsection{Transportation Modeling}

Transportation modeling has been widely used in the planning of hurricane evacuations. Modeling is the process of creating models from a mass of data, equations, and computations that mimic the actions of whatever is represented. Mathematical 
methods are usually used in the modeling process. Barrett et al. (2000) developed a dynamic traffic management modeling framework for a hurricane evacuation. The requirements for the modeling framework consisted of three parts: demand-side, supplyside, and storm-side. These requirements were dynamic, which meant that they would vary with time. The dynamic traffic management model could be used to develop hurricane evacuation policies. It could also be used to develop real-time operational strategies during a hurricane.

Yuan et al. (2006) proposed a framework for the simultaneous optimization of evacuation traffic distribution and assignment. A one-destination evacuation was used to obtain an optimal destination and route assignment by solving a one-destination traffic assignment problem on a modified network representation. The proposed one-destination model was tested with a countywide special event-based evacuation case study. The model was formulated as:

$$
\min \sum_{a} f_{a} c_{a}\left(f_{a}\right)
$$

where

$$
\begin{aligned}
& a=\text { the link, } \\
& f_{a}=\text { the flow on link } a, \text { and } \\
& c_{a}(x)=\text { the cost function on link } a .
\end{aligned}
$$

It was found that the one-destination model showed significant improvement over the traditional multiple-destination model. The proposed framework could be easily used to instruct evacuees to depart to the destinations based on the previous simulation run. 
Lindell and Prater (2007) discussed the development of a Hurricane Evacuation Management Decision Support System (EMDSS) to model the uncertain behaviors of the hurricane and evacuees. The hurricane EMDSS could display the information about the minimum, most, and maximum probable evacuation time estimates in comparison with the earliest, most, and latest probable estimated times of arrival (ETAs) for storm conditions. It could also calculate the economic cost of an evacuation, and lives lost in a late evacuation decision. It could also be used in the actual hurricane's operations.

Cheng et al. (2008) developed a disaggregate destination choice model for hurricane evacuation by using a multinomial logit model with the post-Hurricane Floyd survey data in South Carolina in 1999. The model was expressed as:

$$
P_{i}=\frac{e^{\boldsymbol{\beta}_{\mathbf{1}}^{T} \mathbf{x}}}{\sum_{j=1}^{J} e^{\boldsymbol{\beta}_{\mathbf{j}}^{T} \mathbf{x}}}
$$

where

$$
\begin{aligned}
& P_{i}=\text { the probability of choosing alternative } i, \\
& \mathbf{x}=\text { the vector of attributes of alternative } i, \\
& \boldsymbol{\beta}=\text { the vector of parameters, and } \\
& J=\text { the number of alternatives. }
\end{aligned}
$$

The model was used to investigate the effects of risk areas in the hurricane path or projected path, and destination socioeconomic and demographic characteristics on destination choice behavior. It was tested by comparing the observed destination choices with predicted values. No significant differences were found, indicating that the model may be a good one. The destination choice model had the ability to capture behavioral 
influences at the disaggregate level, while the aggregate models did not. Thus, it could produce more accurate results than the aggregate models.

Noh et al. (2009) proposed trip generation and distribution models that primarily used trip matrices used in traditional travel demand models to estimate demand for shortnotice evacuation, as shown below:

$$
G_{i}=V_{i} \bullet H_{i}-\sum_{t \in T} \sum_{j \in D} Q_{i j}^{t}+\sum_{t \in T} \sum_{j \in D} Q_{j i}^{t} \quad \forall i \in O
$$

where

$$
\begin{aligned}
G_{i}= & \text { the number of vehicles in zone } i \text { at the start of the evacuation, } \\
V_{i}= & \text { the average vehicles per household in zone } i, \\
H_{i}= & \text { the number of households in zone } i, \\
Q_{i j}^{t}= & \text { the vehicles departing from flooding zone } i \text { to other zone } j \text { during time of } \\
& \text { day } t, \\
Q_{j i}^{t}= & \text { the vehicles departing from other zone } j \text { to other flooding zone } i \text { during } \\
& \text { time of day } t, \\
O= & \text { the set of TAZs that must be evacuated on short notice, } \\
D= & \text { the set of all other TAZs not in the set } O \text {, and } \\
T= & \text { the set of periods in the day that occur up to and including the time when a } \\
& \text { disaster occurs, for a given evacuation scenario. }
\end{aligned}
$$

The method used on-hand data typically generated through existing travel demand models at many metropolitan planning organizations. It estimated demand using convenient models for trip generation, trip distribution, and travel time generation for these trips, considering a staged evacuation. A dynamic simulation model was used to 
model the supply characteristics of the roadway network during the evacuation, based on the demand estimates.

Chen and Chou (2009) used a bilevel optimization model to determine the waiting locations and corresponding shelters of a transit-based emergency evacuation plan and dispatch rescue buses to the combinatorial locations. The model was formulated as:

$$
\min Z_{i}=\sum_{i j} c_{i j} q_{j} x_{i j} y_{j}+\sum_{j} f_{j} y_{j}
$$

where

$$
\begin{aligned}
& i=\text { the bus stop number, } \\
& j=\text { the metro station number, } \\
& Z_{i}=\text { the objective value of this optimization problem, } \\
& c_{i j}=\text { the link travel cost between nodes }(i, j) \text {, } \\
& q_{j}=\text { the capacity of the } j \text { th metro station, } \\
& x_{i j}=\text { the fraction of demand at bus stop } i \text { assigned to metro station } j, \\
& d_{i}=\text { the demand at bus stop } i, \\
& y_{j}=\text { the binary variable: if metro station } j \text { is opened to be a shelter, then } y_{j}=1 \text {; } \\
& \text { otherwise, } y_{j}=0 \text {; and } \\
& f_{j}=\text { the cost to build a shelter at metro station } j \text {. }
\end{aligned}
$$

A contraflow simulation was elaborated to disperse the inside and ambient traffic of the target area. The simulation results could be used for modifying routing plans to avoid potential traffic bottlenecks. It was found that the transit-based evacuation plan with the contraflow operations outperformed the same base plan without the contraflow operations. 
Fu et al. (2007) developed an evacuation response curve model by using the sequential logit model. The model was formulated as:

$$
P_{i}=\operatorname{Pr}\left(U_{i}^{e}-U_{i}^{n} \geq 0\right) \prod_{j=1}^{i-1}\left[1-\operatorname{Pr}\left(U_{j}^{e}-U_{j}^{n} \geq 0\right)\right]
$$

where

$$
\begin{aligned}
& P_{i}=\text { the probability of a household choosing to evacuate in time interval } i, \\
& U_{i}^{e}=\text { the utilities of a household evacuating in time interval } i, \\
& U_{i}^{n}=\text { the utilities of a household not evacuating in time interval } i, \\
& U_{j}^{e}=\text { the utilities of a household evacuating in time interval } j \text {, and } \\
& U_{j}^{n}=\text { the utilities of a household not evacuating in time interval } j .
\end{aligned}
$$

The response curve model incorporated variables such as the characteristics of an incoming hurricane, time of day, and evacuation policy decisions. It could model the effect of different conditions on evacuation behavior. The response curve model was tested with a series of scenarios depicting different storm conditions and different evacuation policies. The same model was applied to predict the evacuation response behavior for Hurricane Andrew, and the result was similar to the observed behavior. This suggests that the model developed was a good one.

Wilmot and Mei (2004) compared the relative accuracy of different forms of trip generation models applied to hurricane evacuation. Conventional participation rate, logistic regression, and various forms of neural network models were evaluated and tested using a data set from the evacuation behavior collected in southwestern Louisiana, following Hurricane Andrew in 1992. The comparison results showed that the logistic 
regression and neural network models performed better in predicting evacuation than did the participation rate model. The overall percentage correctly predicted from the logistic regression and neural network models was above $65 \%$.

Fu and Wilmot (2004) used a sequential logit dynamic travel demand model to perform dynamic traffic assignment during a hurricane evacuation. The model had eight variables. Six variables were static, meaning that they did not change with time. The other two were dynamic and included the distance of a hurricane from landfall and the forward speed of a hurricane at a certain time. With the introduction of two dynamic variables, the model performed better than that with only static variables.

$\mathrm{Fu}$ and Wilmot (2006) used survival analysis-based dynamic travel demand models to estimate the probability of a household evacuating within a certain time interval before hurricane landfall. Two dynamic travel demand models, the Cox proportional hazard model and piecewise exponential model, are shown in the following equations, respectively:

$$
h_{i}(t \mid x)=h_{0}(t) e^{\sum_{\mathrm{j}=1}^{\mathrm{p}} \beta_{\mathrm{j}} x_{i j}}
$$

where

$$
\begin{aligned}
h_{i}(t \mid x)= & \text { the hazard for subject } i \text { taking into account influence of predictor } \\
& \text { variables } x_{i j}, \\
h_{0}(t)= & \text { the nonaggregate baseline hazard function of underlying survival } \\
& \text { distribution when all predictor variables } x_{i j} \text { having value of } 0, \\
\beta_{j} \quad= & \text { the regression coefficient for } j \text { th predictor variable, } \\
x_{i j} \quad= & \text { the } j \text { th predictor variable for subject } i, \text { and }
\end{aligned}
$$


$p \quad=$ the number of predictor variables.

$$
h(t)=h_{j} e^{\boldsymbol{\beta}^{\mathrm{T}} \mathbf{x}} \quad a_{j-1} \leq t \leq a_{j}
$$

where

$$
\begin{aligned}
& h(t)=\text { the hazard for time } t, \\
& h_{j}=\text { the baseline hazard for time interval } j, \\
& \mathbf{x}=\text { the vector of predictor variables, } \\
& \boldsymbol{\beta}=\text { the vector of parameters, and } \\
& a \quad=\text { the cutpoint of time interval. }
\end{aligned}
$$

The authors discussed both models in detail. Data from southeastern Louisiana collected in the days leading up to Hurricane Andrew were applied to both models. It was found that both models were able to model the dynamic travel demand during hurricane evacuation. It appeared that the piecewise exponential model performed better than the Cox proportional hazard model.

Brown et al. (2009) described the development of a hurricane evacuation model for the Greater Houston, Texas area. The dynamic traffic assignment model, which incorporated mesoscale simulation of queues on evacuation routes, was integrated into the model to evaluate the performance of major evacuation routes within the Greater Houston area. This model was intended for screening and evaluating the evacuation plans based on systemwide performances and zone-specific clearance times. This model could be used for the comparison of the related system and evacuation corridor performance of alternative policy scenarios. 
Tuydes and Ziliaskopoulos (2006) introduced a Tabu search-based heuristic approach that could optimize the network evacuation contraflow on realistic-size networks. The approach was defined as:

$$
\min \sum_{o \in \mathbf{C}_{\mathbf{R}}} \sum_{d \in \mathbf{C}_{\mathbf{S}} I \in \mathbf{C}_{\mathbf{G}}^{a} \cup \mathbf{C}_{\mathbf{R}}} \sum_{t \in \mathbf{T}} x_{I}^{o d, t} \Delta t
$$

where

$$
\begin{aligned}
& \mathbf{C}_{\mathbf{R}}=\text { the set of source cells, } \\
& \mathbf{C}_{\mathbf{S}}=\text { the set of sink cells, } \\
& \mathbf{C}_{\mathbf{G}}=\text { the set of general cells, } \\
& \mathbf{C}_{\mathbf{G}}^{a}=\text { the set of general cells, } \\
& \mathbf{T}=\text { the set of discrete time intervals, } \\
& I \quad=\text { the cell } i \text { with the extended capacity in the redesigned network, } \\
& o=\text { the source cell for the origin nodes, } \\
& d=\text { the sink cell for the destination nodes, } \\
& o d=\text { the given origin-destination (O-D) pair between which there is some } \\
& t \quad=\text { the time interval, and } \\
& x_{i}^{t}=\text { the number of vehicles in cell } i \text { at time interval } t .
\end{aligned}
$$

The approach relied on insights from an analytical formulation of optimal reversibility design that reduces total system travel time. A hypothetical network evacuation was studied with and without contraflow options. It was found that the total system travel time for the evacuation was reduced significantly by applying the contraflow, compared to not applying contraflow. 
Xie and Turnquist (2009) developed an optimization method to identify an evacuation network reconfiguration when specific routes have to be reserved for emergency vehicles to access the evacuation area. This problem was addressed by first identifying the candidate emergency vehicle routes, then constraining the reconfiguration of the network for evacuees. The proposed model considered two evacuation planning components: lane reversal on roadway sections and crossing elimination at intersections offering a practical advantage to evacuation planning. These strategies complemented one another by increasing capacity in specific directions through the network. The proposed models are formulated as:

$$
\begin{aligned}
& \min t(\mathbf{x}, \mathbf{n})=\sum_{l \varsigma} x_{l \varsigma} t_{l \varsigma}\left(x_{l \varsigma}-n_{\imath \kappa}\right) \\
& t_{\iota \varsigma}\left(x_{\iota \varsigma}-n_{l \kappa}\right)=t_{l \varsigma}^{0}\left(1+\alpha\left(\frac{x_{l \varsigma}}{c_{l \zeta}}\right)\left(n_{l \kappa}\right)\right)
\end{aligned}
$$

where

$$
\begin{aligned}
& t=\text { the free-flow travel time, } \\
& \mathbf{x}=\text { the vector of evacuation flow rate, } \\
& \mathbf{n}=\text { the vector of connectivity indicator, } \\
& x_{t \varsigma}=\text { the evacuation flow rate on link } l \rightarrow \varsigma, \\
& t_{t \varsigma}=\text { the travel time on link } l \rightarrow \varsigma, \\
& n_{t \kappa}=\text { the number of lanes on link pair } l \rightarrow \varsigma \rightarrow \kappa, \\
& t_{t \varsigma}^{0}=\text { the free flow travel time on link } l \rightarrow \varsigma, \\
& c_{t \varsigma}=\text { the capacity of roadway-section on link pair } l \rightarrow \varsigma, \text { and } \\
& \alpha=\text { the coefficient. }
\end{aligned}
$$




\subsubsection{Computer Simulation}

Computer simulation technology has been used to simulate traffic conditions during hurricane evacuations so that transportation planners can test the feasibility of the developed transportation plans for application to a given hurricane evacuation. Theodoulou (2001) used the CORSIM 5.0 simulation model results to evaluate the effectiveness of the contraflow segment on westbound I-10, out of the city of New Orleans. Alternative plans were also developed to compare the effectiveness of the contraflow operation. The simulation results revealed that the use of contraflow lanes could increase the traffic flow significantly. By comparing the alternatives plans, it was found that the plan that used multiple entry nodes in the segment had the largest traffic flow.

Theodoulou and Wolshon (2004) described an alternative method to increase the effectiveness of freeway contraflow during such evacuations. A New Orleans evacuation plan was used as an example to demonstrate how to use CORSIM, a microscopic traffic simulation model, to simulate contraflow freeway operation. The study concluded that the entry point of contraflow operation plays an important role in determining its effectiveness.

Liu et al. (2005) described a case study of an emergency evacuation system integrating both optimization and microscopic simulation methods. The data from Ocean City, Maryland, gathered during hurricane strikes, were used to test the system. The system consists of five modules: an input module, an optimization module, a simulation module, an output module, and a database module. CORSIM was used in the simulation 
module. The system can help users find effective evacuation control strategies in a timely manner.

Chen et al. (2006) conducted agent-based microsimulations to simulate a hurricane evacuation in the Florida Keys. The number of evacuating vehicles was determined based on the following equation:

$$
N_{v}=N_{u} N_{v u} R_{p} R_{o} P_{v u}
$$

where

$$
\begin{aligned}
& N_{v}=\text { the number of evacuating vehicles, } \\
& N_{u}=\text { the number of housing units, } \\
& N_{v u}=\text { the number of vehicles per housing unit, } \\
& R_{p}=\text { the percentage of people participating in an evacuation, } \\
& R_{o}=\text { the occupancy rate of the housing units, and } \\
& P_{v u}=\text { the percentage of vehicle usage. }
\end{aligned}
$$

The simulation results served as a validation to those from a previous report on the hurricane evacuation in the Florida Keys that used macrosimulation. The microsimulation results showed that the evacuation time was much shorter than that of the macrosimulation. The microsimulation results also showed the number of people that became stranded on the evacuation route after the evacuation route became impassible. It was obvious that the agent-based microsimulation could provide the emergency managers and planners with a better understanding of emergency evacuation in order for them to develop proper evacuation plans. 
Lahmar et al. (2006) described a dynamic network optimization-based solution framework. The framework consists of a transportation management function, a logistics support and capacity fine-tuning function, and a validation function, and could help transportation planners and emergency agencies in evaluating transportation capacity infrastructure and conducting an effective and safe evacuation of large metropolitan areas within a reasonable time frame.

Chen (2008) investigated the effectiveness of simultaneous and staged evacuation strategies for hurricane evacuations of Galveston Island, Texas, using agent-based microsimulation techniques. The simultaneous evacuation strategies were compared to staged evacuation strategies. The comparison results indicated that the most efficient staged evacuation strategy could help reduce the evacuation time for Galveston Island by approximately one hour. Agent-based modeling was a powerful technique that was used to simulate individual interactions and capture group behavior resulting from individual interactions in a dynamic system. It could estimate the evacuation clearance time more accurately than the macrosimulation technique.

\subsubsection{Intelligent Transportation Systems}

Intelligent Transportation Systems (ITS) technology has been applied to traffic operation during hurricane evacuations in recent years. ITS improves transportation safety and mobility, and enhances productivity through the use of advanced communications technologies. Morrow (2002) discussed how ITS was implemented during a hurricane evacuation in Florida. Design and operational issues of ITS implementation were discussed. ITS uses field equipment, such as surveillance cameras 
and vehicle detectors, to monitor the real-time traffic conditions on highways. It can provide current traffic information to travelers by using dynamic message signs deployed along highways. It was extremely important for drivers to be informed of up-to-date traffic conditions during a hurricane evacuation so that they can make informed decisions as to whether to continue on the same route or use an alternate route.

\subsubsection{Geographic Information Systems}

Geographic Information Systems (GIS) have been used in hurricane evacuation analysis. Ibaugh (1996) developed a prototype GIS-Transportation (GIS-T) database for a study region that included southwestern coastal counties. The database consists of the transportation resources, hydrographic features, emergency shelter locations, and demographic characteristics of the study region. A hurricane evacuation model was developed to utilize the database to forecast travel demand under evacuation conditions. The travel demand information can be used to analyze the status of the transportation network, such as identifying congested locations. The prototype GIS-T-based system could be used to analyze and evaluate hurricane evacuation scenarios.

Corbley (1999) described how the South Carolina Department of Transportation (SCDOT) applied GIS technology and the Internet to assist in the evacuation preceding Hurricane Floyd in 1999. SCDOT developed a hurricane evacuation system that could monitor the real-time traffic status on the evacuation road network, with the help of traffic counters deployed along the roads. The system integrated GIS with the Internet, enabling staff to use GIS through the Internet without knowledge of how to use GIS. 
This system helped the emergency agency staff to implement the evacuation preceding Hurricane Floyd.

Zhou et al. (2006) introduced an application frame that integrated GIS with the real-time traffic simulation system. Real-time traffic information is critical for both road users and traffic operators. It enables road users to choose the best routes possible and traffic operators to make the right decisions in case of emergency. GIS has the advantage in processing the spatial information. The new integrated system could provide road users with real-time road information in a flexible way.

Kar and Hodgson (2008) used a GIS-based suitability model to determine the suitability of emergency evacuation shelters in 17 counties in Florida, as defined below:

$$
\text { Score }=\left(\sum_{j}^{n} F R_{j} \times w_{j}\right) \times\left(F C_{1} \times F C_{2} \times \ldots \times F C_{n}\right)
$$

where

$$
\begin{aligned}
& \text { Score }=\text { the summary suitability score for the location, } \\
& F R_{j}=\text { the factor rating for factor } j, \\
& w_{j} \quad=\text { the weight assigned to factor } j, \text { and } \\
& F C_{i}=\text { the factor constraint for variable } i .
\end{aligned}
$$

Emergency evacuation shelters were the places for the elderly or lower income populations for temporary housing during hurricane strikes. The suitability of these shelters was important for emergency agencies. The existing and candidate shelters were ranked based on their site suitability. This provided useful information to the emergency agencies in the planning of emergency evacuation shelters. 
Massey (2008) discussed the modernized hurricane evacuation study process, compared to the traditional one. The new process utilized the GIS technology to develop a GIS tool set that used the data from the hurricane evacuation studies and the real-time weather data from the National Weather Service. The community demographic data could be overlaid with the hazards data and the real-time weather data to allow emergency officials to make up-to-date and correct decisions prior to and during the hurricane evacuation.

\subsubsection{Geographically Weighted Regression}

The Geographically Weighted Regression (GWR) is becoming more popular. The GWR is a technique that deals with spatial variations in the predictor variables. The OLS regression, which is the traditional regression method, cannot deal with local spatial variations properly since it assumes the relationship is the same globally. Local spatial variations may result in large model errors. There are a lot of data that are spatially related, such as trip origin and destination locations, property parcel locations, and so forth. Therefore, the GWR may be an appropriate method to model the spatial-related data with local variations.

As for modeling the spatial variations, Brunsdon et al. (1998) discussed the drawback of the linear regression due to existence of the spatial variations in predictor variables. The GWR was introduced as an alternative to model the predictor variables with spatial variations. Brunsdon et al. (1999) also discussed some analytically derived significance tests that allowed a test of no spatial variations. Brunsdon et al. (2001) introduced Akaike's Information Criterion (AIC) and demonstrated how to use AIC to 
compare the GWR models to other models in order to determine which models are best. The definition of AIC is shown below:

$$
\mathrm{AIC}=-2 \log \left(L\left(\hat{\alpha}_{j} \mid x_{1} \cdots x_{n}\right)\right)+2 k_{j}
$$

where

$$
\begin{aligned}
& \text { AIC } \quad=\text { the Akaike Information Criterion, } \\
& \begin{array}{ll}
\hat{\alpha}_{j} & =\text { the maximum likelihood estimate of } \alpha_{j}, \\
L\left(\hat{\alpha}_{j} \mid x_{1} \cdots x_{n}\right) & =\text { the likelihood of } \hat{\alpha}_{j} \text { given the data sample }\left\{x_{1,}, x_{2} \ldots, x_{n}\right\}, \text { and } \\
k_{j} & =\text { the bias. }
\end{array}
\end{aligned}
$$

Ali et al. (2007) found that the GWR approach could identify the spatial variations in the predictor variables that were understated by the standard approaches, like Ordinary Least Square (OLS). It was found that the GWR approach may improve the regional planning and policy making when spatial variations existed.

There are some GWR applications in the transportation field. Zhao and Park (2004) used the GWR to estimate the annual average daily traffic (AADT). The spatial variation of the GWR model and the estimation errors were analyzed. The Ordinary Least Square (OLS) regression was also used to estimate the ADDT. The results from the GWR were compared with those of the OLS. It was concluded that the GWR model produced more accurate results than the OLS, due the existence of spatial variations in predictor variables.

Chow et al. (2006) developed the GWR model to find the relationship between public transit use for home-based work trip purposes and some potential transit use predictor variables. The linear regression model was also developed to find the 
relationship for comparison purposes. The GWR model produced a better result than the linear regression model. It was found that spatial variations existed in the predictor variables.

Hadayeghi et al. (2003) used negative binomial regression to separately model the total number of accidents and severe accidents as a function of socioeconomic, demographic, traffic volume, and roadway characteristics data variables. The GWR was used to check if the spatial variations existed in the predictor variables. It was found that the GWR improved the model developed by negative binomial regression, and the spatial variation only occurred in the predictor variable interchange density. It was also found that the limitation of the GWR technique was the assumption of normally distributed errors that were not valid for modeling accident data.

Hadayeghi et al. (2010) used the Geographically Weighted Poisson Regression (GWPR) to create the collision prediction models that were originally created by Generalized Linear Modeling (GLM). The model was formulated as:

$$
\ln (A)=\ln \left(\beta_{0}\left(\boldsymbol{u}_{i}\right)\right)+\beta_{1}\left(\boldsymbol{u}_{i}\right) \ln (V K T)+\beta_{2}\left(\boldsymbol{u}_{i}\right) X_{2}+\cdots+\beta_{p}\left(\boldsymbol{u}_{i}\right) X_{p}
$$

where

$$
\begin{aligned}
& \ln (A)=\text { the natural } \log \text { of collision frequency, } \\
& V K T=\text { the vehicle kilometers traveled, } \\
& \beta_{j} \quad=\text { the } j \text { th model parameter }(j=0,1,2, \ldots, p), \\
& X_{j} \quad=\text { the } j \text { th explanatory variable }(j=2, \ldots, p), \text { and } \\
& \boldsymbol{u}_{i} \quad=\text { the function of location denoting the coordinates of the } i \text { th point. }
\end{aligned}
$$


It was found that the spatial variations existed in the predictor variables. The results from the GWPR models were compared to those from the GLM models. It showed that the GWPR models performed better than the GLM models.

Clark (2004) explored the relationship between the car ownership and the household income by using both GWR and OLS. There were spatial variations in household income in the study area. The model results from the GWR were compared to those from the OLS. It was found that the GWR model produced better results than the OLS model.

Mulley and Tanner (2009) used the GWR to develop the Vehicle Kilometers Traveled (VKT) model that was originally developed by the OLS regression. The model results from the GWR were compared to those from the OLS. It was found that the model developed by the GWR improved the original model, due to the existence of the spatial variations in the travel behavior variables.

Hu and Mulley (2007) used the GWR to model the relationship between the transport accessibility and the land value to address the issues of spatial variations. It was found that the relationship varied from place to place. The model results from the GWR were compared to those from the OLS. It was concluded that the GWR was more successful in modeling the relationship between the transport accessibility and the land value than the OLS.

Mountain et al. (2007) applied the GWR to model the realistic transportation network conditions by using the long-term previous users' experience of that network. The objective of the GWR application was to evaluate if the GWR is suitable to model the accessibility via transportation networks. It was found that the GWR model produced 
better results than the OLS model due to the existence of spatial variations of predictor variables.

The GWR were also applied in some other fields, such as economics, hydrology, environment, emergency management, and real estate. Huang and Leung (2002) used the GWR to analyze the regional industrialization in the Jiangsu Province, China. By comparing the results from the GWR model to those from the OLS model, it was found that considerable spatial variations existed in the factors that determined the level of industrialization.

Atkinson et al. (2003) used the Geographically Weighted Logistics Regression (GWLR) approach to model the relationship between the presence or absence of river bank erosions and geomorphological variables. It was found that the spatial variations existed in geomorphological variables. This implied that the GWLR approach may be the one that could model the spatially varying geomorphological process.

Calvo and Escolar (2003) proposed the GWR approach to solve the problems of spatial aggregation bias and spatial autocorrelation that would produce the biased estimates of ecological data. It was found that the well-specified GWR approach may result in unbiased and consistent local estimates of ecological data with the presence of extreme spatial variations.

Yu (2006) investigated the spatial variations in China's regional development mechanisms by using the GWR on spatial datasets in the Greater Beijing area, China. The results showed that the spatial variations existed in the regional development mechanisms in the Greater Beijing area. It was concluded that it was important to take into account the spatial variations while modeling the regional development mechanisms. 
Yamashita (2008) used the OLS and GWR techniques to find out how socioeconomic and demographic characteristics contribute to the fire risk at the U.S. Census block group level. The results from the OLS model were compared to those from the GWR model. Although little significant spatial variations were found in the predictor variables by the GWR technique, it provided insights that greatly improved the understanding of the relationships between the fire incidences and socioeconomic and demographic characteristics.

Legg and Bowe (2009) used the GWR tool in Esri ArcGIS 9.3 to analyze the distribution of the listed sales price for single family houses as a function of house square footage and lot size. A global model predicting the listed sales price was also created by using the OLS regression. It was found that the GWR model generated a better result than the OLS model.

\subsection{Summary}

A comprehensive literature search and review was performed and summarized in this section to investigate and assess hurricane evacuation practices. The purposes of the review are to identify the problems pending to be solved, to determine research objectives, and to form the research framework and tasks for this dissertation. The findings from the review are summarized as follows:

- Behavioral Analysis: Behavioral analyses deals with peoples' responses during a hurricane evacuation. The literature reviewed showed that peoples' responses in a hurricane evacuation were affected by many factors, such as the socioeconomic status, demographic information, hurricane forecast information, etc. The 
dissemination of emergency information played an important role in helping people make decisions on whether to evacuate or stay in the event of a hurricane. Consistency in evacuation policy would be helpful for the evacuation process.

- Transportation Planning: The transportation planning for a hurricane evacuation plays an important role in the entire evacuation process. The literature reviewed revealed that multi-agency cooperation and policymaking play important roles in transportation planning for hurricane evacuation. Transportation network planning is a critical part of the evacuation planning. It is also important to take into account the restricted and special needs population in transportation planning for hurricane evacuation.

- Traffic Operation: The traffic operation deals with the operation of the transportation network during hurricane evacuation. The literature reviewed indicated that the contraflow traffic operation for hurricane evacuation is a potential solution to reduce the highway congestion.

- Applied Technology: Various technologies have been applied in hurricane evacuation-related studies. The literature reviewed showed that the advancement of modeling technology helped improve the accuracy of hurricane evacuation models, and the emerging technology, like GWR, changed the way of regression analysis compared to the traditional regression method. Computer simulation has been widely used in simulating traffic conditions during a hurricane evacuation. It provided transportation planners a way to test the transportation solutions before being applied to the real world. 


\section{CHAPTER 3 METHODOLOGY}

The prediction models developed in this research include: the evacuation rate prediction model, evacuation trip prediction model, and evacuation trip distance prediction model. Section 3.1 briefly describes the methodology applied to develop the prediction models. Sections 3.2 to 3.4 describe the methodology applied to develop each model in detail, respectively.

\subsection{Methodology Overview}

The evacuation rate prediction model is used to predict the total number of households that will evacuate during hurricane evacuation. The data to be used to develop this model are the hurricane evacuation survey data. The evacuation trip prediction model is used to predict the number of the households that will evacuate on a given day before hurricane landfall. This model only deals with the evacuees. The data to be used to develop this model are different than that used to develop the evacuation rate prediction model. The survey data only contains the households that evacuated during hurricane evacuation. The evacuation rate prediction model and evacuation trip prediction model are used together to predict the number of the households that will evacuate on a daily basis. The evacuation trip distance prediction model is used to predict the evacuation distance the evacuees will travel during hurricane evacuation. The

data used to develop this model are the same as the data used to develop the evacuation trip prediction model. 
Different statistical methods are used to develop the prediction models since the outcome variable in each model is different from each other, as shown in Table 3-1. It is noted that two statistical methods, the Ordinary Least Square (OLS) and Geographically Weighted Regression (GWR), are used to develop the evacuation trip distance prediction model. The OLS is a linear regression that treats the study area globally. The GWR is based on the linear regression and treats the study area locally. The model will first be developed by the OLS. Then the spatial variations of predictor variables of the model are checked by the statistical diagnostics. The spatial variation means that the predictor variables in a model have different impacts on the outcome variable in different places of the study area. For example, the income level of a household living near the hurricane forecast track may have a bigger impact than the household living far from the hurricane forecast track. If the spatial variations were identified in the model developed, the GWR would be used to develop the same model in lieu of the OLS. The methodology applied to develop the prediction models is shown in Figure 3-1.

Table 3-1: Methodology Applied to Develop the Prediction Models

\begin{tabular}{|l|l|l|}
\hline Model Name & Outcome Variable & Statistical Method(s) \\
\hline Evacuation Rate & Evacuation Status (2 categories) & Binomial Logistic Regression \\
\hline Evacuation Trip & Evacuation Day (3 categories) & Multinomial Logistic Regression \\
\hline Evacuation Distance & $\begin{array}{l}\text { Evacuation Distance } \\
\text { (Quantitative) }\end{array}$ & OLS \\
GWR
\end{tabular}

\subsection{Evacuation Rate Prediction Model}

The outcome variable in the evacuation rate prediction model has two possible values, stayed or evacuated. It is a categorical variable with two categories. Therefore, the binomial logistic regression will be used to develop the evacuation rate prediction 
model. The binomial logistic regression tool in $\mathrm{R}$ Project software will be used to develop this model.

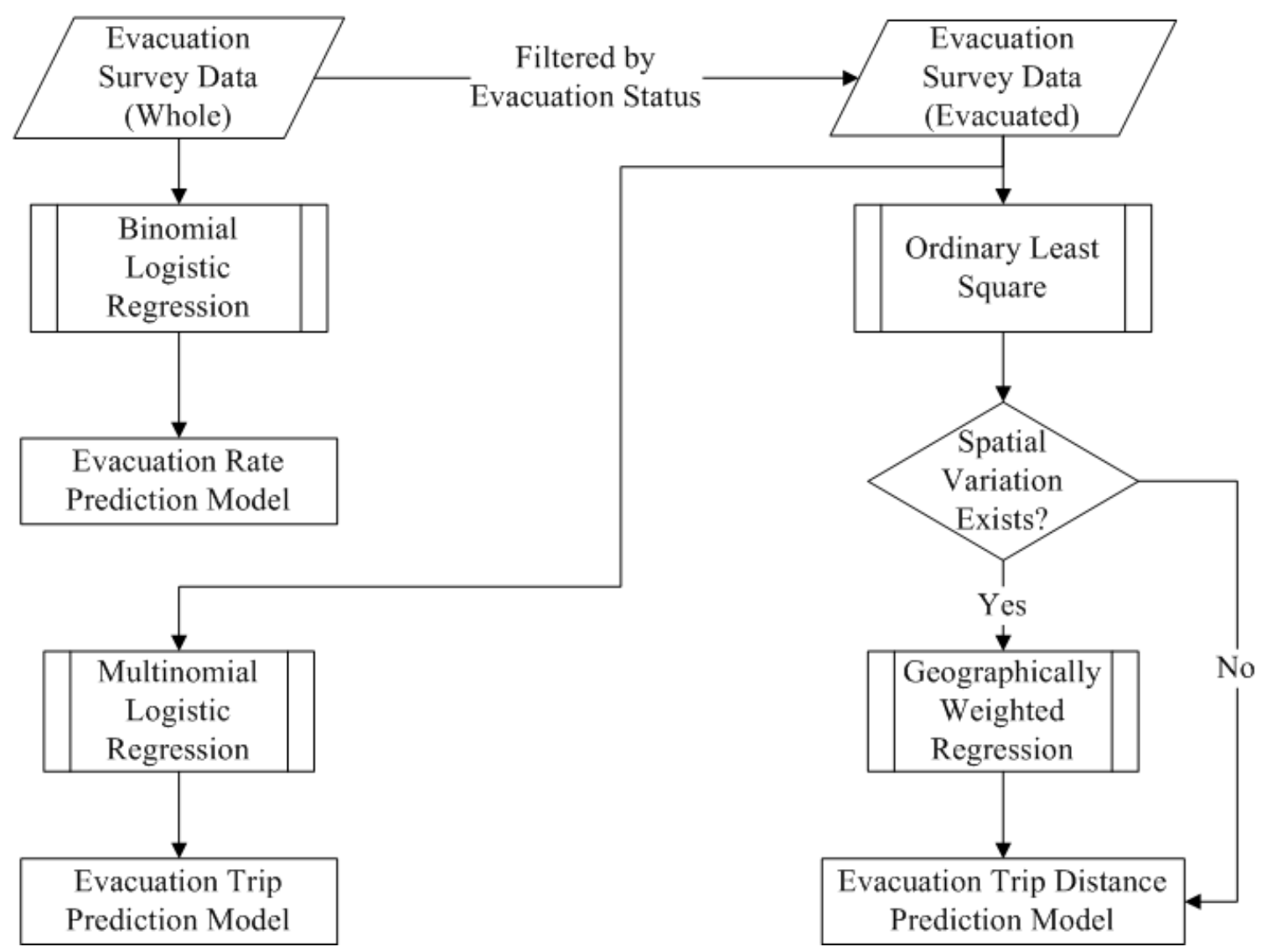

Figure 3-1: Methodology Applied to Develop the Hurricane Evacuation Models

The conditional probability of each outcome category, given the predictor variable matrix, is formulated as follows (Hosmer and Lemeshow, 2000):

$$
\begin{gathered}
P(Y=0 \mid \mathbf{x})=1-P(Y=1 \mid \mathbf{x}) \\
P(Y=1 \mid \mathbf{x})=\frac{e^{g(x)}}{1+e^{g(x)}}=\frac{1}{1+e^{-g(x)}}
\end{gathered}
$$

where

$$
\begin{aligned}
& \mathbf{x}=\text { the predictor variable vector, } \\
& P(Y=0 \mid \mathbf{x})=\text { the conditional probability of the } 1 \text { st outcome category, }
\end{aligned}
$$


$P(Y=1 \mid \mathbf{x})=$ the conditional probability of the 2 nd outcome category, and

$g(\mathbf{x}) \quad=\quad$ the logit function.

The first outcome category is usually selected as the reference category. The probability calculated from the binomial logistic regression is the ratio of the probability of second outcome category and the first outcome category if it is selected as the reference outcome category. The logit function is defined as (Hosmer and Lemeshow, 2000):

$$
g(\mathbf{x})=\ln \left(\frac{P(Y=1 \mid \mathbf{x})}{P(Y=0 \mid \mathbf{x})}\right)=\beta_{0}+\sum_{i=1}^{n} \beta_{i} x_{i}
$$

where

$$
\begin{array}{ll}
n & =\text { the total number of predictor variables, } \\
x_{i} & =\text { the } i \text { th predictor variable, } \\
\beta_{0} & =\text { the constant term in the logit function, and } \\
\beta_{i} & =\text { the coefficient of } x_{i} \text { in the logit function. }
\end{array}
$$

The predictor variable vector represents the collection of the predictor variables in the evacuation rate prediction model, such as age, gender, household size, education level, and income level. There are two possible values in the outcome variable, "Stayed" or "Evacuated." The conditional probability is the probability of the households that will evacuate during the hurricane evacuation if the first outcome category, for example, "Stayed," is selected as the reference category. The probability value will be converted to the number of the households that will evacuate. The method to do the conversion is to categorize the household by the predictor variables in the model. Then, the number of the households in each category can be counted in the study area. Finally, the number of 
households for each category that will evacuate can be calculated by multiplying the number of the households in the corresponding category by the corresponding probability value.

The traditional linear regression uses the maximum likelihood to assess the goodness-of-fit. For the binomial logistic regression, the likelihood function should be constructed in order to calculate the diagnostic statistic. The deviance can be calculated by the following equation (Hosmer and Lemeshow, 2000):

$$
\begin{aligned}
D & =\frac{\text { likelihood of the fitted model }}{\text { likelihood of the saturated model }} \\
& =-2 \sum_{i=1}^{n}\left(y_{i} \ln \left(\frac{\hat{\pi}_{i}}{y_{i}}\right)+\left(1-y_{i}\right) \ln \left(\frac{1-\hat{\pi}_{i}}{1-y_{i}}\right)\right)
\end{aligned}
$$

where

$$
\begin{aligned}
& D=\text { the deviance, } \\
& y_{i}=\text { the } i \text { th outcome variable, and } \\
& \hat{\pi}_{i}=\text { the } i \text { th maximum likelihood estimate of the conditional mean. }
\end{aligned}
$$

The conditional mean in Equation 3-4 is defined as (Hosmer and Lemeshow, 2000):

$$
\pi(\mathbf{x})=\frac{e^{g(\mathbf{x})}}{1+e^{g(\mathbf{x})}}
$$

where

$$
\begin{aligned}
& \pi(\mathbf{x})=\text { the conditional mean, and } \\
& g(\mathbf{x})=\text { the logit function. }
\end{aligned}
$$


The deviance difference between the models without and with the variable can then be used to assess the goodness-of-fit of model. The deviance difference can be calculated as follows (Hosmer and Lemeshow, 2000):

$$
\begin{aligned}
G & =D(\text { model without the variable })-D(\text { model with the variable }) \\
& =-2 \ln \left(\frac{\text { likelihood without the variable }}{\text { likelihood with the variable }}\right)=-2 \ln \left(\frac{\left(\frac{n_{1}}{n}\right)^{n_{1}}\left(\frac{n_{0}}{n}\right)^{n_{0}}}{\prod_{i=1}^{n} \hat{\pi}_{i}^{y_{i}}\left(1-\hat{\pi}_{i}\right)^{\left(1-y_{i}\right)}}\right)
\end{aligned}
$$

where

$$
\begin{aligned}
& G=\text { the deviance difference } \\
& D=\text { the deviance } \\
& n_{1}=\sum y_{i}, \\
& n_{0}=\sum\left(1-y_{i}\right), \text { and } \\
& n=\text { the total number of predictor variables. }
\end{aligned}
$$

\subsection{Evacuation Trip Prediction Model}

The outcome variable in the evacuation trip prediction model has three possible values: an evacuation taking place three days, two days, and one day before hurricane landfall. It is a categorical variable with three categories. Therefore, the multinomial logistic regression will be used to develop the evacuation trip prediction model. The multinomial logistic regression tool in the R Project software will be used to develop this model.

The conditional probability of each outcome category, given the predictor variable matrix, is formulated as follows (Hosmer and Lemeshow, 2000): 


$$
\begin{gathered}
P(Y=0 \mid \mathbf{x})=\frac{1}{1+\sum_{k=1}^{m} e^{g_{k}(\mathbf{x})}} \quad(m \geq 1) \\
P(Y=j \mid \mathbf{x})=\frac{e^{g_{j}(\mathbf{x})}}{1+\sum_{k=1}^{m} e^{g_{k}(\mathbf{x})}} \quad(1 \leq j \leq m \quad \text { and } m \geq 1)
\end{gathered}
$$

where

$$
\begin{aligned}
& P(Y=0 \mid \mathbf{x})=\text { the conditional probability of the 1st outcome category, } \\
& P(Y=j \mid \mathbf{x})=\text { the conditional probability of the } j \text { th outcome category, } \\
& m \quad=\text { the total number of the logit function, which equals the number of } \\
& \text { outcome categories minus } 1 \text {, } \\
& g_{j}(\mathbf{x}) \quad=\text { the logit function for the } j \text { th category, and } \\
& g_{k}(\mathbf{x})=\text { the logit function for the } k \text { th category. }
\end{aligned}
$$

The first outcome category is usually selected as the reference outcome category. The probability of each non-reference outcome category calculated from the multinomial logistic regression is the ratio of the probability of the non-reference outcome category and the reference outcome category. The logit function is defined as (Hosmer and Lemeshow, 2000):

$$
g_{j}(\mathbf{x})=\ln \left(\frac{P(Y=j \mid \mathbf{x})}{P(Y=0 \mid \mathbf{x})}\right)=\beta_{j 0}+\sum_{i=1}^{n} \beta_{j i} x_{i} \quad(1 \leq j \leq m)
$$

where

$$
\begin{array}{ll}
\beta_{j i} & =\text { the coefficient of } x_{i} \text { in the logit function for the } j \text { th category, and } \\
\beta_{j 0} & =\text { the constant term in the logit function for the } j \text { th category. }
\end{array}
$$


The predictor variable in the evacuation trip prediction model is similar to that in the evacuation rate prediction model. There are three possible values for the outcome variable: "Evacuated Three Days before Hurricane Landfall," "Evacuated Two Days before Hurricane Landfall," or "Evacuated One Day before Hurricane Landfall." The conditional probability is the probability of evacuees who will evacuate two days or one day before hurricane landfall if the first outcome category, for example, "Evacuated Three Days before Hurricane Landfall," is selected as the reference category. The method used to calculate the number of the households that will evacuate in the evacuation rate prediction model can be used to calculate the number of the households that will evacuate three days, two days, or one day before hurricane landfall. These numbers are based on those calculated in the evacuation rate prediction model.

For the multinomial logistic regression, the likelihood function should also be constructed in order to calculate the diagnostic statistic. The deviance residual for each category can be calculated by the following equation (Hosmer and Lemeshow, 2000):

$$
d\left(y_{j}, \hat{\pi}_{j}\right)= \pm \sqrt{2\left(y_{j} \ln \left(\frac{y_{j}}{q_{j} \hat{\pi}_{j}}\right)+\left(m_{j}-y_{j}\right) \ln \left(\frac{q_{j}-y_{j}}{q_{j}\left(1-\hat{\pi}_{i}\right)}\right)\right)}
$$

where

$$
\begin{aligned}
& d\left(y_{j}, \hat{\pi}_{j}\right)=\text { the deviance residual for the } j \text { th category, } \\
& q_{j} \quad=\quad \text { the outcome variable for the } j \text { th category, and } \\
& \hat{\pi}_{j} \quad=\text { the maximum likelihood estimate of the conditional mean for the } \\
& j \text { th category. }
\end{aligned}
$$


The conditional mean in Equation 3-10 is defined as (Hosmer and Lemeshow, 2000):

$$
\pi\left(\mathbf{x}_{j}\right)=\frac{e^{g\left(\mathbf{x}_{j}\right)}}{1+e^{g\left(\mathbf{x}_{j}\right)}}
$$

where

$$
\begin{aligned}
& \mathbf{x}_{j}=\text { the predictor variable matrix for the } j \text { th category, } \\
& \pi\left(\mathbf{x}_{j}\right)=\text { the conditional mean for the } j \text { th category, and } \\
& g\left(\mathbf{x}_{j}\right)=\text { the logit function for the } j \text { th category. }
\end{aligned}
$$

The deviance can be calculated by summing up all the squared deviance residuals (Hosmer and Lemeshow, 2000):

$$
D=\sum_{j=1}^{m}\left[d\left(y_{j}, \hat{\pi}_{j}\right)\right]^{2}
$$

where

$$
\begin{aligned}
& D \quad=\text { the deviance, and } \\
& d\left(y_{j}, \hat{\pi}_{j}\right)=\text { the deviance residual for the } j \text { th category. }
\end{aligned}
$$

The deviance difference, $\mathrm{G}$, between the models without and with the variable can then be used to assess the goodness-of-fit of model (Hosmer and Lemeshow, 2000).

$$
G=D(\text { model without the variable })-D(\text { model with the variable })
$$

\subsection{Evacuation Trip Distance Prediction Model}

Both the Ordinary Least Square (OLS) and Geographically Weighted Regression (GWR) will be used to develop the evacuation trip distance prediction model. The OLS is a global regression method that assumes that the regression coefficients are constant in 
the whole study area. The survey data covers the coastal areas of three states: Louisiana, Mississippi, and Alabama. It is possible that the evacuation distances of the households vary from area to area. It may not be appropriate to model the evacuation distance in a study area by a global regression method, which may create a large prediction bias in some areas. In order to take into account the spatial variations that occur in the evacuation distance prediction model, the GWR, a regression method that can model the spatial variation, will be used to develop the model. The statistical diagnostic tests will be performed in the model developed by both regression methods. The results of statistical diagnostic tests are then compared to one another to find out whether or not the spatial variations exist in the evacuation distance prediction model. If so, the model developed by the GWR will be used as the final model. The OLS and GWR tools in Esri ArcGIS 9.3 will be used to develop the model.

The evacuation distance prediction models developed by the OLS and GWR are shown in the following equations (Fotheringham et al., 2002), respectively:

$$
y=\beta_{0}+\sum_{i=1}^{n} \beta_{i} x_{i}+\varepsilon
$$

where

$$
\begin{aligned}
& y=\text { the outcome variable, } \\
& n=\text { the number of predictor variables, } \\
& x_{i}=\text { the } i \text { th predictor variable, } \\
& \beta_{i}=\text { the } i \text { th coefficient for } x_{i}, \text { and } \\
& \varepsilon \quad=\text { the error term. }
\end{aligned}
$$




$$
y(\mathbf{g})=\beta_{0}(\mathbf{g})+\sum_{i=1}^{n} \beta_{i}(\mathbf{g}) x_{i}+\varepsilon
$$

where

$$
\begin{aligned}
& y(\mathbf{g})=\text { the outcome variable given the location matrix } \mathbf{g}, \text { and } \\
& \beta_{i}(\mathbf{g})=\text { the } i \text { th coefficient given the location matrix } \mathbf{g} .
\end{aligned}
$$

The regression coefficients of the models developed by the OLS and GWR are estimated by the following equations (Fotheringham et al., 2002), respectively:

$$
\hat{\boldsymbol{\beta}}=\left(\mathbf{X}^{\mathrm{T}} \mathbf{X}\right)^{-1} \mathbf{X}^{\mathrm{T}} \mathbf{Y}
$$

where

$$
\begin{aligned}
& \hat{\boldsymbol{\beta}}=\text { the estimator vector of coefficient, } \\
& \mathbf{X}=\text { the predictor variable vector, and } \\
& \mathbf{Y}=\text { the outcome variable vector. }
\end{aligned}
$$

$$
\hat{\boldsymbol{\beta}}(\mathbf{g})=\left(\mathbf{X}^{\mathrm{T}} \mathbf{W}(\mathbf{g}) \mathbf{X}\right)^{-1} \mathbf{X}^{\mathrm{T}} \mathbf{W}(\mathbf{g}) \mathbf{Y}
$$

where

$$
\begin{aligned}
& \hat{\boldsymbol{\beta}}(\mathbf{g})=\text { the estimator vector of coefficient given the location matrix } \mathbf{g} \text {, and } \\
& \mathbf{W}(\mathbf{g})=\text { the weighting matrix given the location matrix } \mathbf{g} \text {. }
\end{aligned}
$$

It is noted that the only difference between Equation 3-14 and Equation 3-15 is that the model developed by the GWR has the weighting matrix $\mathbf{W}(\mathbf{g})$. There are two popular weighting functions that are used in the GWR. They are bi-square and Gaussian, as shown in the following equations (Fotheringham et al., 2002), respectively: 


$$
\begin{aligned}
& W(\mathrm{~g})= \begin{cases}{\left[1-\left(\frac{d}{h}\right)^{2}\right]^{2}} & \text { when } d<h \\
0 & \text { otherwise }\end{cases} \\
& \mathcal{W}(\mathrm{g})=e^{-0.5\left(\frac{d}{h}\right)^{2}}
\end{aligned}
$$

where

$$
\begin{aligned}
& \begin{aligned}
\mathcal{w}(\mathrm{g})= & \text { the weight for the current location, } \\
d= & \text { the Euclidean distances between the current location and the other } \\
& \text { locations, and } \\
h \quad= & \text { bandwidth. }
\end{aligned}
\end{aligned}
$$

The Gaussian weighting function is usually used in the GWR.

The predictor variable in the evacuation trip distance prediction model is similar to that in the evacuation trip prediction model. The outcome variable is the evacuation distance. The OLS will first be used to develop the model. If spatial variations exist, the GWR will then be used to develop the model. After that, the model can be used in the study area because it is based on the household. Finally, the evacuation distance for each household can be predicted by running the model against each household in the study area.

Since the OLS is a global regression model, the R-squared value of the model developed by the OLS will be calculated in order to assess the goodness-of-fit of the model, as shown in the following equation (Fotheringham et al., 2002):

$$
R^{2}=1-\frac{R S S}{C T S S}
$$


where

$$
\begin{aligned}
& R^{2}=\text { the global } \mathrm{R} \text {-squared value, } \\
& R S S=\text { the residual sum of squares, and } \\
& C T S S=\text { the corrected total sum of squares. }
\end{aligned}
$$

The residual sum of squares and total sum of squares for the global model are defined as (Fotheringham et al., 2002):

$$
\begin{gathered}
R S S=\sum_{i=1}^{n}\left(y_{i}-\hat{y}_{i}\right)^{2} \\
C T S S=\sum_{i=1}^{n}\left(y_{i}-\bar{y}\right)^{2}
\end{gathered}
$$

where

$$
\begin{aligned}
& y_{i}=\text { the } i \text { th outcome value, and } \\
& \hat{y}_{i}=\text { the } i \text { th predicted value. } \\
& \bar{y} \quad=\text { the mean of the outcome values. }
\end{aligned}
$$

Since the GWR is a local regression method that is different from the global regression method, a similar R-squared value, called the local R-squared value, will be calculated so that the goodness-of-fit of the model developed by the GWR can be assessed. The local R-squared value can be calculated by the following equation (Fotheringham et al., 2002):

$$
r_{j}^{2}=1-\frac{R S S^{w}}{C T S S^{w}}
$$

where

$$
\begin{aligned}
& r_{j}^{2}=\text { the } j \text { th local R-squared value, } \\
& R S S^{w}=\text { the geographically weighted residual sum of squares, and }
\end{aligned}
$$


$C T S S^{w}=$ the geographically weighted corrected total sum of squares.

The residual sum of squares and total sum of squares for the GWR model are defined as (Fotheringham et al., 2002):

$$
\begin{aligned}
& R S S^{w}=\sum_{i=1}^{n} w_{j i}\left(y_{i}-\hat{y}_{i}\right)^{2} \\
& T S S^{w}=\sum_{i=1}^{n} w_{j i}\left(y_{i}-\bar{y}\right)^{2}
\end{aligned}
$$

where

$$
w_{j i} \quad=\text { the } i \text { th weighting value of } j \text { th observed value. }
$$

\subsection{Summary}

Three statistical methods were proposed to develop the prediction models. The binomial logistic regression is used to develop the evacuation rate prediction model since the outcome variable is dichotomous. The multinomial logistic regression is used to develop the evacuation trip prediction model since the outcome variable is polychotomous. For the evacuation trip distance prediction model, the OLS will first be used to develop the model. If spatial variations are found, the GWR will then be used to develop the model. 


\section{CHAPTER 4 \\ DATA PREPARATION}

The data for developing and evaluating the prediction models were obtained from the Hurricane Katrina and Hurricane Ivan evacuation surveys. In this research, the survey data from Hurricane Katrina will be used for model development and the survey data from Hurricane Ivan will be used for model evaluation. Since the two survey data sets have similar data items, only the survey data from Hurricane Katrina are summarized in this chapter. The discussion focuses on data description, data processing, and data accuracy.

\subsection{Data Description}

The original Hurricane Katrina survey data contains a comprehensive list of items. These items include households' experiences during Hurricane Katrina, households' responses to Hurricane Katrina, the way households assess their risk level, households' decision-making processes, promoting and constraining factors while making evacuation decisions, hurricane-related knowledge, attitudes before and after Hurricane Katrina, etc. Not all of the data items are used to develop the prediction models. This dissertation mainly focuses on how the potential socio-economic data and hurricane forecast information that may affect the households' behaviors during hurricane evacuation. The households' behaviors in this dissertation involve evacuation status, evacuation day, and evacuation distance. The evacuation status is whether the household evacuates or stays during a hurricane strike. The evacuation day represents the number of days before hurricane landfall when the household evacuates. Evacuation distance is defined as the 
straight line distance between the evacuation origin and destination of the evacuee, for the purpose of simplicity. These behaviors are modeled by the statistical methods, such as the logistic regression, Ordinary Least Square (OLS), and Geographically Weighted Regression (GWR). Table 4-1 shows the Hurricane Katrina evacuation survey data selected for developing the prediction models.

Table 4-1: Evacuation Survey Data Selected for Developing Prediction Models

\begin{tabular}{|c|c|}
\hline Name & Value \\
\hline Evacuation Status & $\begin{array}{ll}1 & \text { Stayed } \\
2 & \text { Evacuated } \\
3 & \text { Don't Know }\end{array}$ \\
\hline Evacuated on Friday (August 26, 2005) & \begin{tabular}{ll|}
1 & Yes \\
2 & No
\end{tabular} \\
\hline Evacuated on Saturday (August 27, 2005) & $\begin{array}{ll}1 & \text { Yes } \\
2 & \text { No } \\
\end{array}$ \\
\hline Evacuated on Sunday (August 28, 2005) & $\begin{array}{ll}1 & \text { Yes } \\
2 & \text { No }\end{array}$ \\
\hline $\begin{array}{l}\text { Evacuation Destination Located in Your } \\
\text { Neighborhood }\end{array}$ & $\begin{array}{ll}1 & \text { Neighborhood } \\
2 & \text { Somewhere Else } \\
3 & \text { Don't Know } \\
\end{array}$ \\
\hline $\begin{array}{l}\text { Evacuation Destination Located in Your } \\
\text { County }\end{array}$ & $\begin{array}{ll}1 & \text { Yes } \\
2 & \text { No } \\
3 & \text { Don't Know } \\
\end{array}$ \\
\hline City and State You Evacuated to & String \\
\hline Gender & $\begin{array}{ll}1 & \text { Male } \\
2 & \text { Female } \\
\end{array}$ \\
\hline Own or Rent & $\begin{array}{ll}1 & \text { Own } \\
2 & \text { Rent } \\
3 & \text { Own Mobile Home } \\
4 & \text { Other } \\
5 & \text { Don't Know } \\
\end{array}$ \\
\hline Age & Age \\
\hline Household Size & The total number of people in a household (HH) \\
\hline Age $\leq 6$ & The number of people under 6 in a $\mathrm{HH}$ \\
\hline $7 \leq$ Age $\leq 18$ & The number of people between 7 and 18 in a $\mathrm{HH}$ \\
\hline $19 \leq$ Age $\leq 64$ & The number of people between 19 and 64 in a $\mathrm{HH}$ \\
\hline Age $\geq 65$ & The number of people over 65 in a $\mathrm{HH}$ \\
\hline Race & $\begin{array}{ll}1 & \text { White } \\
2 & \text { Black } \\
3 & \text { Asian } \\
4 & \text { American Indian } \\
5 & \text { Other, Specify } \\
6 & \text { Don't Know } \\
\end{array}$ \\
\hline
\end{tabular}


Table 4-1: Evacuation Survey Data Selected for Developing Models (Continued)

\begin{tabular}{|c|c|}
\hline Name & Value \\
\hline Marital Status & $\begin{array}{ll}1 & \text { Single } \\
2 & \text { Married } \\
3 & \text { Widowed } \\
4 & \text { Divorced } \\
5 & \text { Separated } \\
6 & \text { Never Married } \\
7 & \text { Other } \\
8 & \text { Don't Know }\end{array}$ \\
\hline Education Level & $\begin{array}{ll}1 & \text { Grade School } \\
2 & \text { Some High School } \\
3 & \text { High School Graduate } \\
4 & \text { Some College } \\
5 & \text { College Graduate } \\
6 & \text { Graduate Degree } \\
7 & \text { Don't Know } \\
\end{array}$ \\
\hline Income Level & $\begin{array}{ll}1 & \text { Under } \$ 10,000 \\
2 & \$ 10,000-\$ 20,000 \\
3 & \$ 20,000-\$ 30,000 \\
4 & \$ 30,000-\$ 50,000 \\
5 & \$ 50,000-\$ 80,000 \\
6 & \text { Over } \$ 80,000 \\
7 & \text { Don't Know } \\
\end{array}$ \\
\hline Latitude & Latitude of Survey Household Location \\
\hline Longitude & Longitude of Survey Household Location \\
\hline
\end{tabular}

There are a total of 811 survey data, covering the northern gulf coast areas of three states: Louisiana, Mississippi, and Alabama. These coastal areas are those impacted by Hurricane Katrina. The state of Louisiana was the most affected state by Hurricane Katrina. Table 4-2 shows the distribution of the sample size of survey data by states. It is noted that the sample size for Louisiana is the largest, accounting for about $45 \%$ of the total sample size. Figure $4-1$ shows the survey data locations. It can be seen from the map that the survey data locations in Louisiana are concentrated in the city of New Orleans area, and the survey data locations in Alabama are mostly located around the city of Mobile, while the survey data locations in Mississippi are along the coastal areas. 
Table 4-2: Sample Size of Hurricane Katrina Evacuation Survey Data

\begin{tabular}{|c|c|c|}
\hline State & Sample Size & Percentage \\
\hline Alabama & 196 & $24.2 \%$ \\
\hline Louisiana & 367 & $45.3 \%$ \\
\hline Mississippi & 248 & $30.5 \%$ \\
\hline Total & 811 & $100 \%$ \\
\hline
\end{tabular}

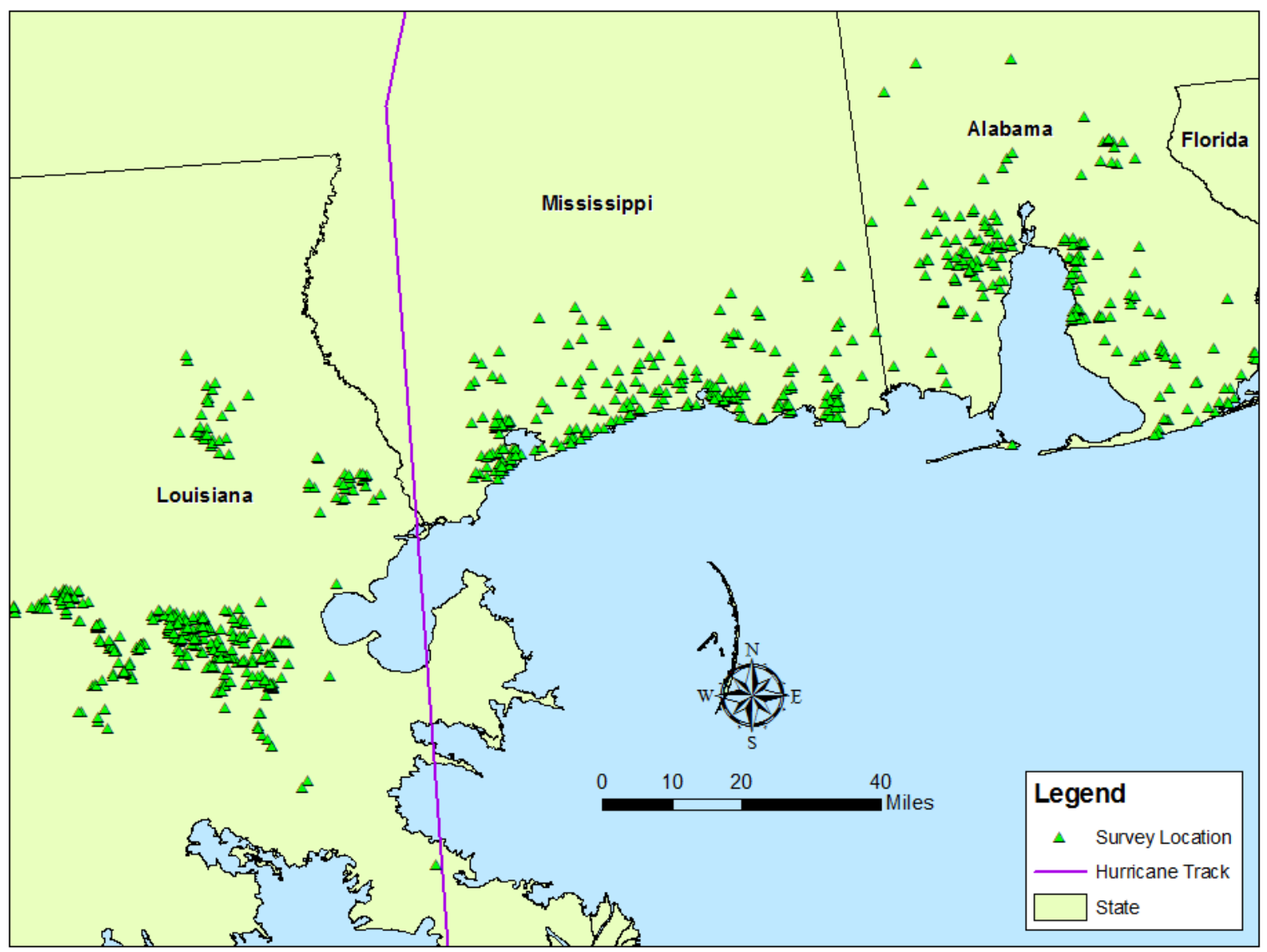

Figure 4-1: Hurricane Katrina Evacuation Survey Data Locations

Hurricane forecast information can be obtained from the National Hurricane Center (NHC). Hurricane forecast information includes the current location, forecasted locations, maximum sustained wind speed, forward speed, and forward direction. The hurricane forecast data that is used to develop the prediction models is hurricane distance. For the purpose of simplicity, the hurricane distance is defined as the straight line distance between the survey location and the hurricane location at the time of evacuation. 
Households tend to be more concerned when a hurricane is on its way. The closer a hurricane approaches, the more likely households are to evacuate their homes.

\subsection{Data Processing}

There are two variables that are not readily available. One is the predictor variable "Hurricane Distance" in the evacuation rate prediction model and evacuation trip prediction model. Since the geographic coordinates of the location of evacuees' homes and hurricane locations are readily available, the hurricane distance can be calculated using GIS software, such as Esri's ArcGIS. The hurricane distance is used to evaluate how hurricane forecast information affects the evacuation day.

The other variable is the outcome variable "Evacuation Distance" in the evacuation trip distance prediction model. The survey data contain the origin and destination information of evacuees. The origin data contains the geographic coordinate of every household's home, for example, the longitude and latitude. The destination data contains the names of the locations to which the evacuees were headed. Figure 4-2 shows the evacuation destination locations. There are three variables containing the destination information: "Evacuation Destination Located in Your Neighborhood," "Evacuation Destination Located in Your County," and "City and State You Evacuated to," as shown in Table 4-3. Table 4-3 also shows the assumption made when calculating the evacuation trip distance. The first two variables indicate that the evacuation trip distance is generally short. The variable "City and State You Evacuated to" contains evacuation destinations with city and state information. The geographic coordinates of the centroids of the destination cities can be obtained by the geocoding process. With 
both the geographic coordinates of origins and destinations available, the evacuation trip distance can be calculated by GIS software. The evacuation trip distance can be used as one of the factors in determining how long the evacuation routes should be. With more evacuees traveling long distances, there will be more vehicles traveling on the longer stretch of the evacuation routes.

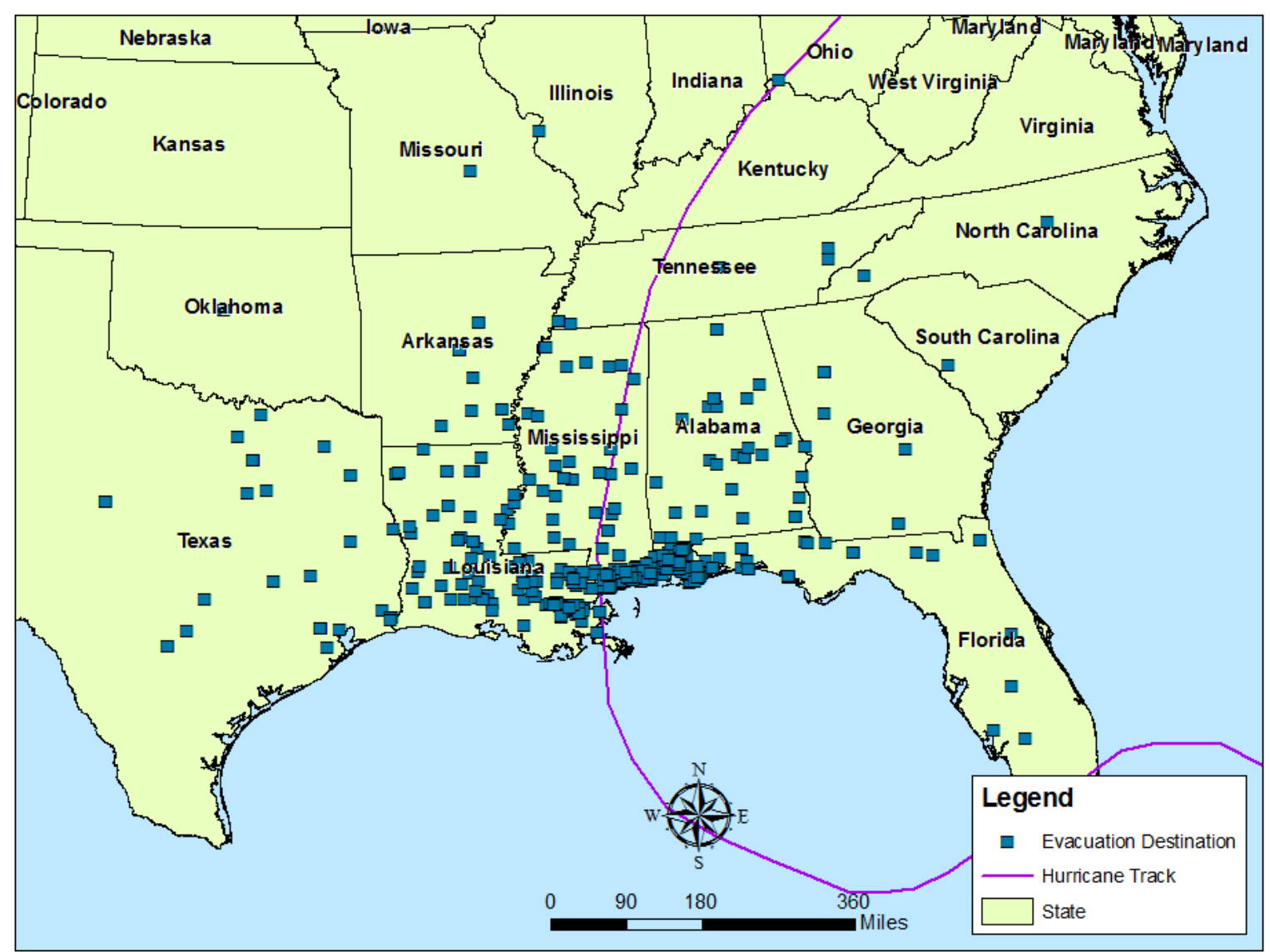

Figure 4-2: Hurricane Katrina Evacuation Destination Locations

The outcome variable "Evacuation Day" is derived from "Evacuate on Friday," "Evacuate on Saturday," and "Evacuate on Sunday." The variable has the category value of 1 (three days before hurricane landfall), 2 (two days before hurricane landfall), and 3 (one day before hurricane landfall). 
Table 4-3: Evacuation Destination Types and Assumptions

\begin{tabular}{|l|l|l|}
\hline Evacuation Destination & Data Available & Assumption \\
\hline $\begin{array}{l}\text { Within Household's } \\
\text { Neighborhood }\end{array}$ & N/A & $\begin{array}{l}\text { Centroid of the Zip Code the } \\
\text { Household is Located at }\end{array}$ \\
\hline $\begin{array}{l}\text { Out of Household's } \\
\text { Heighborhood but Within }\end{array}$ & N/A & $\begin{array}{l}\text { Centroid of the County the } \\
\text { Household is Located at }\end{array}$ \\
\hline Out of Household's County & $\begin{array}{l}\text { Names of Destination } \\
\text { City and State }\end{array}$ & $\begin{array}{l}\text { Centroid of the City the Household } \\
\text { evacuated to }\end{array}$ \\
\cline { 2 - 3 } & $\begin{array}{l}\text { Names of Destination } \\
\text { State }\end{array}$ & $\begin{array}{l}\text { Centroid of the State the Household } \\
\text { evacuated to }\end{array}$ \\
\hline
\end{tabular}

By checking the Hurricane Katrina evacuation survey data selected for developing the prediction models, it was found that some variables have either missing values or are out-of-range. By checking the distribution of the survey data, it was found that a block of the survey data has invalid values, which accounts for about $11 \%$ of the survey data. The block of data includes the variables "Own or Rent," "Age," "Marital Status," "Education Level," "Race," and "Income Level." They have to be removed from the survey data. Figure 4-3 shows the percentage of invalid values for different variables. For example, the invalid values for the variable "Education Level" accounted for more than $40 \%$ of the 811 survey data records. The missing values of the variable "Education Level" were found to overlap all of the aforementioned block of data that were removed from the survey data. After this removal, there remained about $30 \%$ of the survey data with invalid values and they were subsequently removed.

It is noted that all of the categorical variables have a category called "Don't Know." Some have a category called "Other." These categories are not meaningful. It will also be difficult to apply the model with the predictor variables that contain those categories. Therefore, the corresponding data records were removed from the survey data. 


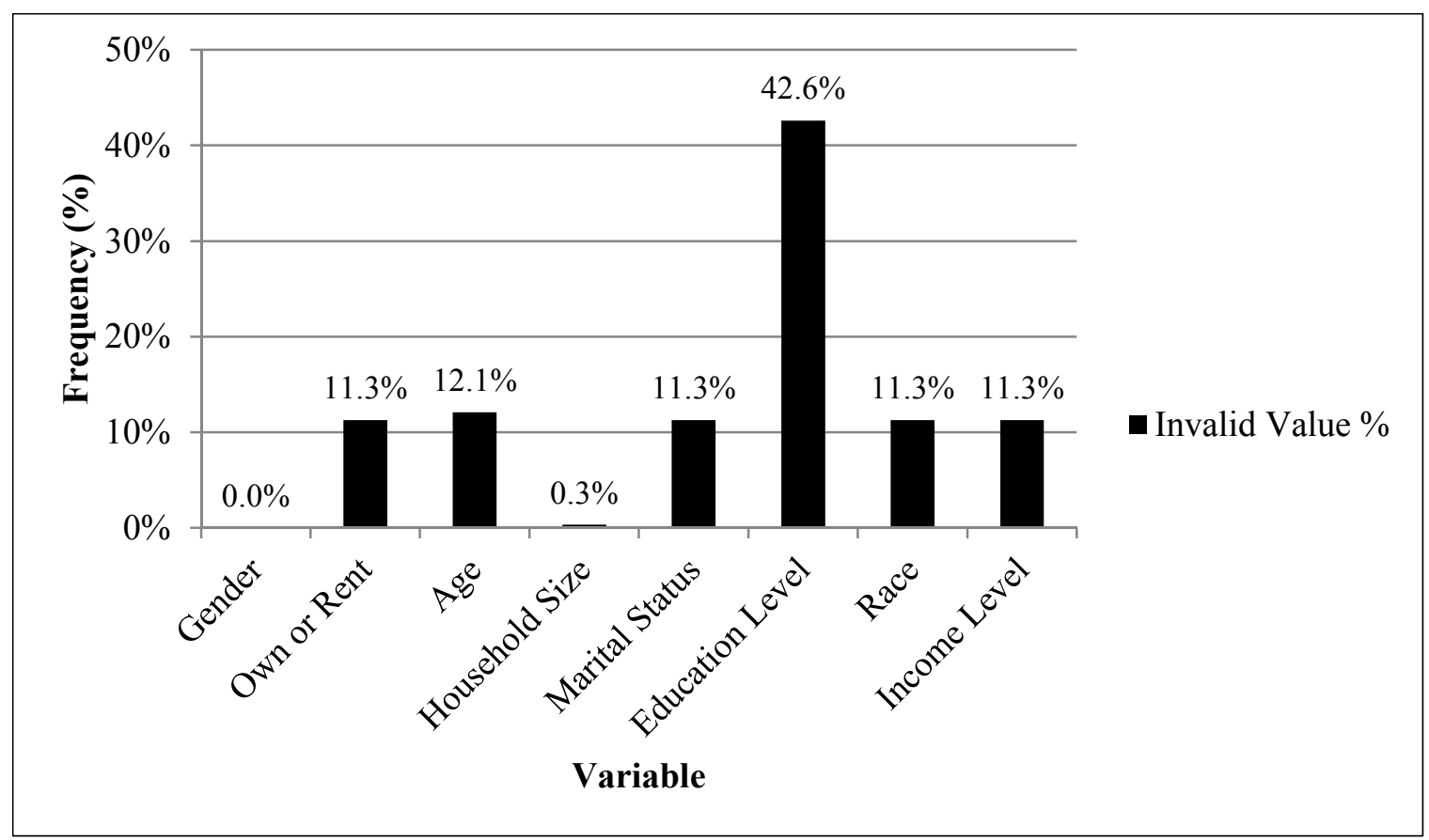

Figure 4-3: Frequency of Invalid Values in Variables

Before using the logistic regression to develop the prediction models, it is necessary to check if there are any empty or small cells in the categorical predictor variables. The cell is defined as the item in the contingency table of the outcome variable and one of the categorical predictor variables. The cell size is the frequency of each combination. Table 4-4 shows the contingency table of the outcome variable "Evacuation Status" and the predictor variable "Race." Small or empty cells may create difficulties in developing the model by using the logistic regression. The category in the categorical variable that has small or empty cells should either be removed or merged with others, depending on the characteristics of the categorical variables. By inspecting Table 4-4, three empty cells, which have a frequency value of 0 , and one small cell, which has a frequency value of 2 , were found. There are two ways to deal with the empty or small cells. One is to merge different categories, and the other is to remove the corresponding data records. As an example, the category "Asian" cannot be merged with 
the category "American Indian," since these two categories are exclusive. Therefore, the corresponding data records should be removed from the survey data. A good example of the categories in the categorical variable that can be merged with others is the variable "Income level." Table 4-5 shows the Hurricane Katrina evacuation survey data that will be used to develop the prediction models after all of the survey data are processed.

Table 4-4: Contingency Table of Evacuation Status and Race

\begin{tabular}{|c|c|c|}
\hline Evacuation Status & Stayed & Evacuated \\
\hline White & 234 & 107 \\
\hline Black & 25 & 7 \\
\hline Asian & 0 & 0 \\
\hline American Indian & 2 & 0 \\
\hline
\end{tabular}

Table 4-5: Processed Hurricane Katrina Evacuation Survey Data

\begin{tabular}{|l|l|}
\hline Name & Value \\
\hline Evacuation Status & 1 Stayed \\
& 2 Evacuated \\
\hline Evacuation Day & 1 Three days before hurricane landfall \\
& 2 Two days before hurricane landfall \\
& 3 One day before hurricane landfall \\
\hline Evacuation Distance & The straight line distance between the location of \\
& an evacuee's home and the hurricane location at \\
& the time when that evacuee left his/her home \\
\hline Gender & 1 Male \\
& 2 Female \\
\hline Own or Rent & 1 Own \\
& 2 Rent \\
\hline Age & 3 Own Mobile Home \\
\hline Household Size & Age \\
\hline Age $\leq 6$ & The total number of people in a household (HH) \\
\hline $7 \leq$ Age $\leq 18$ & The number of people under 6 in a HH \\
\hline $19 \leq$ Age $\leq 64$ & The number of people between 7 and 18 in a HH \\
\hline Age $\geq 65$ & The number of people between 19 and 64 in a HH \\
\hline Marital Status & The number of people over 65 in a HH \\
& 1 Single \\
& 2 Married \\
& 3 Widowed \\
& 4 Divorced \\
& 55 Separated \\
6 & 6 Never Married \\
\hline
\end{tabular}


Table 4-5: Processed Hurricane Katrina Evacuation Survey Data (Continued)

\begin{tabular}{|l|l|}
\hline Name & Value \\
\hline Education Level & 1 Grade School \\
& 2 Some High School \\
& 3 High School Graduate \\
& 4 Some College \\
& 5 College Graduate \\
& 6 Graduate Degree \\
\hline Race & 1 White \\
& 2 Black \\
& 3 Asian \\
\hline Income Level & 4 American Indian \\
& 1 Under $\$ 10,000$ \\
& 2 \$10,000 - \$20,000 \\
& 3 \$20,000 - \$30,000 \\
& 4 \$30,000 - \$50,000 \\
& 5 \$50,000 - \$80,000 \\
\hline Latitude & 6 Over $\$ 80,000$ \\
\hline Longitude & Latitude of Survey Household Location \\
\hline Hurricane Distance & Longitude of Survey Household Location \\
\hline
\end{tabular}

The evacuation trip prediction model and evacuation trip distance model only deal with the evacuees' survey data. After the data were processed, it was found that the sample size of the survey data for the evacuees is 77 , which is relatively small. This is caused by the high percentage of invalid data in the variable "Education Level," which were removed from the survey data. When the survey with the smaller sample size is used to develop the prediction model, model accuracy may be affected. Therefore, it is necessary to create an alternative survey data by removing the variable "Education Level" from the original survey data, and process them again. Table 4-6 shows the sample size comparison of the Hurricane Katrina evacuation survey data with and without the variable "Education Level." Table 4-6 also suggests that the sample size of the alternative survey data processed is larger than that of the original survey data processed. Both the alternative and original survey data will be used to develop each of the three 
prediction models. The results of the two models for each prediction model will be compared to one another in order to find the better model.

Table 4-6: Sample Size of Hurricane Katrina Evacuation Survey Data

\begin{tabular}{|c|c|c|}
\hline \multirow{2}{*}{ Model Name } & \multicolumn{2}{|c|}{ Sample Size } \\
\cline { 2 - 3 } & With "Education Level" Variable & Without "Education Level" Variable \\
\hline Evacuation Rate & 276 & 504 \\
\hline $\begin{array}{c}\text { Evacuation Trip } \\
\text { Evacuation Distance }\end{array}$ & 77 & 297 \\
\hline
\end{tabular}

\subsection{Data Accuracy}

The variable "Hurricane Distance" was calculated based on the hurricane locations obtained from the National Hurricane Center (NHC). The accuracy of this variable depends on the accuracy of hurricane forecasts. Hurricane forecasts are also subject to errors. Figure 4-4 (NHC 2008) shows the cumulative distribution of a fiveyear official Atlantic basin tropical cyclone track forecast errors. In the track forecast errors, it was noted that the 67 th percentile of forecast errors for all of the forecast periods showed the large forecast errors for 48 hours or more. The 67 th percentiles of forecast errors was used to create the "forecast error cone" displayed in the NHC's track forecast web graphics. These forecast errors would affect the behavior of the household that may stay or evacuate. The prediction models developed may produce different results with updated hurricane forecast information because the prediction models used "Hurricane Distance" as one of the predictor variables. 


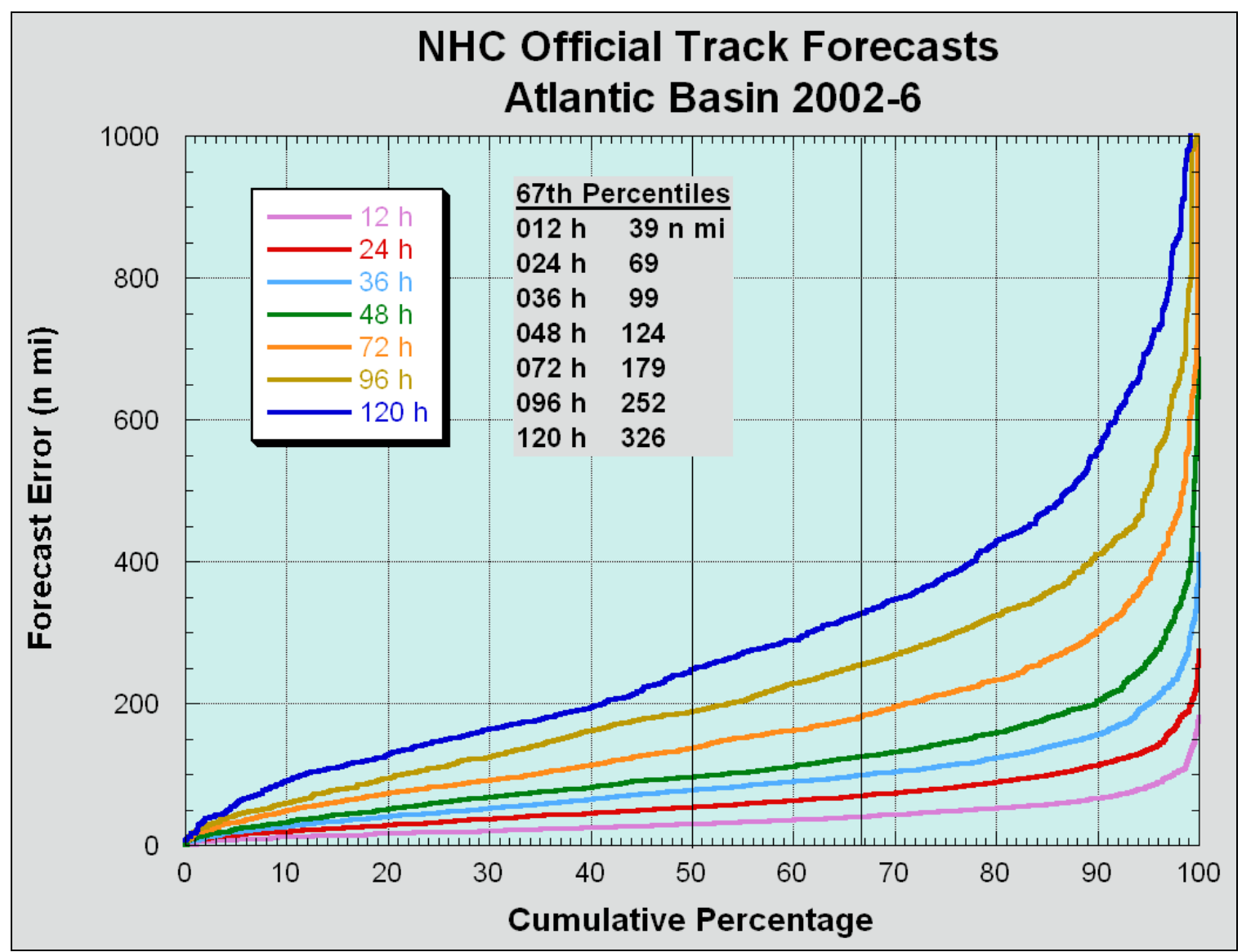

Figure 4-4: Cumulative Distribution of Five-Year Official Atlantic Basin Tropical Cyclone Track Forecast Errors

Hurricane Katrina made landfall as a Category 3 storm on the morning of Monday, August 29, 2005, in southeastern Louisiana. The NHC issued a five-day forecast of a hurricane at each advisory. Due to hurricane forecasting errors, the actual forecast locations may be very different from the forecast locations of four days to one day in advance, as shown in Table 4-7. The forecast tracks of Hurricane Katrina, from five days to one day before landfall, were compared, as shown in Figure 4-5. The figure reveals that the hurricane forecast tracks of Hurricane Katrina, from five to three days before landfall, had this hurricane make landfall in the Florida Panhandle area, which was further east of the actual landfall location. The variable "Hurricane Distance" was 
calculated based on the actual hurricane location. Figure 4-6 shows the different forecast locations of Hurricane Katrina at 11:00 AM, on August 28, 2005. The forecast locations may have a big impact on the variable "Hurricane Distance." Thus, it may affect a household's behavior during a hurricane evacuation.

Table 4-7: Forecast Locations of Hurricane Katrina at 11:00 AM 8/28/2005

\begin{tabular}{|l|c|c|c|c|c|}
\hline & \multicolumn{5}{|c|}{ Forecast Time } \\
\cline { 2 - 6 } & $11: 00 \mathrm{AM}$ & $11: 00 \mathrm{AM}$ & $11: 00 \mathrm{AM}$ & $11: 00 \mathrm{AM}$ & $11: 00 \mathrm{AM}^{1}$ \\
$8 / 24 / 2005$ & $8 / 25 / 2005$ & $8 / 26 / 2005$ & $8 / 27 / 2005$ & $8 / 28 / 2005$ \\
\hline $\begin{array}{l}\text { Location } \\
\text { (Longitude, } \\
\text { Latitude) }\end{array}$ & $27.0 \mathrm{~N}$, & $28.1 \mathrm{~N}$, & $27.1 \mathrm{~N}$, & $25.3 \mathrm{~N}$, & $26.0 \mathrm{~N}, 88.1 \mathrm{~W}$ \\
\hline
\end{tabular}

Note: 1. This is the actual location of Hurricane Katrina at 11:00 AM, 8/28/2005.

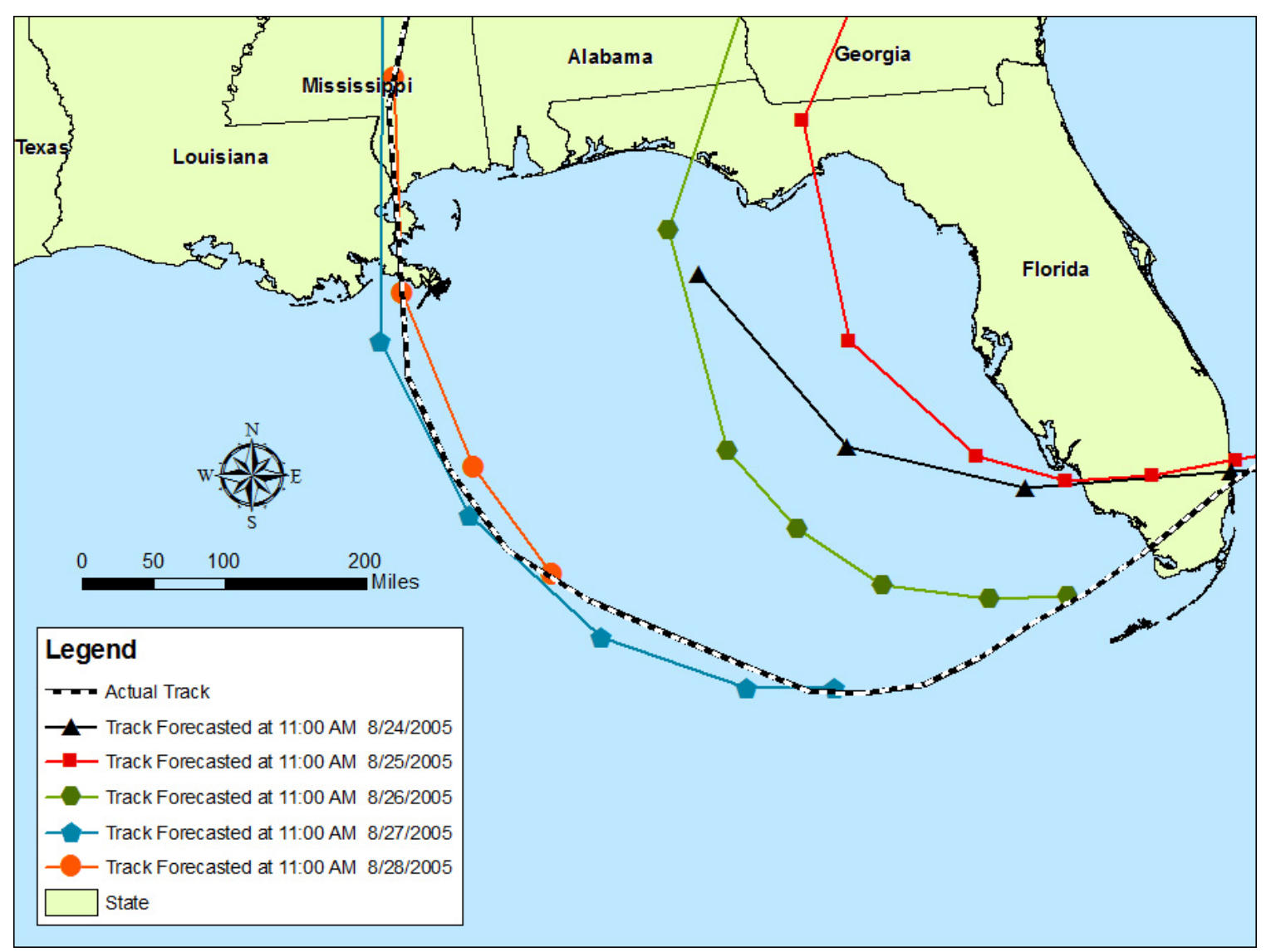

Figure 4-5: Different Forecast Tracks of Hurricane Katrina 


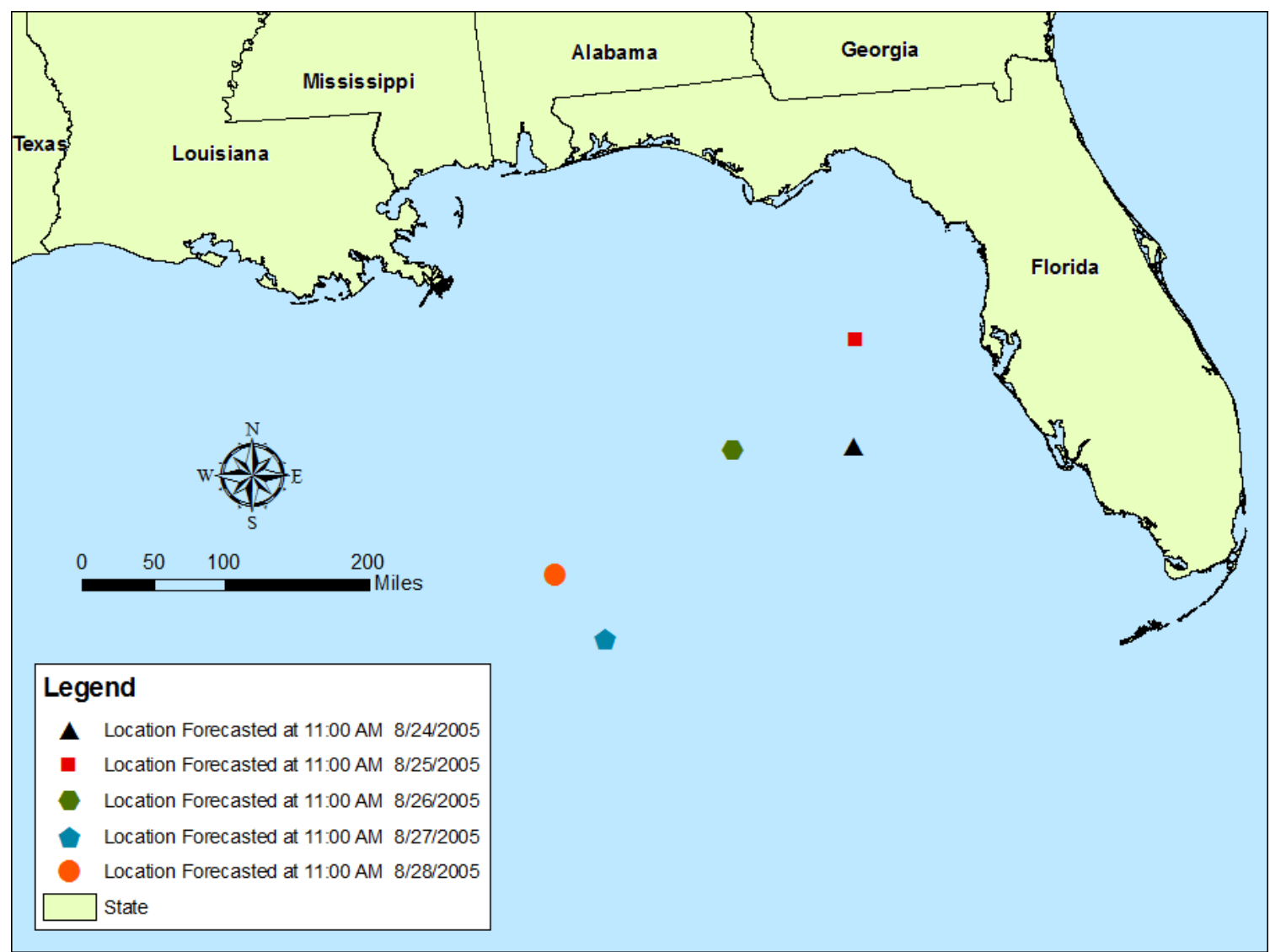

Figure 4-6: Forecast Locations of Hurricane Katrina at 11:00 AM, 8/28/2005

\subsection{Summary}

The data used to develop and evaluate the prediction models were taken from the Hurricane Katrina and Ivan evacuation survey data. The original survey data contains a comprehensive list of items. In this dissertation, only the socio-economic and hurricane forecast data were used to develop the prediction models. Hurricane forecast data were obtained from the NHC. It was recognized that the hurricane forecast data are subject to errors that may affect the model's accuracy. The survey data were processed by removing the invalid data, for example, out of range and empty data, from the original survey data. The new variables that are necessary to develop the prediction models were 
created from the existing survey data. Cross-table checking for the categorical predictor variables against the outcome variable was also performed. During the data processing, it was found that almost half of the variable "Education Level" has empty values that make the sample size of the survey data much smaller for developing the prediction models. An alternative survey data was created by removing the variable "Education Level" from the original survey data. Both the alternative and original survey data are to be used to develop the prediction models, and the better models will then be selected by comparing the model results from two data sets. 


\section{CHAPTER 5 MODEL DEVELOPMENT}

The prediction models for predicting evacuation daily trips and the evacuation trip distance during a hurricane evacuation consist of three models that were developed by using the Hurricane Katrina evacuation survey data. The methods to develop the prediction models are binomial logistic regression, multinomial logistic regression, Ordinary Least Square (OLS), and Geographically Weighted Regression (GWR). The three prediction models to be developed are the evacuation rate prediction model, evacuation trip prediction model, and evacuation trip distance prediction model. The evacuation rate prediction model and evacuation trip prediction model are used together to predict the evacuation daily trips.

\subsection{Evacuation Rate Prediction Model}

The evacuation rate prediction model was developed to find the relationship between the probability of the household that evacuates and the influential factors that lead to evacuation. The evacuation rate can be calculated from the probability of the household that evacuated. The evacuation rate is the ratio of the number of the households that evacuated over the total number of the households that stayed and evacuated. The hurricane forecast data, i.e., hurricane distance, is time-based, which shows the relationship between the hurricane forecast data and the time when the decision to evacuate was made. Because the surveys did not include data for the households that did not evacuate, it was difficult to model the non-evacuated households' behaviors with the hurricane forecast data. Hence, the hurricane forecast data was not 
included in the variable list that was used to develop the model. Since the outcome variable "Evacuation Status" has two categories, the binomial logistic regression is used to develop the evacuation rate prediction model.

There are two sets of survey data that were used to develop the evacuation rate prediction model. The only difference between them is that one data set includes the variable "Education Level," while the other does not. Table 5-1 shows the two sets of variables used to develop the model after data processing.

Table 5-1: Variables for Evacuation Rate Model

\begin{tabular}{|c|c|c|}
\hline \multirow{2}{*}{ Variable Type } & \multicolumn{2}{|c|}{ Variable Name } \\
\cline { 2 - 3 } & With Education Level Variable & Without Education Level Variable \\
\hline Outcome Variables & Evacuation Status & Evacuation Status \\
\hline \multirow{4}{*}{ Predictor Variables } & Gender & Gender \\
& Own or Rent & Own or Rent \\
& Age & Age \\
& Household Size & Household Size \\
& Age $\leq 6$ & Age $\leq 6$ \\
& $7 \leq$ Age $\leq 18$ & $7 \leq$ Age $\leq 18$ \\
& $19 \leq$ Age $\leq 64$ & $19 \leq$ Age $\leq 64$ \\
& Age $\geq 65$ & Age $\geq 65$ \\
& Marital Status & Marital Status \\
& Education Level & Race \\
& Race & Income Level \\
& Income Level & \\
\hline
\end{tabular}

The diagnostic statistics of the model predictor variables' coefficients and the log-likelihood test of the model are used to evaluate whether or not the model developed is a good fit. If the p-values of both statistical diagnostics are less than or close to the level of 0.05 , the model developed is said to be a good or an acceptable fit. The modeling process started with fitting all of the predictor variables into the model. Then, the criteria mentioned above were used to check the model's goodness-of-fit. If the 
model developed was not a good fit, the model would be redeveloped by removing one or several of the predictor variables from the previous model until the best model goodnessof-fit result was obtained. The statistical software, R Project, was used to run the binomial logistic regression against the survey data. Two different models were developed from the two survey data sets, respectively. The model coefficients and statistical diagnostic results of the models developed are shown in Table 5-2 and Table 53 , respectively.

Table 5-2: Result of Evacuation Rate Model Developed from Data with Education Level Variable

\begin{tabular}{|c|c|c|c|c|}
\hline Variable & Coefficient & Standard Error & Z-value & P-value \\
\hline (Intercept) & -0.9710 & 0.1482 & -6.5530 & 0.000 \\
\hline $7 \leq$ Age $\leq 18$ & 0.2022 & 0.1371 & 1.475 & 0.140 \\
\hline \multicolumn{5}{|c|}{ Model Log-likelihood Test } \\
\hline Chi-square & 2.1356 & P-value & 0.094 \\
\hline
\end{tabular}

Table 5-3: Result of Evacuation Rate Model Developed from Data without Education Level Variable

\begin{tabular}{|c|c|c|c|c|}
\hline Variable & Coefficient & Standard Error & Z-value & P-value \\
\hline (Intercept) & 0.4433 & 0.0984 & 4.5060 & 0.000 \\
\hline Own or Rent: Rent & -0.5864 & 0.3915 & -1.4980 & 0.134 \\
\hline Age $\leq 6$ & 0.3282 & 0.2192 & 1.4980 & 0.134 \\
\hline \multicolumn{5}{|c|}{ Model Log-likelihood Test } \\
\hline Chi-square & 5.1943 & P-value & 0.037 \\
\hline
\end{tabular}

In Table 5-2, the p-value of the diagnostic statistics of the predictor variable $" 7 \leq$ Age $\leq 18$ " is 0.140 , which is not statistically significant at the level of 0.05 . In Table 5-3, the p-values of the diagnostic statistics of the predictor variables "Own or Rent" and "Age $\leq 6$ " are both 0.134 , which is not statistically significant at the level of 0.05 . The pvalues of the log-likelihood test of the two models are 0.094 and 0.037 , respectively. The 
p-value of the log-likelihood test of the model shown in Table 5-3 is statistically significant at the level of 0.05 , while the p-value of the other model shown in Table 5-2 is not. Although the p-values of the diagnostic statistics of the two predictor variables shown in Table 5-3 are not statistically significant at the level of 0.05 , these p-values show that there is some relationship between the outcome variable "Evacuation Status," and the predictor variables "Own or Rent" and "Age $\leq 6$." Therefore, the model developed by the survey data without the education level variable is selected as the evacuation rate prediction model.

To interpret the results of the evacuation rate prediction model, for example, the relationship between the outcome variable "Evacuation Status" and each of the predictor variables, the predictor variable that is being interpreted will be assigned a series of values, while the rest of the predictor variables are being held constant at certain reasonable values. There are two predictor variables "Own or Rent" and "Age $\leq 6$ " in the evacuation rate prediction model. Figure 5-1 shows the relationship between the outcome variable and the predictor variables. Figure 5-2 shows the age distribution of evacuees for both the homeowner and renter. The findings from the final evacuation rate prediction model are discussed, as follows:

- Figure 5-1 shows that the probability of evacuating for the household with three people under age six is about $10 \%$ higher than that for the household with no one under age six, for the homeowner and renter, respectively. This suggests that the household with more people under age six as a whole is more likely to evacuate than that with fewer people under age six during a hurricane evacuation. This is consistent with the fact that the parents are often more concerned with their young 
children's safety. This suggests that the probability of evacuating is in proportion to the number of people under age six in the household during the hurricane evacuation.

- Figure 5-1 also shows that the probability of evacuating for the homeowner is about $10 \%$ higher than that for the home renter during a hurricane evacuation. This indicates that the household with the same number of people under age six is more likely to evacuate, in terms of the homeowner than for the home renter. Figure 5-2 shows that the number of people under age six in the household for the homeowner accounts for about $6 \%$ of the number of evacuees. There are no people in the household under age six for the home renter. This explains the higher probability of evacuating for the homeowner than the home renter during the hurricane evacuation.

- There are four age groups in the survey data. They are "Age $\leq 6, "$ "7 $\leq$ Age $\leq 18$," "19 $\leq$ Age $\leq 64$," and "Age $\geq 18$." The number in each age group represents the number of people within the corresponding range of ages in a household. The total of the four age groups equals to the value of the variable "Household Size." Only one age group, "Age $\leq 6$," was found to have a relationship with the evacuation status. This implies that the probability of evacuating is not sensitive to people above age six.

- The other variables, such as the age, household size, gender, marital status, race, and income level, were not identified as the predictor variables that have noticeable impacts on the probability of evacuating during a hurricane evacuation. 


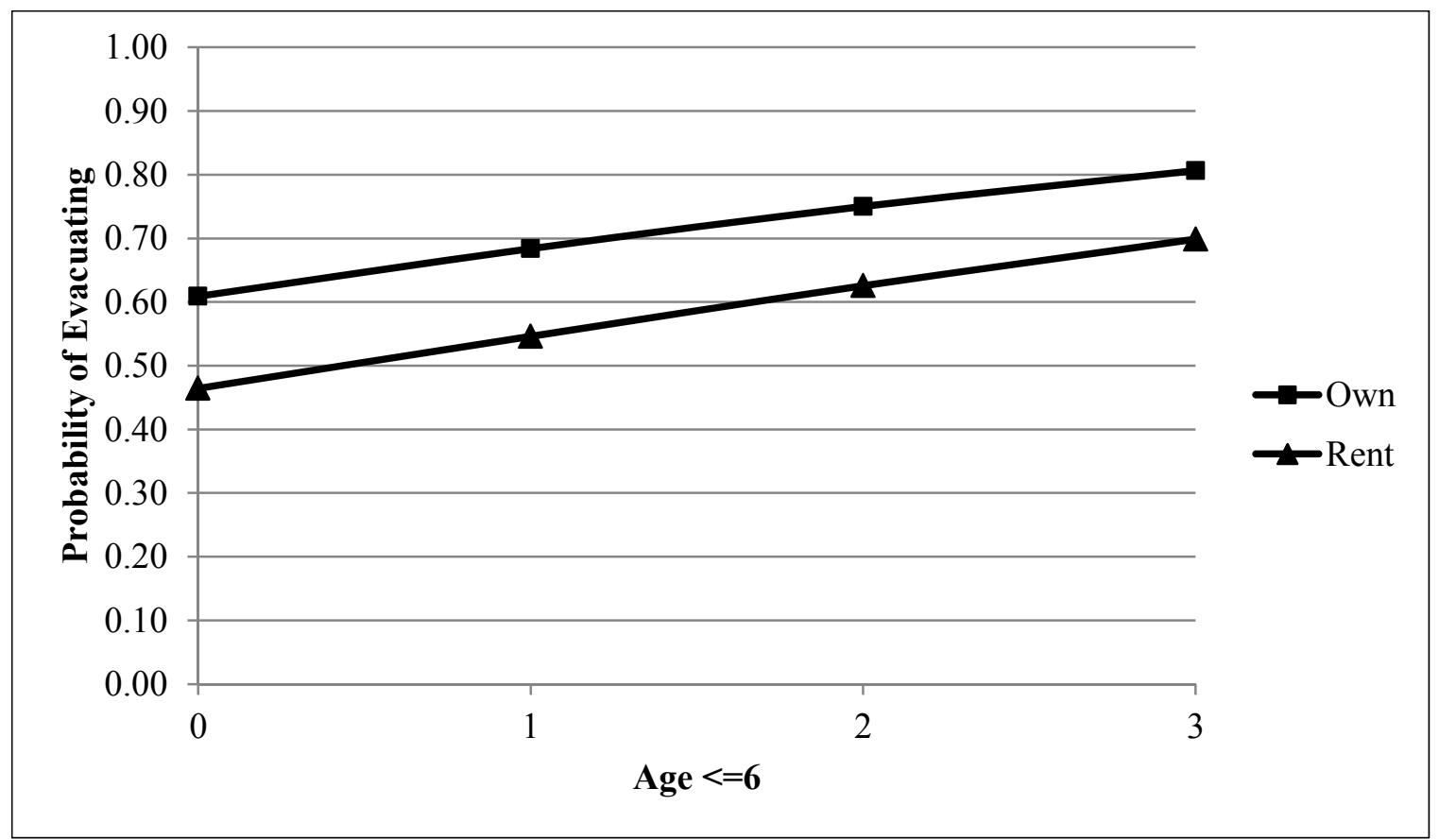

Figure 5-1: Probability of Evacuating vs. Age $\leq 6$

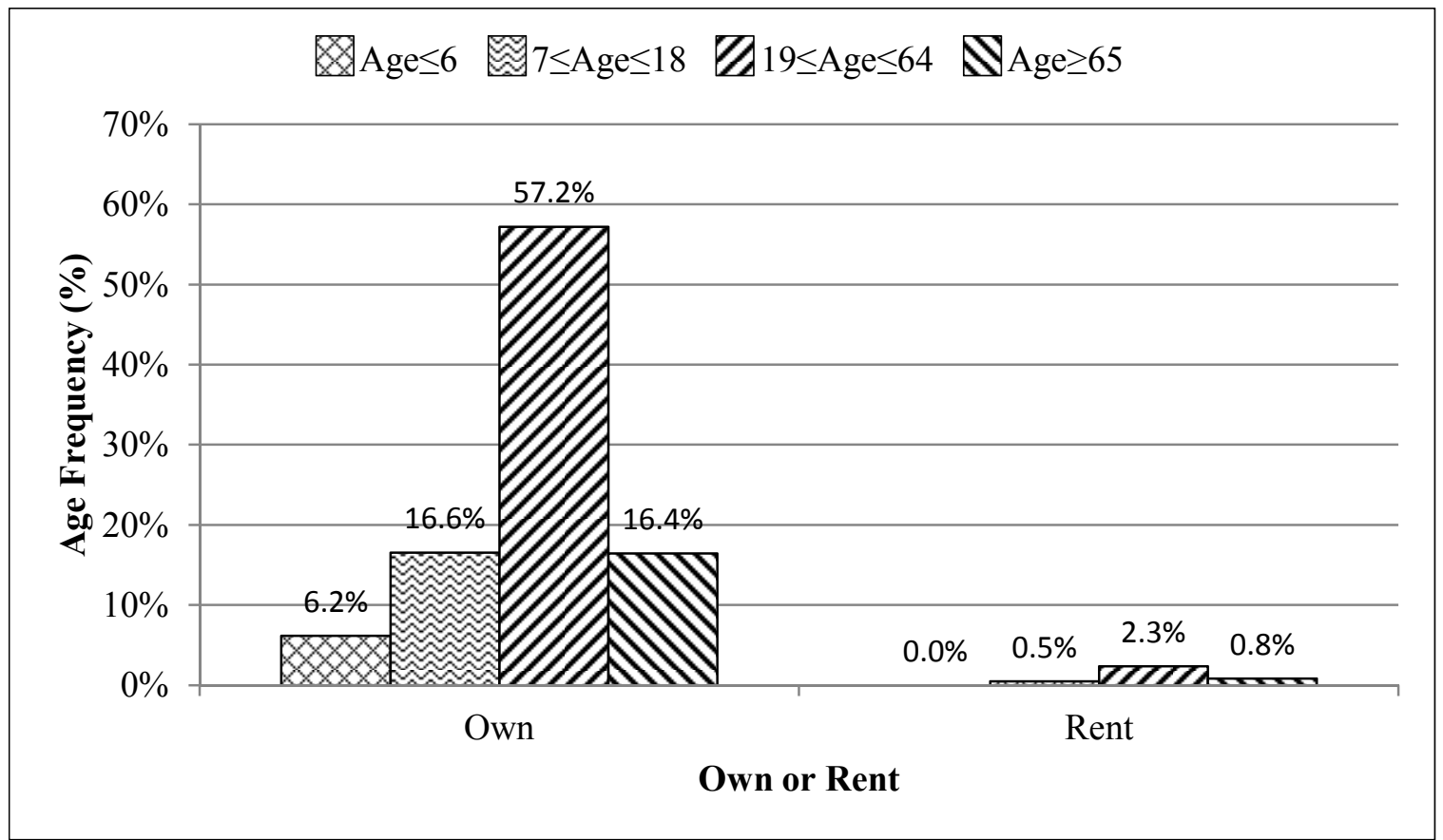

Figure 5-2: Age Distribution of Evacuees for Homeowner and Renter

The final evacuation rate prediction models are shown in the following equations:

$$
P(Y=0 \mid \mathbf{x})=1-P(Y=1 \mid \mathbf{x})
$$




$$
\begin{gathered}
P(Y=1 \mid \mathbf{x})=\frac{1}{1+e^{-g(\mathbf{x})}} \\
g(\mathbf{x})=+0.4433-0.5864(\text { Own or Rent })+0.3282(\text { Age } \leq 6)
\end{gathered}
$$

where

$$
\begin{aligned}
\mathbf{x} & =\text { the predictor variable matrix, } \\
P(Y=0 \mid \mathbf{x})= & \text { the conditional probability of the household that will not evacuate } \\
& \text { in a hurricane given } \mathbf{x} \text {, and } \\
P(Y=1 \mid \mathbf{x})= & \text { the conditional probability of the household that will evacuate in } \\
& \text { a hurricane given } \mathbf{x} .
\end{aligned}
$$

\subsection{Evacuation Trip Prediction Model}

The evacuation trip prediction model is developed to find the relationship between the probabilities of the households that will evacuate three days, two days, or one day before hurricane landfall, and the influential factors. The number of trips generated three days, two days, or one day before hurricane landfall can then be calculated from the corresponding probability. Since the outcome variable "Evacuation Day" has three categories, the multinomial logistic regression is used to develop the evacuation trip prediction model.

The survey data was processed by the method discussed in Chapter 4. There are two sets of survey data that were used to develop the evacuation trip prediction model. Table 5-4 shows the two sets of variables used to develop the model after data processing. It is noted in Table 5-4 that the variable "Education Level" was not included in the data set with the education level variable due to the existence of the empty or small cells 
found in each category of the variable. Therefore, the variable "Education Level" was removed from the variable list.

Table 5-4: Variables for Evacuation Trip Model

\begin{tabular}{|c|c|c|}
\hline \multirow{2}{*}{ Variable Type } & \multicolumn{2}{|c|}{ Variable Name } \\
\cline { 2 - 3 } & With Education Level Variable & Without Education Level Variable \\
\hline Outcome Variables & Evacuation Day & Evacuation Day \\
\hline \multirow{4}{*}{ Predictor Variables } & Gender & Gender \\
& Age & Age \\
& Household Size & Household Size \\
& Age $\leq 6$ & Age $\leq 6$ \\
& $7 \leq$ Age $\leq 18$ & $7 \leq$ Age $\leq 18$ \\
& $19 \leq$ Age $\leq 64$ & $19 \leq$ Age $\leq 64$ \\
& Age $\leq 65$ & Age $\geq 65$ \\
& Hurricane Distance & Income Level \\
& & Hurricane Distance \\
\hline
\end{tabular}

The model developing process used to develop the evacuation rate prediction model was applied in order to develop the evacuation trip prediction model. The $\mathrm{R}$ Project software was also used to run the multinomial logistic regression against the selected Hurricane Katrina evacuation survey data. Two different models were developed from the two survey data sets, respectively. The model coefficients and statistical diagnostic results of the models developed are shown in Table 5-5 and Table 56 , respectively.

In Table 5-5, the p-values of the diagnostic statistics of the predictor variables "Age" and " $7 \leq$ Age $\leq 18$ " for the scenario of two days before hurricane landfall are 0.086 and 0.060 , respectively. Although they are not statistically significant at the level of 0.05 , they are both close to the level of 0.05 . In Table 5-6, the p-value of the diagnostic statistics of the predictor variable and "Age $\leq 6$ " for the scenario of two days before hurricane landfall is 0.077 , which is also close to the level of 0.05 . The p-values of the 
log-likelihood test of the two models are 0.046 and 0.043 , respectively. They are both statistically significant at the level of 0.05 . Therefore, both models developed are considered good fits.

Table 5-5: Result of Evacuation Trip Model Developed from Data with Education Level Variable

\begin{tabular}{|c|c|c|c|c|}
\hline Variable $^{*}$ & Coefficient & Standard Error & T-value & P-value \\
\hline alt1:(Intercept) & 12.0223 & 5.9304 & 2.0272 & 0.043 \\
\hline alt2: (Intercept) & 14.0430 & 5.9379 & 2.3650 & 0.018 \\
\hline alt1: Age & -0.1392 & 0.0810 & -1.7196 & 0.086 \\
\hline alt2: Age & -0.1637 & 0.0811 & -2.0186 & 0.044 \\
\hline alt $1: 7 \leq$ Age $\leq 18$ & -0.8382 & 0.4462 & -1.8784 & 0.060 \\
\hline alt2: $7 \leq$ Age $\leq 18$ & -0.9904 & 0.4568 & -2.1679 & 0.030 \\
\hline \multicolumn{5}{|c|}{ Model Log-likelihood Test } \\
\hline Chi-square & \multicolumn{2}{|c|}{9.6718} & P-value & 0.046 \\
\hline
\end{tabular}

Notes: *. "alt1" and "alt2" represent the scenarios of the evacuation day being two days and one day before hurricane landfall, respectively.

Table 5-6: Result of Evacuation Trip Model Developed from Data without Education Level Variable

\begin{tabular}{|c|c|c|c|c|}
\hline Variable $^{*}$ & Coefficient & Standard Error & T-value & P-value \\
\hline alt1:(Intercept) & 1.6421 & 0.2820 & 5.8235 & 0.000 \\
\hline alt2: (Intercept) & 2.5443 & 0.2683 & 9.4829 & 0.000 \\
\hline alt1: Age $\leq 6$ & -0.5559 & 0.3143 & -1.7688 & 0.077 \\
\hline alt2: Age $\leq 6$ & -0.7497 & 0.3039 & -2.4670 & 0.014 \\
\hline \multicolumn{5}{|c|}{ Model Log-likelihood Test } \\
\hline Chi-square & 6.3343 & P-value & 0.042 \\
\hline
\end{tabular}

Notes: *. "alt1" and "alt2" represent the scenarios of the evacuation day being two days and one day before hurricane landfall, respectively.

It is noted in Table 5-5 that the predictor variable "Age" was included in the model developed by the survey data with the education level variable. The evacuation usually takes place on the household basis. The age depends on a specific person instead of a household. A typical household consists of two adults and their children. It is also 
difficult to determine exactly who made the decision to evacuate a certain number of days before hurricane landfall, based on the survey data. Even though the age data is readily available, it is still challenging to apply the model with the predictor variable "Age" to the study area. In order to take the issue above into account, this model was redeveloped by excluding the predictor variable "Age" from the survey data with the education level variable. The result of the redeveloped evacuation trip prediction model is shown in Table 5-7.

Table 5-7: Result of Redeveloped Evacuation Trip Model Developed from Data with Education Level Variable

\begin{tabular}{|c|c|c|c|c|}
\hline Variable $^{*}$ & Coefficient & Standard Error & T-value & P-value \\
\hline alt1:(Intercept) & 2.7106 & 0.7611 & 3.5617 & 0.000 \\
\hline alt2: (Intercept) & 3.3214 & 0.7542 & 4.4036 & 0.000 \\
\hline alt1: Age $\leq 6$ & -0.8015 & 0.5160 & -1.5533 & 0.120 \\
\hline alt2: Age $\leq 6$ & -1.3851 & 0.8002 & -1.7309 & 0.083 \\
\hline \multicolumn{5}{|c|}{ Model Log-likelihood Test } \\
\hline Chi-square & 6.7671 & P-value & 0.034 \\
\hline
\end{tabular}

Notes: *. "alt1" and "alt2" represent the scenarios of the evacuation day being two days and one day before hurricane landfall, respectively.

Table 5-7 shows that the p-values of the diagnostic statistics of the predictor variables and "Age $\leq 6$ " for the two scenarios are 0.120 and 0.083 , respectively. Although the p-value of the log-likelihood test of the model is 0.034 , which is statistically significant at the level of 0.05 , both p-values of the diagnostic statistics of the predictor variables are not statistically significant at the level of 0.05 . Therefore, this model is not considered a good fit. By comparing the models shown in Table 5-6 and Table 5-7, it was determined that the model developed by using the survey data without the education level variable is selected as the evacuation trip prediction model. 
The way that was used to interpret the results of the evacuation rate prediction model was also used to interpret the results of the evacuation trip prediction model. There is one predictor variable "Age $\leq 6$ " in the evacuation trip prediction model. The relationship between the outcome variable and the predictor variable is shown in Figure 5-3. The findings from the evacuation trip prediction models are discussed, as follows:

- Figure 5-3 shows that the probability of the household with three people under age six evacuating three days before hurricane landfall is approximately $25 \%$ higher than that of the household with no people under age six. The probability of the household with three people under age six evacuating one day before hurricane landfall is approximately $25 \%$ lower than that of the household with no people under age six. Figure 5-3 also shows that the probability of the household with three people under age six evacuating three and two days before hurricane landfall is approximately 0.60 . This is consistent with the fact that the parents are more concerned with their young children's safety, and they tend to leave earlier. Figure 5-3 implies that the probability of the household evacuating three days before hurricane landfall is in proportion to the number of people under age six in the household, and the probability of the household evacuating one day before hurricane landfall is inverse proportion to the number of people under age six in the household.

- The probability of the household who evacuates two days before the hurricane landfall is not sensitive to the number of people under age six in the same household. 
- Although the model shown in Table 5-5 was not selected as the final model, this model includes the predictor variables "Age" and "7 $\leq$ Age $\leq 18$." This implies that the age and the number of people between 7 and 18 in the household may have distinctive impacts on the probability of the household evacuating three days, two days, and one day before hurricane landfall. Since the age depends on a specific person in the household, it creates difficulties to apply this model to another study area.

- The gender, income level, and hurricane distance were not identified as the predictor variables that have the relationship with the probability of the household evacuating a certain number of days before hurricane landfall.

- The rental status, marital status, race, and education level were not included in the model due to the existence of empty or small cells across most categories in those variables.

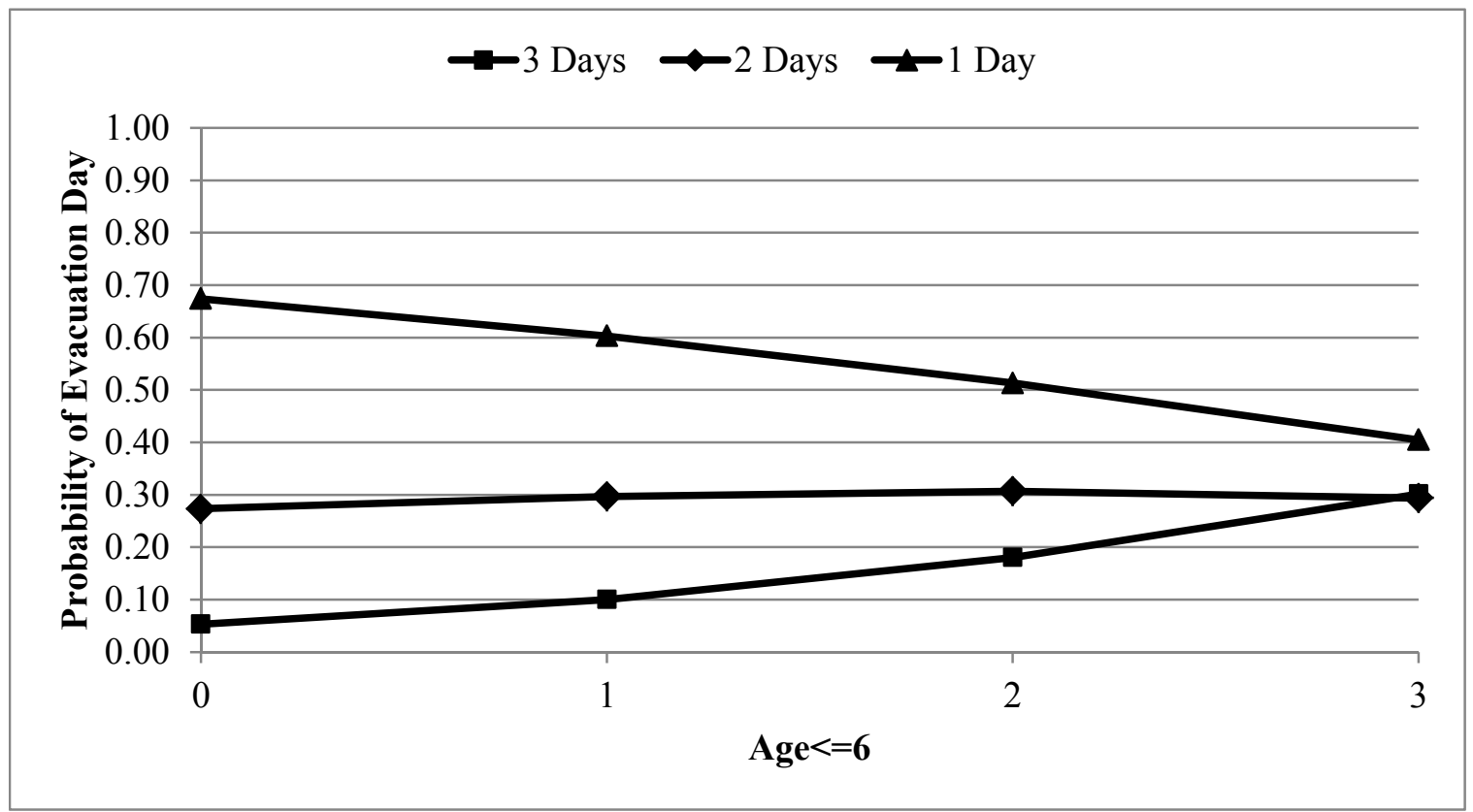

Figure 5-3: Probability of Evacuation Day vs. Age $\leq 6$ 
The final evacuation trip prediction model is shown in the following equation:

$$
\begin{gathered}
P(Y=0 \mid \mathbf{x})=1-P(Y=1 \mid \mathbf{x})-P(Y=2 \mid \mathbf{x}) \\
P(Y=1 \mid \mathbf{x})=\frac{e^{g_{1}(\mathbf{x})}}{1+e^{g_{1}(\mathbf{x})}+e^{g_{2}(\mathbf{x})}} \\
P(Y=2 \mid \mathbf{x})=\frac{e^{g_{2}(\mathbf{x})}}{1+e^{g_{1}(\mathbf{x})}+e^{g_{2}(\mathbf{x})}} \\
g_{1}(\mathbf{x})=+1.6421-0.5559(\text { Age } \leq 6) \\
g_{2}(\mathbf{x})=+2.5443-0.7497(\text { Age } \leq 6)
\end{gathered}
$$

where

$$
\begin{aligned}
& P(Y=0 \mid \mathbf{x})=\text { the conditional probability of the household that will evacuate } \\
& \quad \text { three days before hurricane landfall given } \mathbf{x}, \\
& P(Y=1 \mid \mathbf{x})=\text { the conditional probability of the household that will evacuate } \\
& \quad \text { two days before hurricane landfall given } \mathbf{x} \text {. and } \\
& P(Y=2 \mid \mathbf{x})=\text { the conditional probability of the household that will evacuate } \\
& \quad \text { one day before hurricane landfall given } \mathbf{x} .
\end{aligned}
$$

\subsection{Evacuation Trip Distance Prediction Model}

The evacuation trip distance prediction model was developed to find the relationship between the distance the evacuee travels and the influential factors. The OLS and GWR were used to develop the model.

The data used to develop the evacuation trip distance prediction model are the same data sets used to develop the evacuation tip prediction model. Table 5-8 shows the 
two sets of variables used to develop the model after data processing. The model developing process used to develop the evacuation trip prediction model was applied in order to develop the evacuation trip distance prediction model. The model goodness-offit is measured by the model R-Squared value. The larger the value, the better a model is. The OLS was first used to develop the model. The model was then diagnosed to check if the spatial variation existed. If so, the GWR would be used to develop the model to address the spatial variation.

Table 5-8: Variables for Evacuation Distance Model

\begin{tabular}{|c|c|c|}
\hline \multirow{2}{*}{ Variable Type } & \multicolumn{2}{|c|}{ Variable Name } \\
\cline { 2 - 3 } & With Education Level Variable & Without Education Level Variable \\
\hline Outcome Variables & Evacuation Distance & Evacuation Distance \\
\hline \multirow{4}{*}{ Predictor Variables } & Gender & Gender \\
& Own or Rent & Own or Rent \\
& Age & Age \\
& Household Size & Household Size \\
& Age $\leq 6$ & Age $\leq 6$ \\
& $7 \leq$ Age $\leq 18$ & $7 \leq$ Age $\leq 18$ \\
& $19 \leq$ Age $\leq 64$ & $19 \leq \leq$ Age $\leq 64$ \\
& Age $\geq 65$ & Age $\geq 65$ \\
& Marital Status & Marital Status \\
& Education Level & Race \\
& Race & Income Level \\
& Income Level & Hurricane Distance \\
& Hurricane Distance &
\end{tabular}

Figure 5-4 and Figure 5-5 show the frequency and cumulative distribution of the outcome variable "Evacuation Distance." Figure 5-4 indicates that the frequency distribution is unbalanced and skewed to the right. Therefore, it is necessary to transform the evacuation distance by using its natural logarithm in order to address the skewness. It is also noted from Figure 5-5 that about $90 \%$ of the evacuation distance is within 400 miles. The OLS and GWR tools in ArcGIS 9.3 were used to develop the model. The 
model coefficients and statistical diagnostic results of the model developed by the OLS with two data sets are shown in Table 5-9 and Table 5-10, respectively.

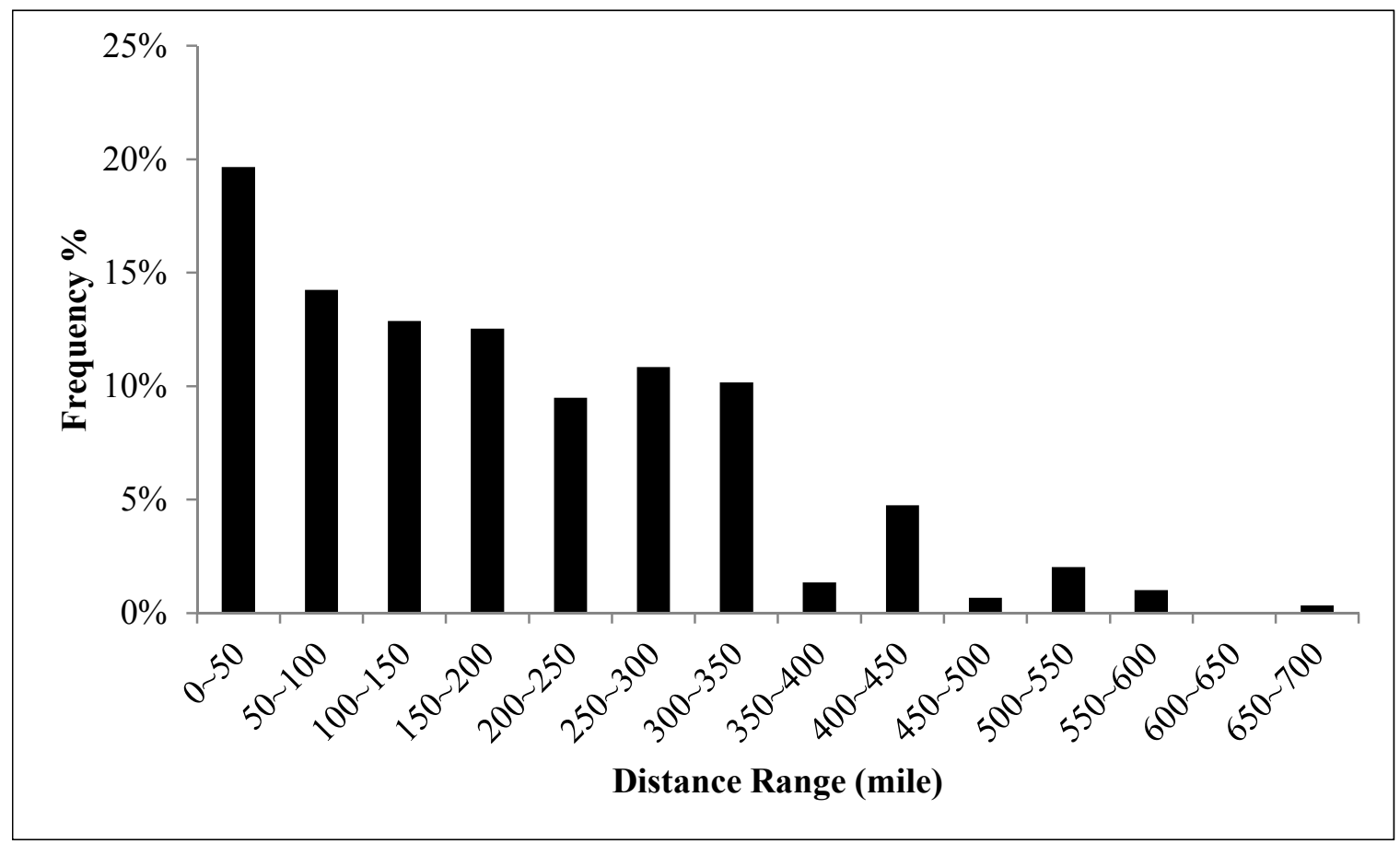

Figure 5-4: Frequency Distribution of Evacuation Distance without Education Variable

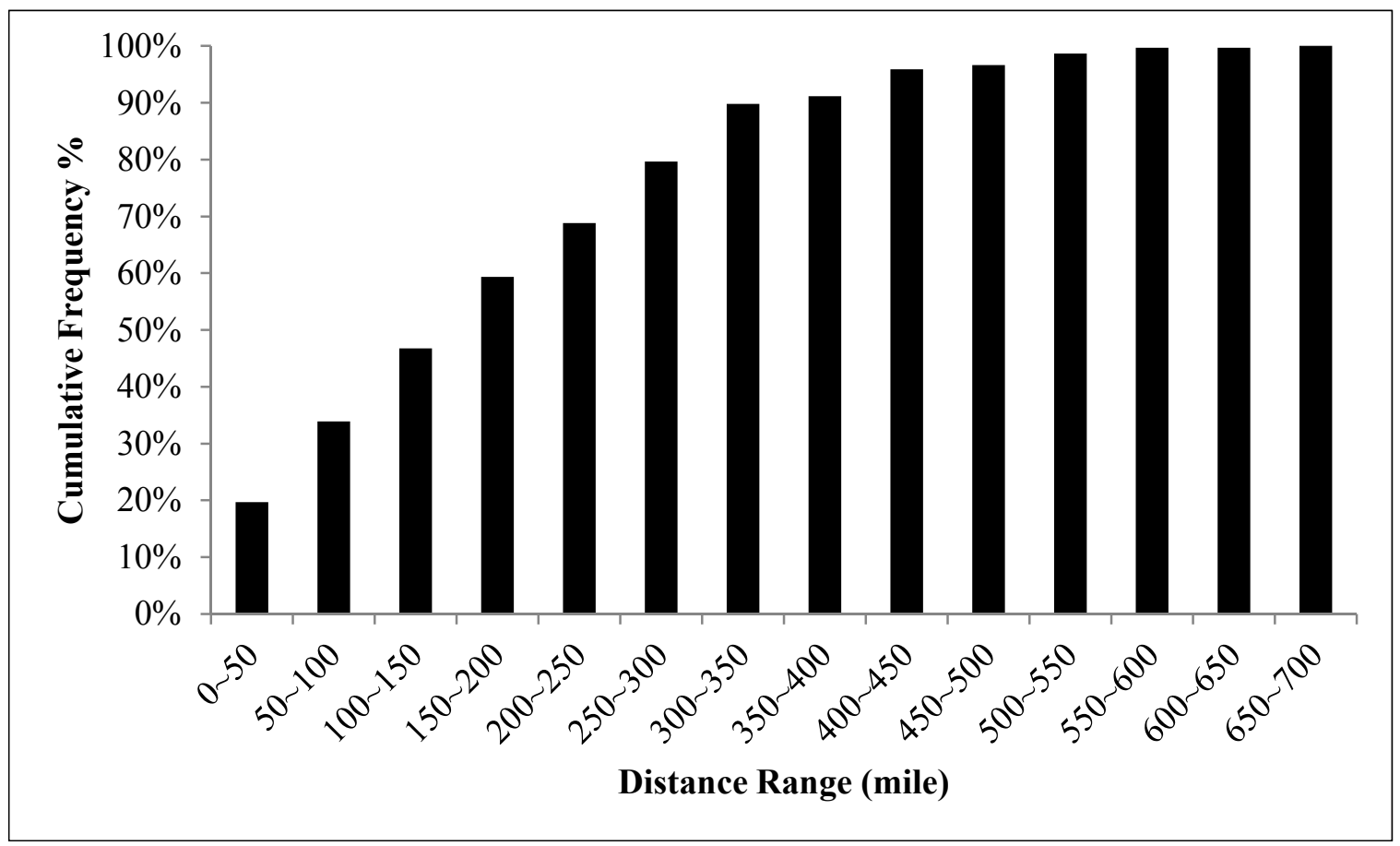

Figure 5-5: Cumulative Distribution of Evacuation Distance without Education Variable 
Table 5-9: Result of Evacuation Distance Model Developed by OLS from Data with Education Level Variable

\begin{tabular}{|c|c|c|c|c|c|}
\hline Variable & Coefficient & $\begin{array}{c}\text { Robust } \\
\text { Standard } \\
\text { Error }\end{array}$ & $\begin{array}{c}\text { Robust } \\
\text { T-value }\end{array}$ & $\begin{array}{c}\text { Robust } \\
\text { P-value }\end{array}$ & $\begin{array}{c}\text { Variance } \\
\text { Inflation } \\
\text { Factor }\end{array}$ \\
\hline (Intercept) & 11.6251 & 0.4791 & 24.2641 & 0.000 & N/A \\
\hline Age $\leq 6$ & 0.2294 & 0.1431 & 1.6026 & 0.114 & 1.20 \\
\hline Income Level: $10 \mathrm{~K} \sim 20 \mathrm{~K}$ & -0.6702 & 0.3163 & -2.1190 & 0.038 & 1.72 \\
\hline Income Level: $20 \mathrm{~K} \sim 30 \mathrm{~K}$ & -0.9504 & 0.4023 & -2.3625 & 0.021 & 2.24 \\
\hline Income Level: 30K 50K & -0.6529 & 0.4906 & -1.3307 & 0.188 & 2.63 \\
\hline Income Level: 50K 80K & -0.6843 & 0.2574 & -2.6583 & 0.010 & 3.32 \\
\hline Income Level: $\geq 80 \mathrm{~K}$ & -1.4736 & 0.3144 & -4.6864 & 0.000 & 3.33 \\
\hline Hurricane Distance & 0.0038 & 0.0013 & 2.8969 & 0.005 & 1.11 \\
\hline \multicolumn{7}{|c|}{ Model Diagnostic Statistics } & AIC & 256.1054 \\
\hline Sample Size & 76 & 0.201 & Adjusted R-Squared & 0.118 \\
\hline R-Squared & 2.4369 & P-value & 0.027 \\
\hline Joint F-Statistic & 30.5351 & P-value & 0.000 \\
\hline Joint Wald Statistic & 8.9866 & P-value & 0.254 \\
\hline Koenker (BP) Statistic & 36.1405 & P-value & 0.000 \\
\hline The Jarque-Bera Statistic & 0.1413 & P-value & 0.001 \\
\hline
\end{tabular}

Table 5-10: Result of Evacuation Distance Model Developed by OLS from Data without Education Level Variable

\begin{tabular}{|c|c|c|c|c|c|}
\hline Variable & Coefficient & $\begin{array}{c}\text { Robust } \\
\text { Standard } \\
\text { Error }\end{array}$ & $\begin{array}{c}\text { Robust } \\
\text { T-value }\end{array}$ & $\begin{array}{c}\text { Robust } \\
\text { P-value }\end{array}$ & $\begin{array}{c}\text { Variance } \\
\text { Inflation } \\
\text { Factor }\end{array}$ \\
\hline (Intercept) & 10.0862 & 0.6113 & 16.4994 & 0.000 & N/A \\
\hline Age $\leq 6$ & 0.2577 & 0.0922 & 2.7965 & 0.006 & 1.04 \\
\hline Income Level: $10 \mathrm{~K} \sim 20 \mathrm{~K}$ & 0.9610 & 0.6222 & 1.5446 & 0.124 & 2.38 \\
\hline Income Level: $20 \mathrm{~K} \sim 30 \mathrm{~K}$ & 1.0667 & 0.5980 & 1.7838 & 0.076 & 3.11 \\
\hline Income Level: 30K 50K & 1.1605 & 0.5992 & 1.9368 & 0.054 & 4.27 \\
\hline Income Level: $50 \mathrm{~K} \sim 80 \mathrm{~K}$ & 1.1322 & 0.5812 & 1.9480 & 0.052 & 5.20 \\
\hline Income Level: $\geq 80 \mathrm{~K}$ & 1.0675 & 0.5868 & 1.8194 & 0.070 & 5.74 \\
\hline Hurricane Distance & 0.0026 & 0.0007 & 3.5895 & 0.000 & 1.04 \\
\hline \multicolumn{7}{|c|}{ Model Diagnostic Statistics } & AIC & 971.6319 \\
\hline Sample Size & 296 & 0.090 & Adjusted R-Squared & 0.068 \\
\hline R-Squared & 4.0724 & P-value & 0.000 \\
\hline Joint F-Statistic & 34.5853 & P-value & 0.000 \\
\hline Joint Wald Statistic & 28.8743 & P-value & 0.000 \\
\hline Koenker (BP) Statistic & 65.2428 & P-value & 0.000 \\
\hline The Jarque-Bera Statistic & 0.0786 & P-value & 0.830 \\
\hline
\end{tabular}


For the model shown in Table 5-10, the Koenker Statistic is statistically significant at the level of 0.05 , indicating that the spatial variation existed in the model. However, the Moran's Index of the model is not statistically significant at the level of 0.05, showing that the spatial autocorrelation existed in the model. The Jarque-Bera Statistics of both models are statistically significant at the level of 0.05 , indicating that both models may be misspecified. Model misspecification is an indication that some key variables were missing from the model or the spatial variations may exist in the model. The OLS model with the statistically significant Koenker Statistic at the level of 0.05 is often a good candidate for the GWR analysis. Therefore, the model shown in Table 5-10 was redeveloped by using the GWR with the survey data with no education level variable. The model coefficients and statistical diagnostic results of the evacuation trip prediction model developed by the GWR are shown in Table 5-12. Since the model that was developed using the GWR is a local model, the model coefficients are shown as the range value instead of the specific value in Table 5-12.

The two models developed by the OLS were compared with one another, side by side. The comparison results are shown in Table 5-11. The table reveals that more than half of the coefficients were or were near statistically significant at the level of 0.05 for both models. The model Adjusted R-Squared values of both models show the low global model performance. The Koenker Statistic of the model shown in Table 5-9 is not statistically significant at the level of 0.05 , suggesting that the spatial variation did not exist in the model. However, the Moran's Index of the model is statistically significant at the level of 0.05 , showing that the spatial autocorrelation existed in the model. Spatial autocorrelation violates underlying assumptions of many traditional non-spatial statistical 
methods, like the OLS. Thus, spatial autocorrelation creates a major difficulty in using traditional statistical methods to model the spatial variations. This means that the model shown in Table 5-9 is not acceptable.

Table 5-11: Comparison of Two Models Developed by OLS

\begin{tabular}{|c|c|c|}
\hline \multirow{2}{*}{ Variable } & \multicolumn{2}{|c|}{ Significance Status } \\
\cline { 2 - 3 } & $\begin{array}{c}\text { With Education Level } \\
\text { Variable }\end{array}$ & $\begin{array}{c}\text { Without Education Level } \\
\text { Variable }\end{array}$ \\
\hline Age $\leq 6$ & Not Significant & Significant \\
\hline Income Level: $10 \mathrm{~K} \sim 20 \mathrm{~K}$ & Significant & Not Significant \\
\hline Income Level: $20 \mathrm{~K} \sim 30 \mathrm{~K}$ & Significant & Near Significant \\
\hline Income Level: $30 \mathrm{~K} \sim 50 \mathrm{~K}$ & Not Significant & Near Significant \\
\hline Income Level: $50 \mathrm{~K} \sim 80 \mathrm{~K}$ & Significant & Near Significant \\
\hline Income Level: $\geq 80 \mathrm{~K}$ & Significant & Near Significant \\
\hline Hurricane Distance & Significant & Significant \\
\hline \multirow{3}{*}{ Model Diagnostic Statistics } & \multicolumn{2}{|c|}{ Diagnostic Result } \\
\cline { 2 - 3 } & With Education Level & Without Education Level \\
Sample Size & Relatively Small & Variable \\
\hline Variance Inflation Factor & No Variable Redundancy & No Variable Redundancy \\
\hline Adjusted R-Squared & Low Model Performance & Low Model Performance \\
\hline Joint F-Statistic & Model Significant & Model Significant \\
\hline Joint Wald Statistic & Model Significant & Model Significant \\
\hline Koenker (BP) Statistic & No Spatial Variation & Spatial Variation \\
\hline The Jarque-Bera Statistic & Model Misspecification & Model Misspecification \\
\hline Moran's Index of Standard Residual & Spatial Autocorrelation & No Spatial Autocorrelation \\
\hline The Joint Wald Staic
\end{tabular}

Notes: *. The Joint Wald Statistic shall be referenced when the Koenker (BP) Statistic is significant.

Table 5-12: Result of Evacuation Distance Model Developed by GWR from Data without Education Level Variable

\begin{tabular}{|c|c|c|c|}
\hline Variable & \multicolumn{3}{|c|}{ Value } \\
\hline Age $\leq 6$ & \multicolumn{3}{|c|}{$-0.0913 \sim 0.8459$} \\
\hline Income Level: $10 \mathrm{~K} \sim 20 \mathrm{~K}$ & \multicolumn{3}{|c|}{$-0.4767 \sim 2.2107$} \\
\hline Income Level: $20 \mathrm{~K} \sim 30 \mathrm{~K}$ & \multicolumn{3}{|c|}{$-0.6743 \sim 2.6682$} \\
\hline Income Level: $30 \mathrm{~K} \sim 50 \mathrm{~K}$ & \multicolumn{3}{|c|}{$-0.1480 \sim 2.0356$} \\
\hline Income Level: $50 \mathrm{~K} \sim 80 \mathrm{~K}$ & \multicolumn{3}{|c|}{$-0.4053 \sim 2.3228$} \\
\hline Income Level: $\geq 80 \mathrm{~K}$ & \multicolumn{3}{|c|}{$-0.3284 \sim 1.7183$} \\
\hline Hurricane Distance & \multicolumn{3}{|c|}{$0.0005 \sim 0.0143$} \\
\hline \multicolumn{4}{|c|}{ Model Diagnostic Statistics } \\
\hline Sample Size & 296 & $\mathrm{AIC}$ & 921.1804 \\
\hline R-Squared & 0.359 & Adjusted R-Squared & 0.264 \\
\hline
\end{tabular}




\begin{tabular}{|c|c|c|c|}
\hline Condition Number & $12.70 \sim 16.73$ & Local R-Squared & $0.052 \sim 0.578$ \\
\hline Moran's Index of Standard Residual & 0.0109 & P-value & 0.970 \\
\hline
\end{tabular}

The histogram of the standard residual reveals that its distribution is an asymmetric bell-shaped curve with some skewness to the left, as shown in Figure 5-6. The spatial distribution of standard residual indicates that over- and under- estimates of evacuation distance occurred at different locations with no signs of high or low standard residual values clustering based on the Moran's Index results, as shown in Figure 5-7. The spatial distribution of local R-Squared suggests that the local model performance is moderate in the gulf coast in Alabama, and low in the gulf coast in Louisiana and Mississippi, as shown in Figure 5-8. Hurricane Katrina was forecasted to make landfall in the Florida Panhandle area, which is east of the actual landfall location, three days before hurricane landfall. The area with moderate model performance was near that forecast track. The area with low model performance was on the far left side of that track. The model performance may be affected by forecast uncertainty. 


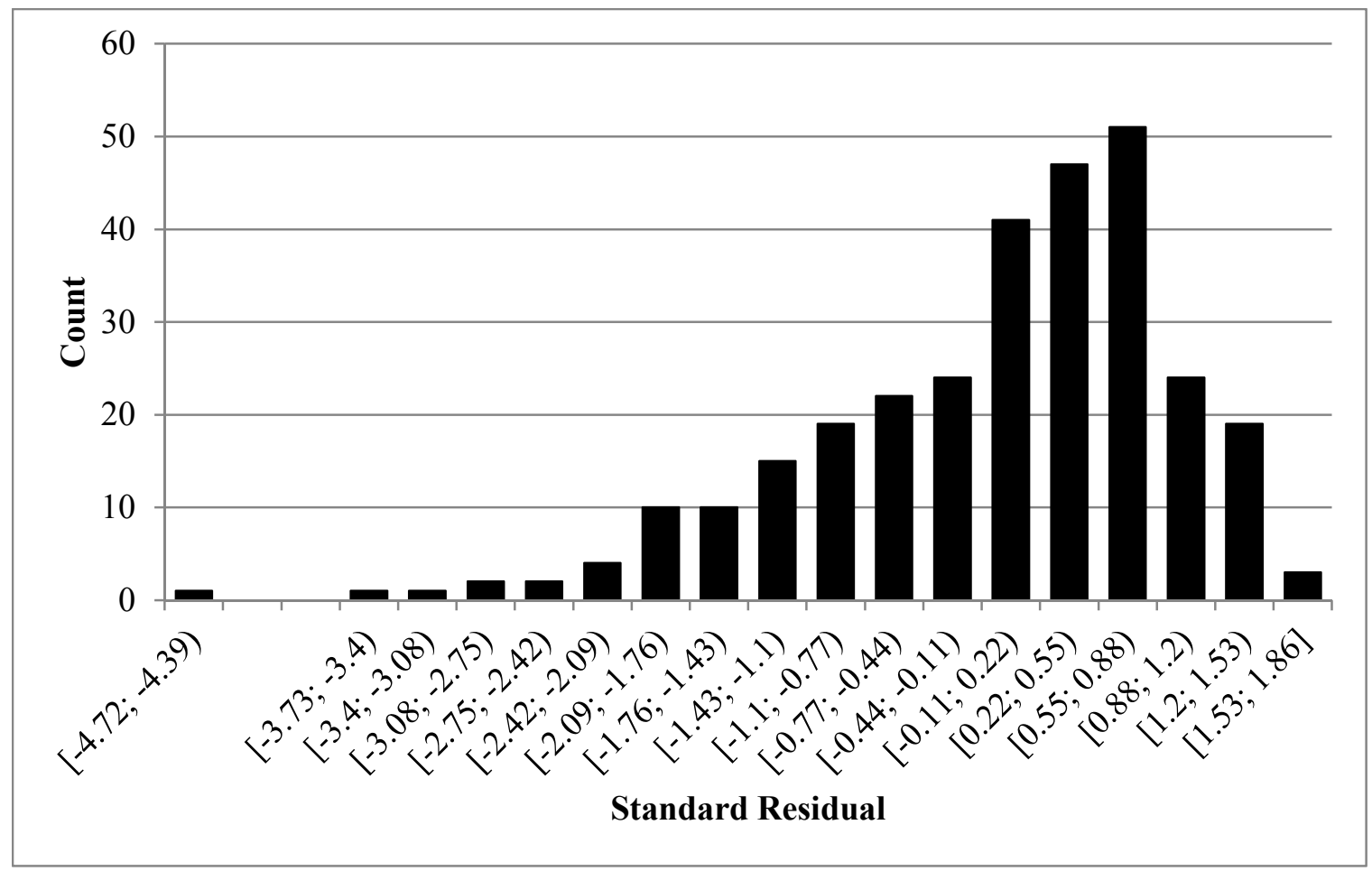

Figure 5-6: GWR Standard Residual Distribution

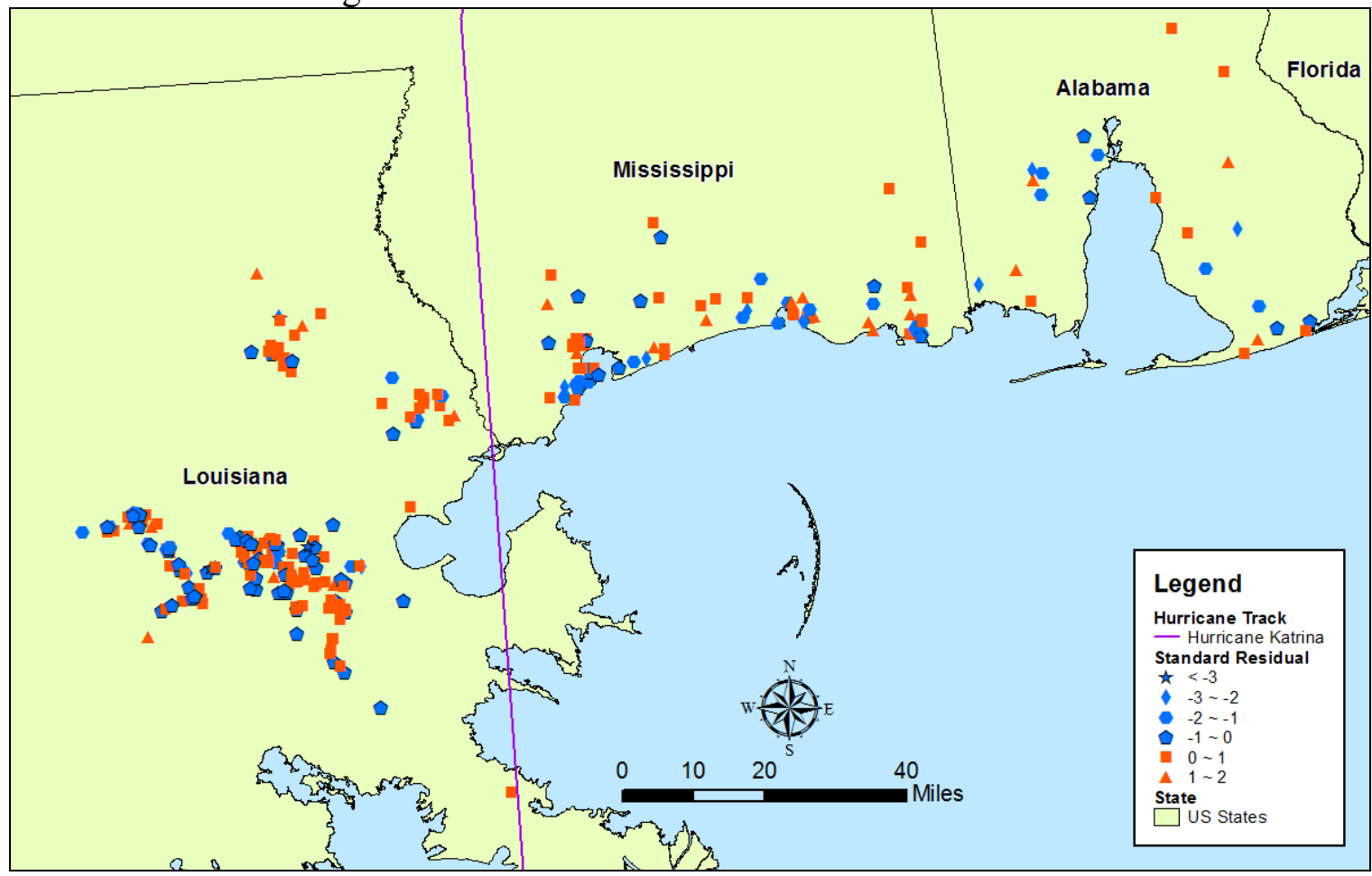

Figure 5-7: Distribution Map of GWR Standard Residual 


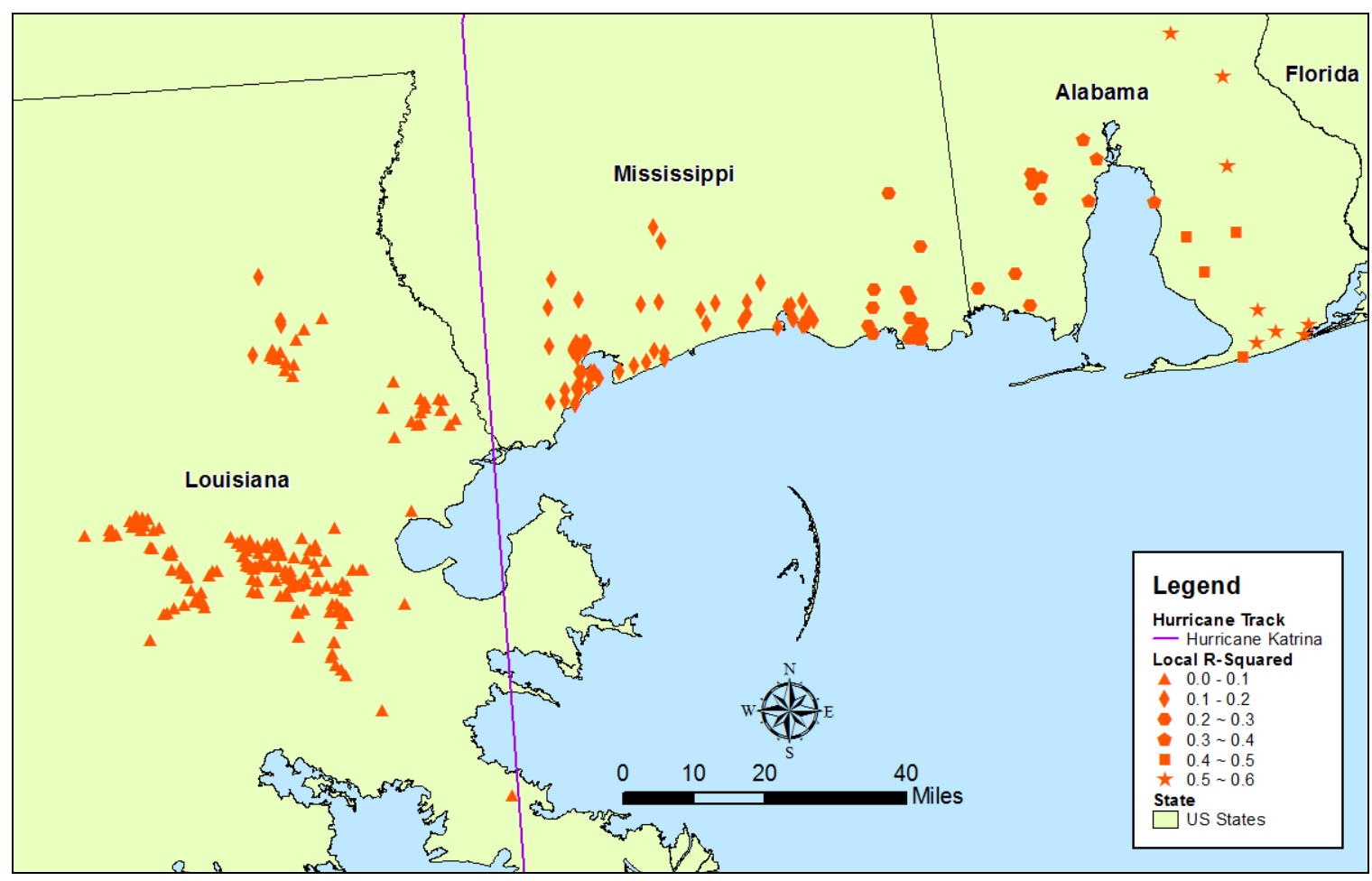

Figure 5-8: Distribution Map of GWR Local R-Squared

In order to facilitate the interpretation of the results of the evacuation trip distance prediction model, the distribution maps of the predictor variables "Age $\leq 6$ " and "Income Level" were generated, as shown in Figure 5-9 to Figure 5-12. The distribution maps of the model coefficients were generated to interpret the results of the model, as shown in Figure 5-13 to Figure 5-19. These maps show how each coefficient affects the evacuation distance. The findings from the evacuation trip distance prediction model are discussed as follows:

- The evacuation distance of the household with more people under age six tends to be longer than that with fewer people under age six, during a hurricane evacuation. The farther the distance from the hurricane-impacted area, the safer the household. This is consistent with the fact that the parents are more concerned with their young children's safety. It is also noted that the coefficient of the predictor 
variable "Age $\leq 6$ " is negative in the extreme southeastern Mississippi, which means that the evacuation distance of the households in this area tends to be shorter than the rest of the study area. This area is located between the different forecasted tracks of Hurricane Katrina. The spatial variation of the predictor variable "Age $\leq 6$ " may be caused by the uncertainty of the hurricane track forecast. It is suggested that the evacuation distance of the households living along the forecasted hurricane track with more people under age six tends to be longer than the rest of the study area.

- The evacuation distance of the households with a higher income tends to be longer than that with a lower income. The evacuation distance of the household with a medium income varies from shorter to longer. This is consistent with the fact that the cost of a longer evacuation distance is higher than that of a shorter evacuation distance. It is also noted that the coefficients of low and high income levels are negative in the gulf coast near the borders of Louisiana and Mississippi, which means that the evacuation distance of the households in this area tends to be shorter than the rest of the study area. This area is located between the different forecasted tracks of Hurricane Katrina. The spatial variation of the low and high income levels may also be caused by the uncertainty of the hurricane track forecast. It is suggested that the evacuation distance of the households living along the forecasted hurricane track with a higher income tends to be longer than the rest of the study area.

- The coefficient of hurricane distance changes from low in southeastern Louisiana to high in southern Alabama. This suggests that the hurricane distance tends to 
have a greater impact on the evacuation distance in southern Alabama than southeastern Louisiana. The forecast track of Hurricane Katrina three days before hurricane landfall had the landfall location in the Florida Panhandle area, resulting in the shorter hurricane distance. This may explain the longer evacuation distance of the households living in southern Alabama than the rest of the study area. Therefore, the evacuation distance of the households living along the forecasted hurricane track with a shorter hurricane distance tends to be longer than the rest of the study area.

- The age, household size, owning or renting, gender, marital status, and race were not identified as the predictor variables that have noticeable impacts on the evacuation distance.

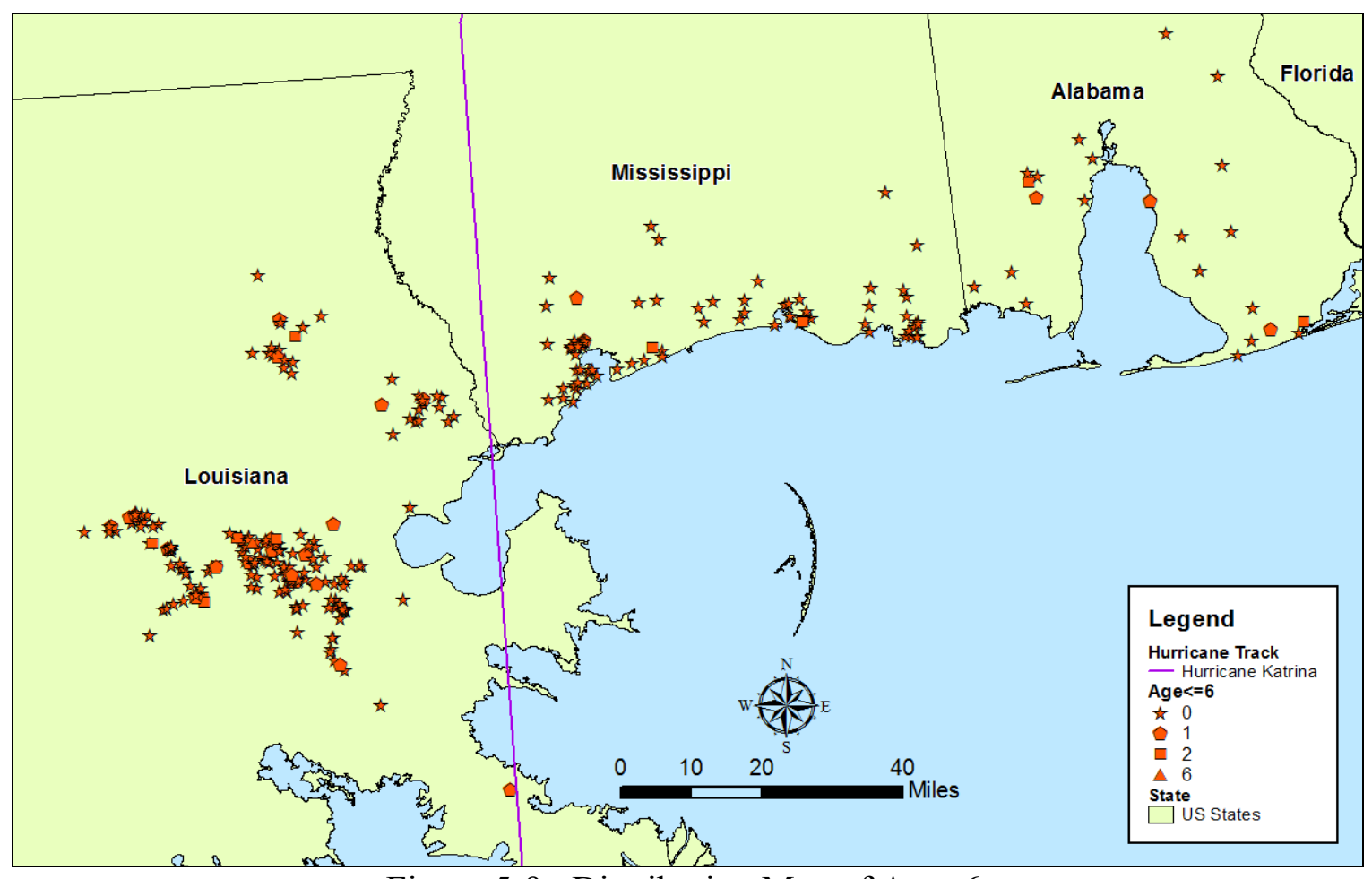

Figure 5-9: Distribution Map of Age $\leq 6$ 


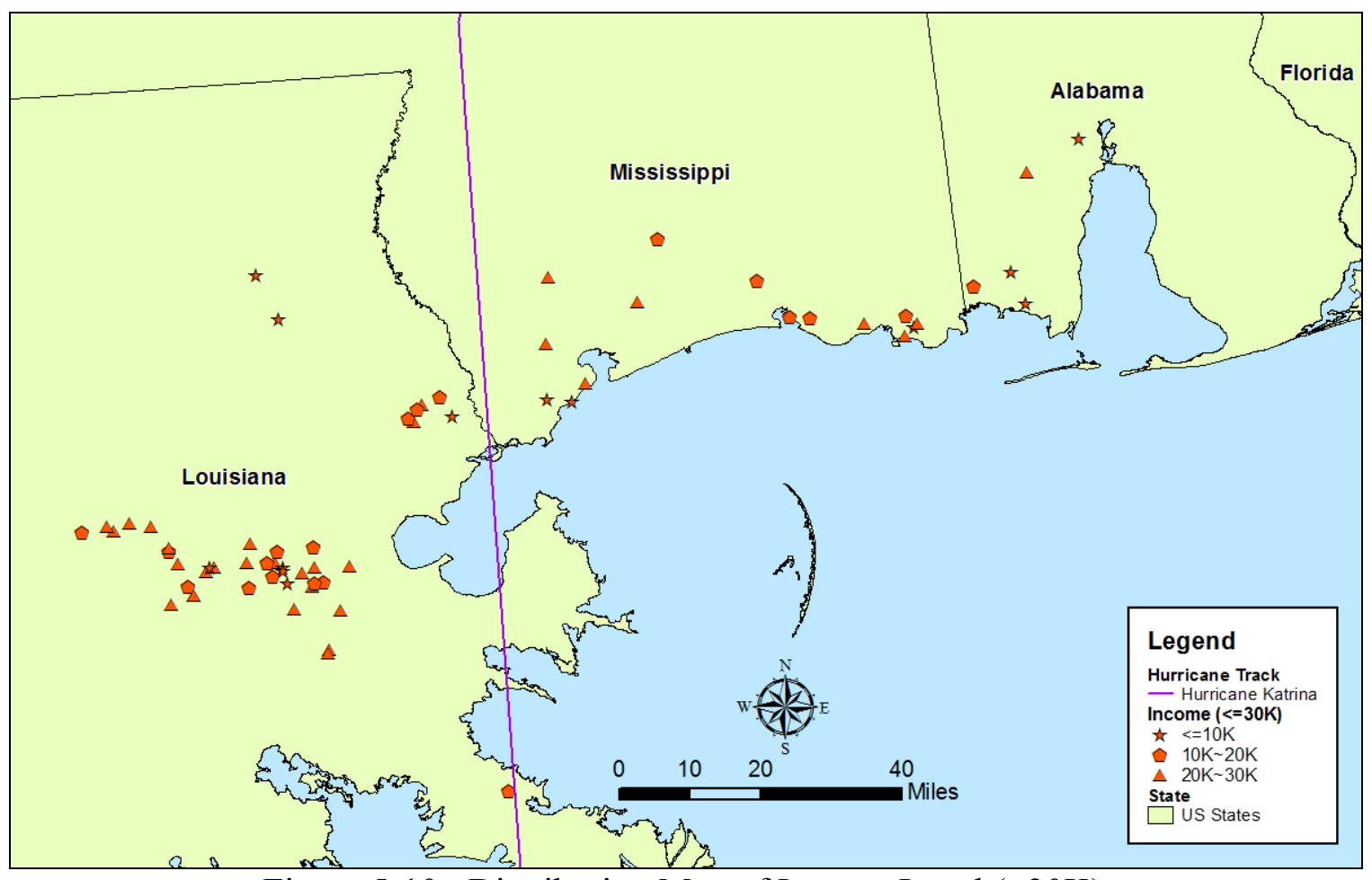

Figure 5-10: Distribution Map of Income Level $(\leq 30 \mathrm{~K})$

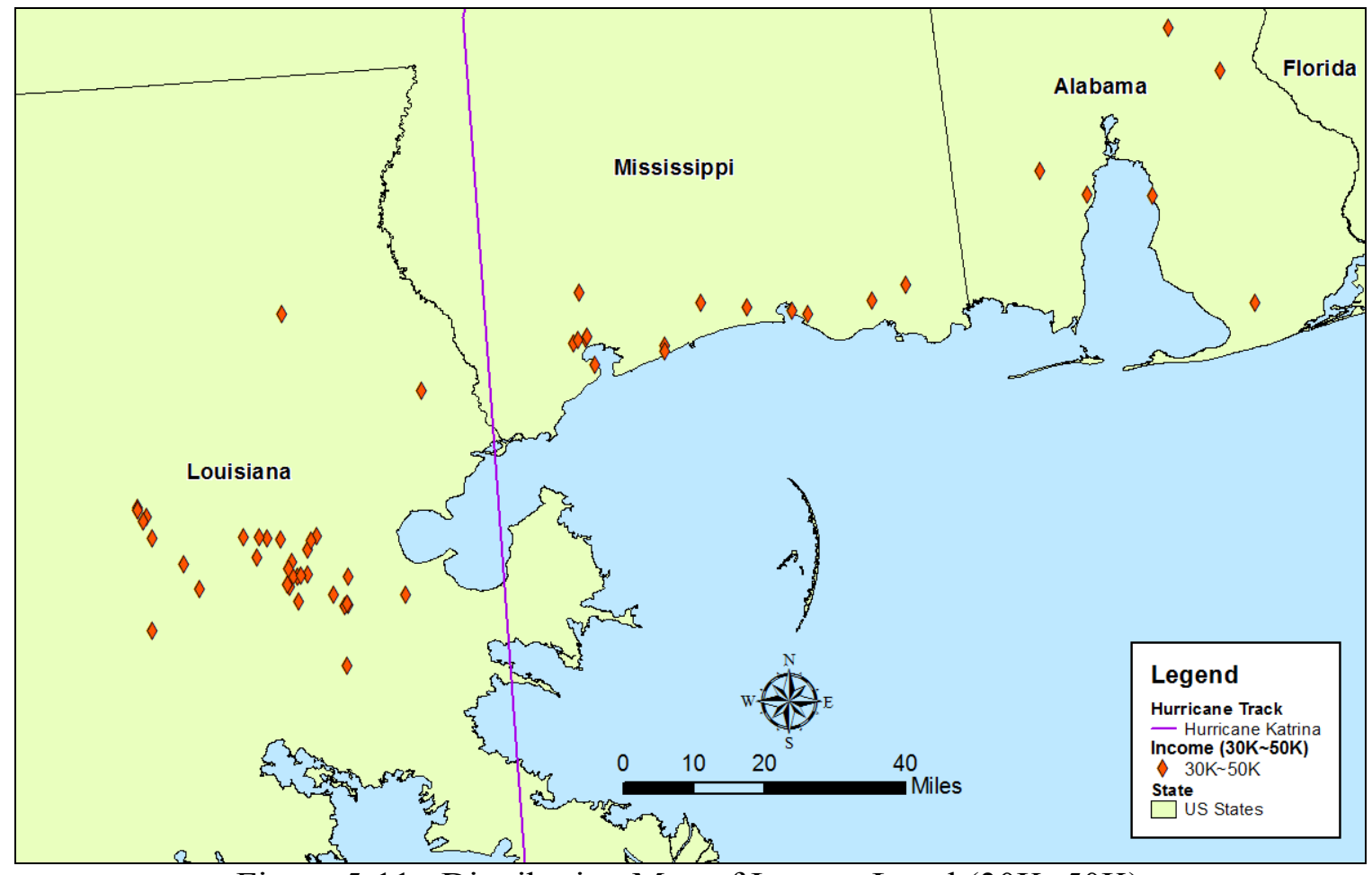

Figure 5-11: Distribution Map of Income Level (30K 50K) 


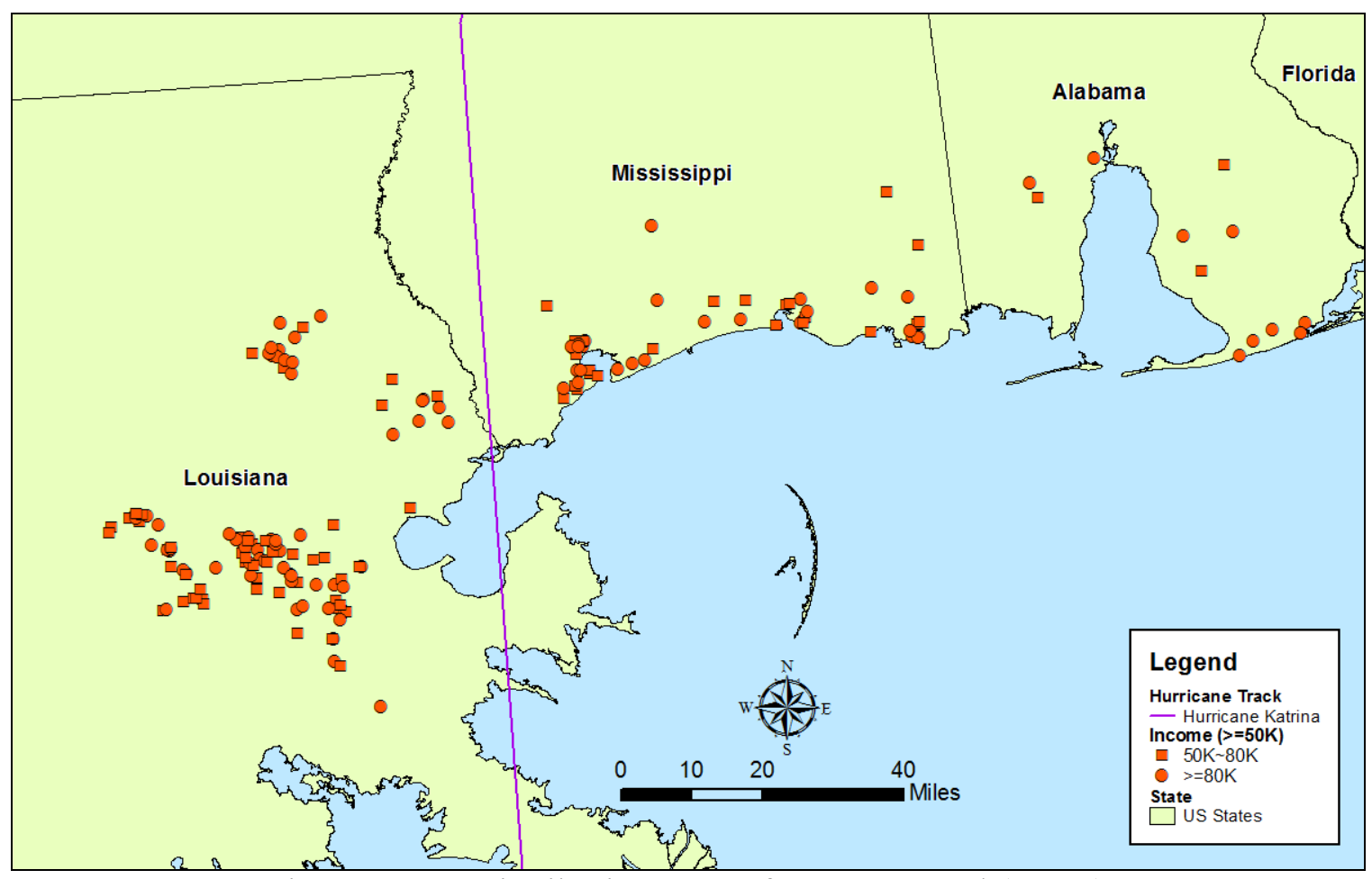

Figure 5-12: Distribution Map of Income Level ( $\geq 50 \mathrm{~K})$

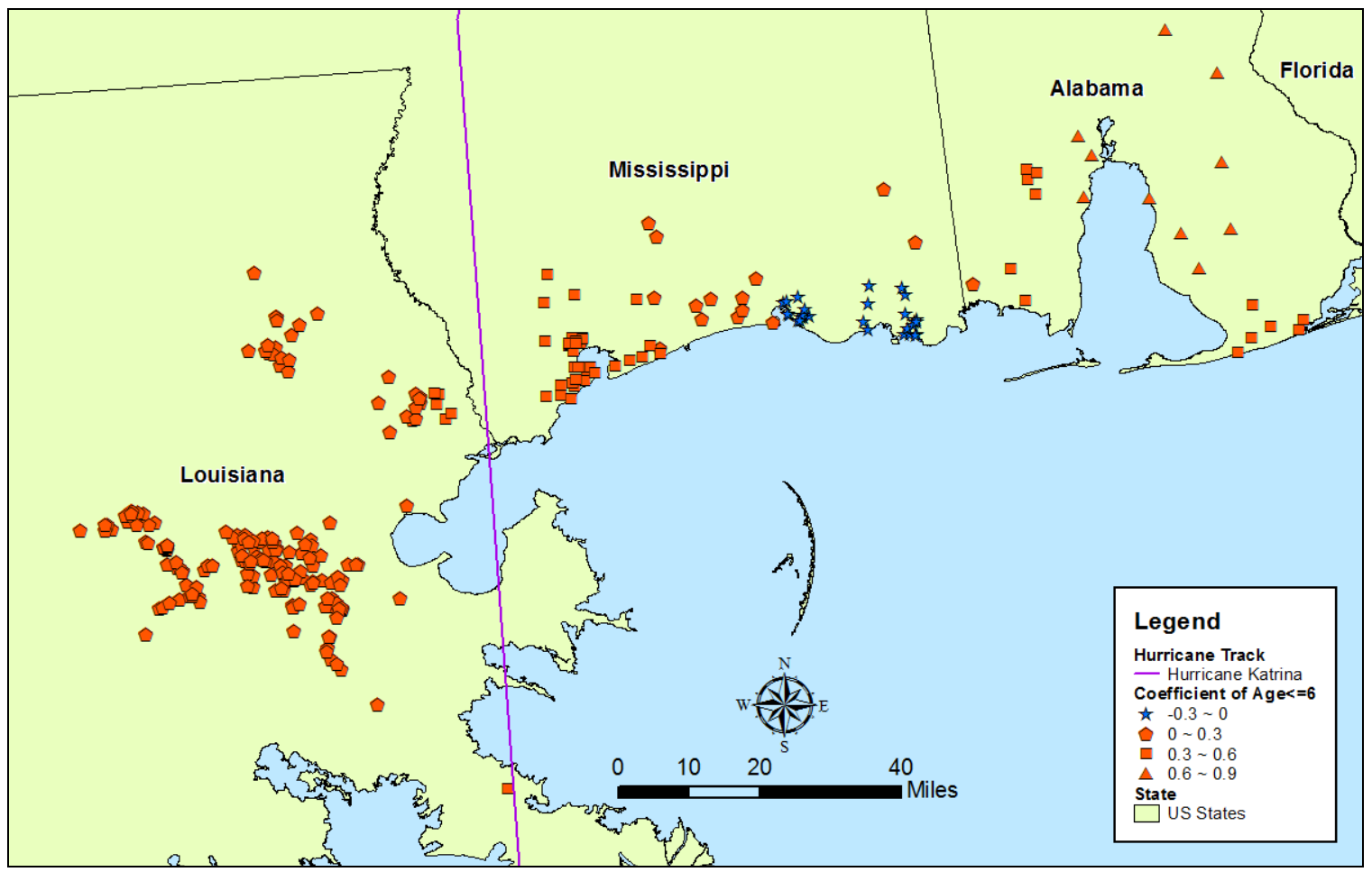

Figure 5-13: GWR Coefficient Distribution of Age $\leq 6$ 


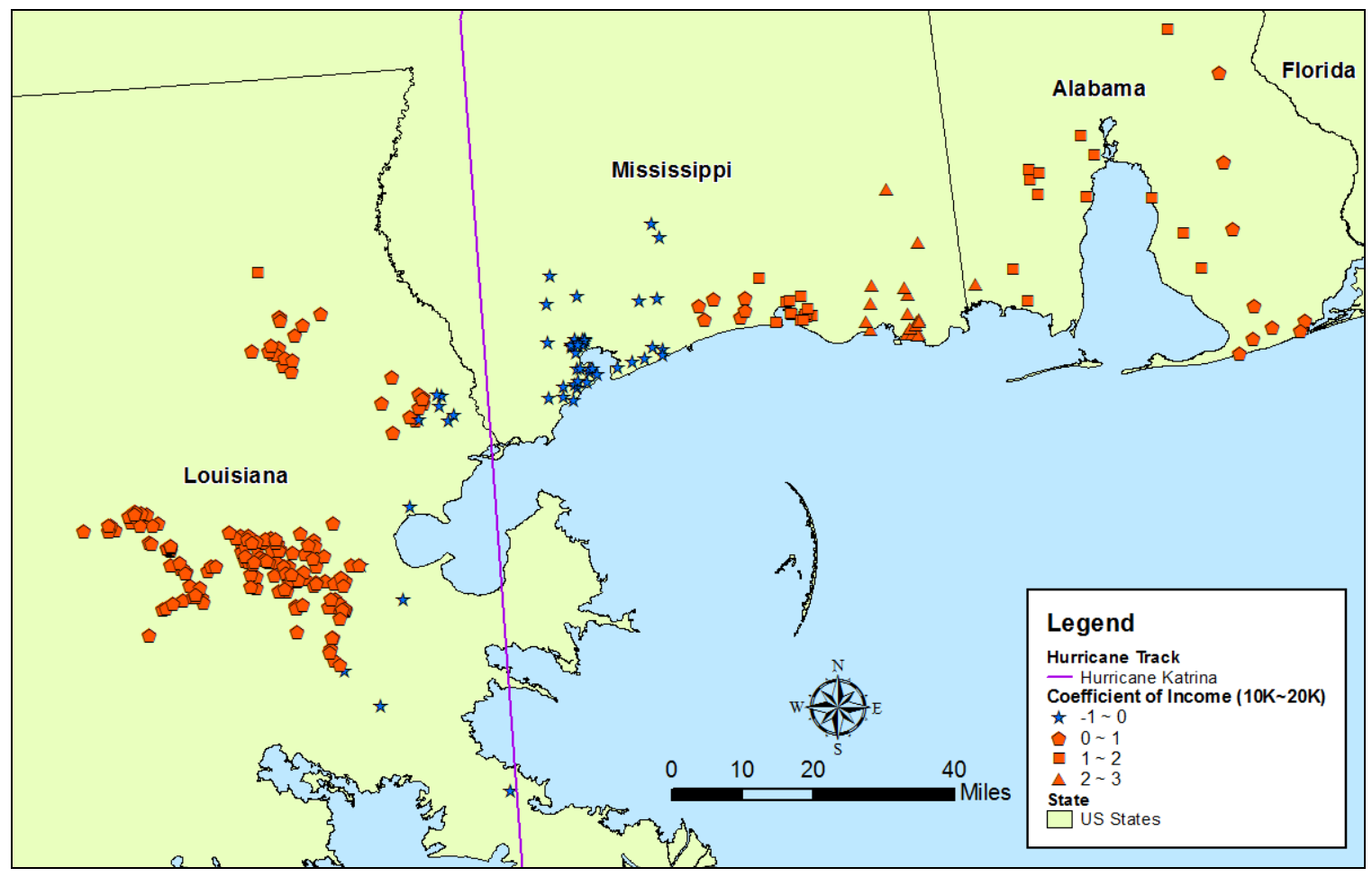

Figure 5-14: GWR Coefficient Map of Income Level (10K 20K)

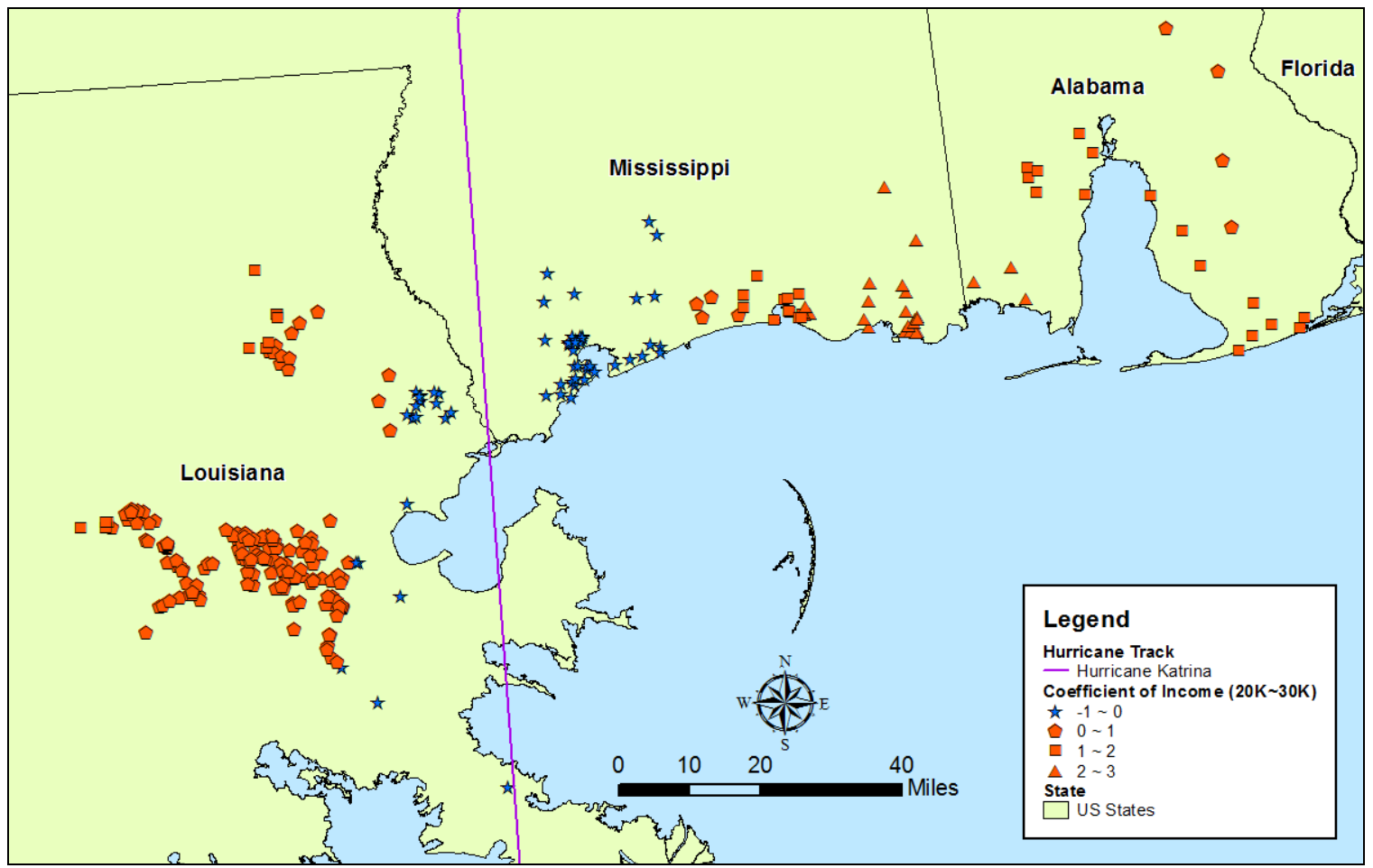

Figure 5-15: GWR Coefficient Map of Income Level (20K 30K) 


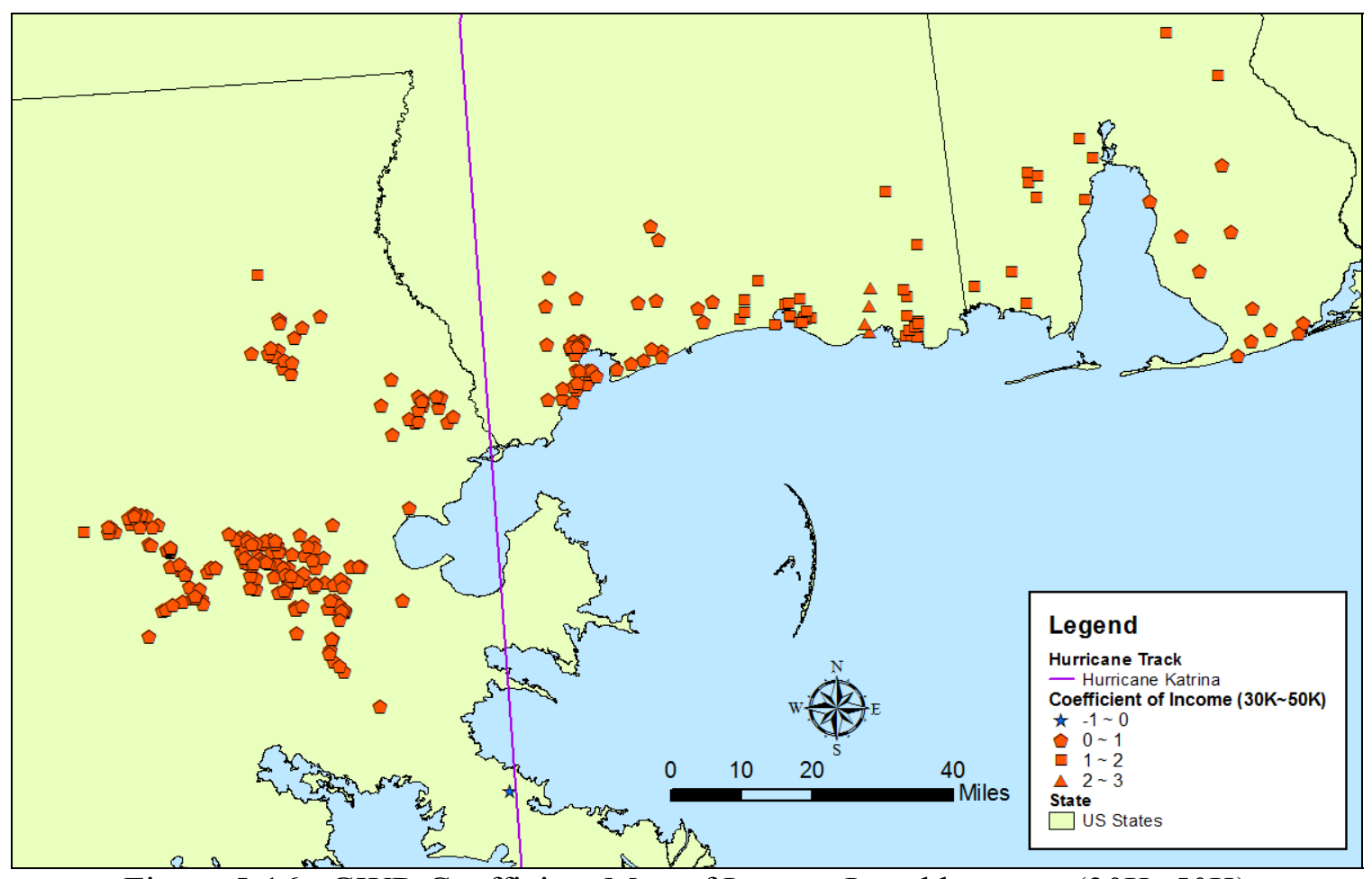

Figure 5-16: GWR Coefficient Map of Income Level between $(30 \mathrm{~K} \sim 50 \mathrm{~K})$

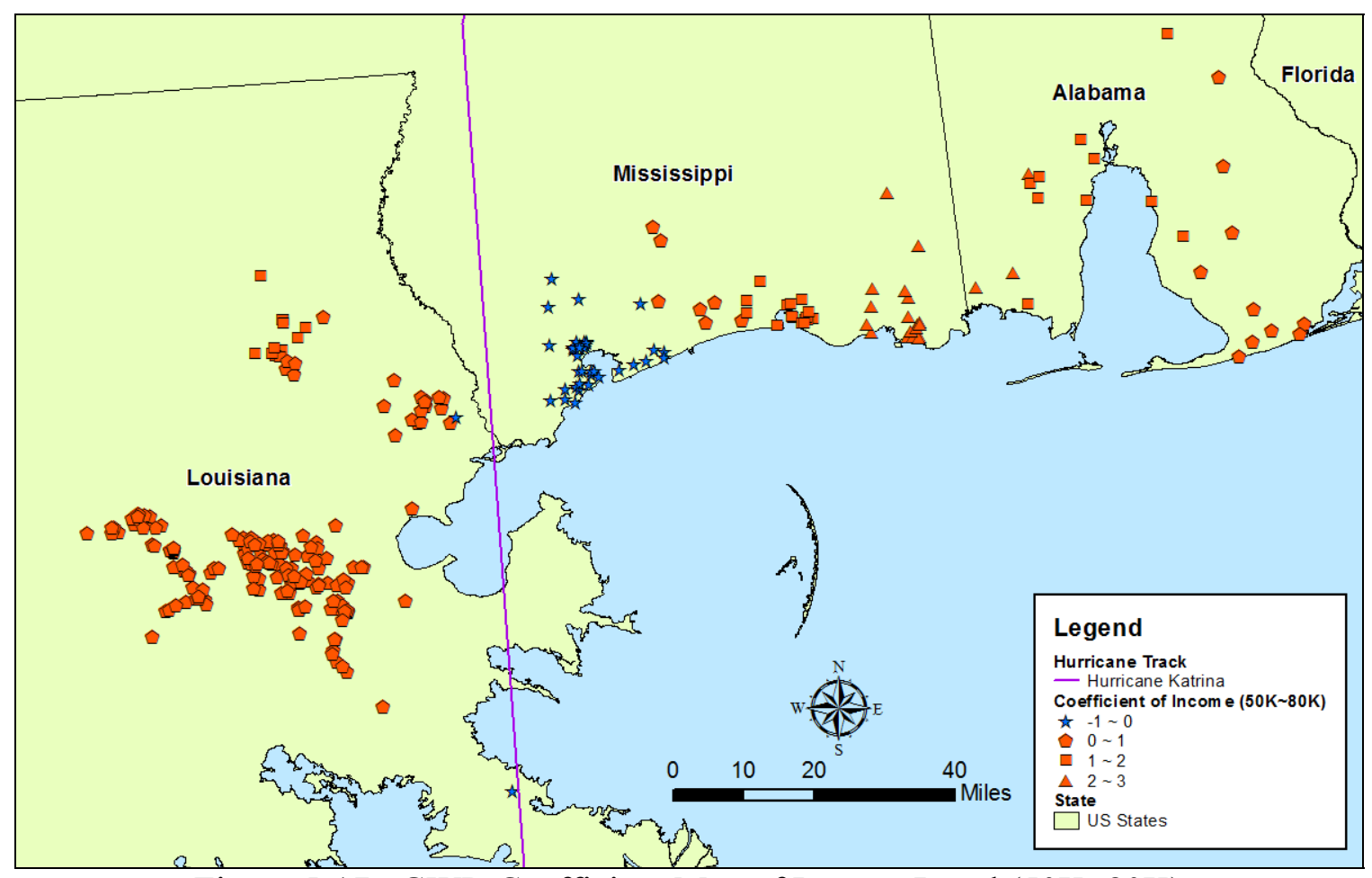

Figure 5-17: GWR Coefficient Map of Income Level (50K 80K) 


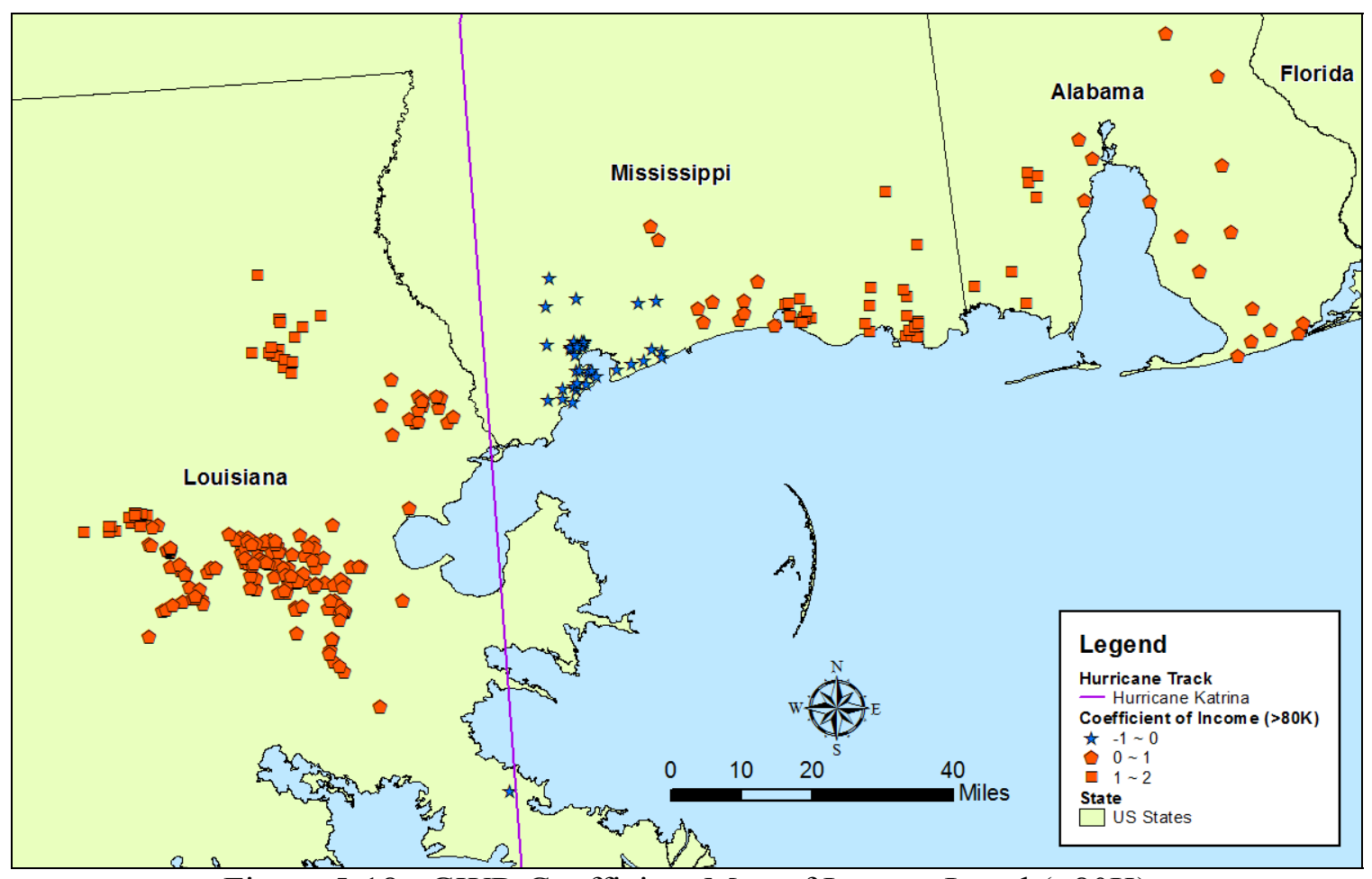

Figure 5-18: GWR Coefficient Map of Income Level ( $\geq 80 \mathrm{~K})$

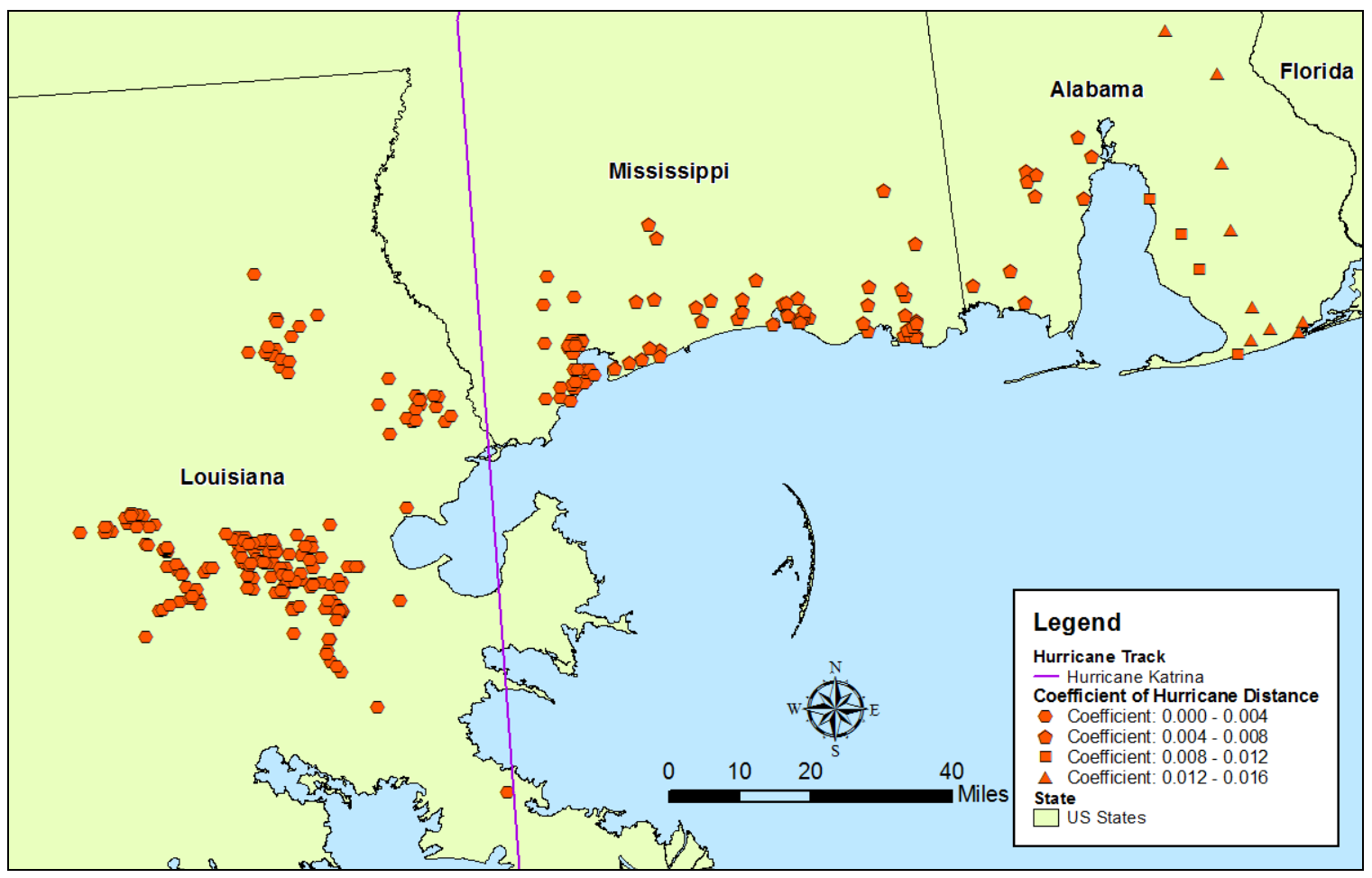

Figure 5-19: GWR Coefficient Map of Hurricane Distance 
GWR generates a separate regression equation for every feature analyzed in the survey data. Therefore, the number of equations equals the sample size of the survey data. One of the regression equations in the evacuation trip distance prediction model is shown in the following equation:

$$
\begin{aligned}
\ln (\text { Evacuation Distance })= & +11.5508+0.2564(\text { Age } \leq 6) \\
& +0.3951(\text { Income }, 10 \mathrm{~K} \sim 20 \mathrm{~K}) \\
& +0.5666(\text { Income }, 20 \mathrm{~K} \sim 30 \mathrm{~K}) \\
& +0.6182(\text { Income }, 30 \mathrm{~K} \sim 50 \mathrm{~K}) \\
& +0.5694(\text { Income }, 50 \mathrm{~K} \sim 80 \mathrm{~K}) \\
& +0.7477(\text { Income }, \geq 80 \mathrm{~K})+0.0006(\text { Hurricane Distance })
\end{aligned}
$$

\subsection{Summary}

Three prediction models were developed. Each model was first developed by using the two sets of survey data, one of which includes the education level variable and one that does not. The two models were then compared with one another based on the statistical diagnostic results. Finally, the model with the better overall performance was selected as the final one.

The final evacuation rate prediction model was developed based on the survey data without the education level variable. This model shows that the homeowners and the households with more people under age six are more likely to evacuate than the home renters and the households with less people under age six during a hurricane evacuation, respectively.

The final evacuation trip prediction model was developed based on the survey data without the education level variable. This model indicates that the probability of evacuation three days before hurricane landfall is in proportion to the number of people 
under age six in a household, the probability of evacuation one day before hurricane landfall is inverse proportion to the number of people under six in a household, and the probability of evacuation two days before the hurricane landfall is not sensitive to the number of people under age six in the same household.

The evacuation trip distance prediction model was first developed by the OLS based on the survey data without the education level variable. It was found that the spatial variation existed in the OLS model. The GWR was then used to develop the final evacuation trip distance prediction model. This model suggests that the evacuation distance of the households living along the forecasted hurricane track tends to be longer than that of the rest of the study area. 


\section{CHAPTER 6 \\ MODEL EVALUATION}

Three prediction models were developed: the evacuation rate prediction model, evacuation trip prediction model, and evacuation trip distance prediction model. After these models were developed, it was necessary to evaluate the models before applying them. Since these models were developed by different statistical methods, different methods should be adopted to evaluate the models. The purpose of the model evaluation process is to assess the validity and performance of the models developed, which may be affected by the quality of the survey data.

\subsection{Evaluation Methodology}

In order to evaluate the models developed, other hurricane evacuation survey data is usually required to evaluate how good the models are. Therefore, Hurricane Ivan evacuation survey data was obtained to evaluate the models. Hurricane Ivan is one of the most intense hurricanes in history, which made landfall on the extreme eastern Alabama Gulf Coast. In comparison to the landfall location of Hurricane Katrina, whose survey data was used to develop the prediction models, the two landfall locations are not far from each other. Hurricane Ivan evacuation survey data has similar data items to Hurricane Katrina evacuation survey data. The survey data was processed by the similar method that was used to process Hurricane Katrina evacuation survey data, before it was used to evaluate the models. The processed survey data was then used to check the percentage of correct prediction of the prediction models. 
Aside from evaluating the model performance by using other set of data, the statistical diagnostic method should also be used to evaluate the models' performance. Each model was evaluated separately due to the different methods used to develop different prediction models. The model evaluation process is discussed in the following sections.

\subsection{Evacuation Rate Prediction Model}

The first part of evaluating the evacuation rate prediction model is to calculate the percentage of correct prediction. Hurricane Ivan evacuation survey data was used to perform the evaluation. The result from the model is the probability value representing the probability of the household that evacuated. It is necessary to convert the probability value into the number of households that evacuated. In order to carry out this conversion, the households need to be categorized by the predictor variables in the model.

There are two predictor variables in the model, which are "Own or Rent" and "Age $\leq 6$." Therefore, the household was categorized by these two predictor variables. For example, the household that owns the home and has one person under age six is one of the categories. The variable "Own or Rent" has two values, "Own the Home" and "Rent the Home." The variable "Age $\leq 6$ " has four values, "0," "1," "2," and "3." Therefore, the total number of categories is eight. The number of households in each category was then counted based on the survey data. The number of predicted households that evacuated for each category was calculated by multiplying the frequency of each category by its corresponding probability value. Finally, the predicted number 
was compared to the observed number of the corresponding category in order to calculate the percentage of correct prediction.

Table 6-1 shows the evaluation results of the evacuation rate prediction model. It was noted that the percentage of correct predictions for half of the categories is above $75 \%$, which indicates that the model produced reasonably good results for the corresponding categories. For the other half of the categories, that percentage is almost unavailable due to the lack of the corresponding data. The overall percentage of correct prediction is $81.04 \%$, indicating that the model as a whole produced a good result.

Table 6-1: Evaluation Result of Evacuation Rate Model

\begin{tabular}{|c|c|c|c|c|c|c|c|}
\hline \multirow{2}{*}{$\begin{array}{c}\text { Category } \\
\text { No }\end{array}$} & \multicolumn{2}{|c|}{ Predictor Variable } & \multirow{2}{*}{$\begin{array}{l}\text { Predicted } \\
\text { Evacuation } \\
\text { Probability }\end{array}$} & \multirow{2}{*}{ Frequency } & \multicolumn{2}{|c|}{$\begin{array}{c}\text { Number of Household } \\
\text { Evacuated }\end{array}$} & \multirow{2}{*}{$\begin{array}{c}\text { Correct } \\
\text { Prediction } \\
\%\end{array}$} \\
\hline & Own/Rent ${ }^{*}$ & Age $\leq 6$ & & & Predicted & Observed & \\
\hline 1 & 0 & 0 & 0.609 & 442 & 269.178 & 212 & $78.76 \%$ \\
\hline 2 & 0 & 1 & 0.684 & 35 & 23.940 & 22 & $91.90 \%$ \\
\hline 3 & 0 & 2 & 0.750 & 15 & 11.250 & 10 & $88.89 \%$ \\
\hline 4 & 0 & 3 & 0.807 & 0 & 0 & 0 & $\mathrm{~N} / \mathrm{A}$ \\
\hline 5 & 1 & 0 & 0.464 & 29 & 13.456 & 13 & $96.61 \%$ \\
\hline 6 & 1 & 1 & 0.546 & 1 & 0.546 & 1 & $54.60 \%$ \\
\hline 7 & 1 & 2 & 0.626 & 0 & 0 & 0 & $\mathrm{~N} / \mathrm{A}$ \\
\hline 8 & 1 & 3 & 0.699 & 0 & 0 & 0 & $\mathrm{~N} / \mathrm{A}$ \\
\hline \multicolumn{5}{|c|}{ Total } & 318.37 & 258 & $81.04 \%$ \\
\hline
\end{tabular}

Note: *. $0-$ Own and $1-$ Rent

Unlike the traditional linear regression model, the binomial logistic regression model uses the log-likelihood value as the diagnostic statistics instead of the R-Squared value. The log-likelihood test was used to test the goodness-of-fit of the model by comparing the full model with the empty model. The "empty" model has only one parameter (intercept). The full model has multiple predictor variables. The probability distribution of the test statistic can be approximated by a chi-square distribution with the 
degrees of freedom difference between the two models. The log-likelihood test of the evacuation rate prediction model shows the chi-square values of 5.1943 with the p-value of 0.037 . Since the p-value is statistically significant at the level of 0.05 , it can be said that the model developed was significantly better than the empty model at the level of 0.05 .

For the coefficients of the evacuation rate prediction model, it was found that the predictor variables of the model were not statistically significant at the level of 0.05 . However, the p-values of the diagnostic statistics of the predictor variables are both 0.134 , which is not far from 0.05. This indicates that the predictor variables "Own or Rent" and "Age $\leq 6$ " still have some relationship with the outcome variable "Evacuation Status."

By considering the results of the percentage of the correct prediction and the model diagnostic statistics, the performance of the evacuation rate prediction model is acceptable as a whole.

\subsection{Evacuation Trip Prediction Model}

The method to calculate the percentage of correct prediction in the evacuation trip prediction model is similar to that in the evacuation rate prediction model. The difference between them is that the evacuation trip prediction model deals with the probability of the households that evacuated three days, two days, or one day before hurricane landfall. There is one predictor variable in the model, which is "Age $\leq 6$." The evacuation day and the variable "Age $\leq 6$ " were used to categorize the household. The evacuation day has three values, "Three Days," "Two Days," and "One Day" before hurricane landfall. Therefore, the total number of categories is 12 . Table 6-2 shows the 
evaluation results of the evacuation trip prediction model. It was noted that the percentage of correct prediction of two categories with sufficient observed samples are above $90 \%$. The rest of the categories have few observed samples, and the corresponding percentage of correct prediction is not reliable. The overall percentage of correct prediction is $98.93 \%$, indicating that the model as a whole produced a good outcome.

Table 6-2: Evaluation Result of the Evacuation Trip Model

\begin{tabular}{|c|c|c|c|c|c|c|c|}
\hline \multirow{2}{*}{$\begin{array}{c}\text { Category } \\
\text { No }\end{array}$} & \multirow[t]{2}{*}{ Age $\leq 6$} & \multirow{2}{*}{$\begin{array}{l}\text { Predicted } \\
\text { Evacuation } \\
\text { Probability }\end{array}$} & \multirow{2}{*}{$\begin{array}{c}\text { Evacuation } \\
\text { Day }\end{array}$} & \multirow[t]{2}{*}{ Frequency } & \multicolumn{2}{|c|}{$\begin{array}{c}\text { Number of Household } \\
\text { Evacuated }\end{array}$} & \multirow{2}{*}{$\begin{array}{c}\text { Correct } \\
\text { Prediction } \\
\%\end{array}$} \\
\hline & & & & & Predicted & Observed & \\
\hline 1 & 0 & 0.053 & 3 & 176 & 9.328 & 3 & $32.16 \%$ \\
\hline 2 & 1 & 0.100 & 3 & 11 & 0.100 & 1 & $10.00 \%$ \\
\hline 3 & 2 & 0.180 & 3 & 7 & 0.180 & 1 & $18.00 \%$ \\
\hline 4 & 3 & 0.301 & 3 & 0 & 0 & 0 & N/A \\
\hline 5 & 0 & 0.273 & 2 & 176 & 48.048 & 45 & $93.66 \%$ \\
\hline 6 & 1 & 0.297 & 2 & 11 & 3.267 & 4 & $81.68 \%$ \\
\hline 7 & 2 & 0.307 & 2 & 7 & 2.149 & 5 & $42.98 \%$ \\
\hline 8 & 3 & 0.294 & 2 & 0 & 0 & 0 & $\mathrm{~N} / \mathrm{A}$ \\
\hline 9 & 0 & 0.674 & 1 & 176 & 118.624 & 128 & $92.68 \%$ \\
\hline 10 & 1 & 0.603 & 1 & 11 & 6.633 & 6 & $90.46 \%$ \\
\hline 11 & 2 & 0.513 & 1 & 7 & 3.591 & 1 & $27.85 \%$ \\
\hline 12 & 3 & 0.405 & 1 & 0 & 0 & 0 & N/A \\
\hline & & Total & & & 191.92 & 194 & $98.93 \%$ \\
\hline
\end{tabular}

Similar to the binomial logistic regression, the multinomial logistic regression also uses the log-likelihood value as the diagnostic statistics to test the goodness-of-fit of the model by comparing the full model with the empty model. The log-likelihood test of the evacuation trip prediction model shows the chi-square value of 6.3343 with the pvalue of 0.042 . Since 0.042 is statistically significant at the level of 0.05 , it can be said that the model is significantly better than the empty model at the level of 0.05 . 
As to the coefficients of the evacuation trip prediction model, it was found that the coefficient of the predictor variable "Age $\leq 6$ " in the model for the scenario of one day before hurricane landfall is statistically significant at the level of 0.05 . The coefficient of the predictor variable "Age $\leq 6$ " in the model for the scenario of two days before hurricane landfall is nearly statistically significant at the level of 0.05 . This suggests that the number of people under age six is a good predictor of the evacuation day.

By considering the results of the percentage of the correct prediction and the model diagnostic statistics, the performance of the evacuation trip prediction model is good as a whole.

\subsection{Evacuation Trip Distance Prediction Model}

The evacuation trip distance prediction model was developed by two statistical methods, the Ordinary Least Square (OLS) and Geographically Weighted Regression (GWR). As mentioned, the reason for using two methods is that the spatial variations may exist in the outcome variable "Evacuation Distance." It means that the evacuation distance may not only be affected by the predictor variables, but also by the location. The global model developed by the OLS may not correctly explain the whole study area. The GWR is one of the statistical methods that can model the spatial variations.

The OLS was first used to develop the model. It was found that one of the diagnostic statistics, Koenker (BP) Statistic, was statistically significant at the level of 0.05 , indicating that spatial variations existed in the model developed by the OLS. Then, the GWR was used to develop the model. By comparing the Akaike Information Criterion (AIC) value of the OLS and GWR model, it was found that the AIC value of the 
GWR model is less than that of the OLS model, and the difference between them is more than three, suggesting that it may be beneficial to use the GWR rather than the OLS to develop the model.

The Hurricane Ivan evacuation survey data was used to evaluate the evacuation trip distance prediction model. The evacuation distance in the Hurricane Ivan evacuation survey data was a distance range instead of an evacuation destination that can be used to calculate the evacuation distance. Therefore, the decision rule for evaluating the model was simply checking if the predicted evacuation distance was within the distance range. The evaluation result showed that $41.75 \%$ of the evacuation trip distance was correctly predicted by the evacuation trip distance prediction model.

The model developed by the GWR is a local model that takes into account the geographical location weighting. One of the distinct differences between the OLS and GWR is that the GWR model has a diagnostic statistic called Local R-Squared. Local RSquared is different from R-Squared because it is a measure of local model goodness-offit. It represents how well the local regression model fits the observed values. High Local R-Squared values indicate that the local model performance is good. By checking the Local R-Squared values from the GWR model, it was found that about $64 \%$ of the values fell within 0 and 0.1 , suggesting that the performances of more than half of the local models are low, as shown in Figure 6-1. Both the R-Squared value (0.359) and Adjusted R-Squared value (0.264) indicate that the performance of the global model is medium.

The standard residual is the standardized residual that is the difference between the observed value and the fitted value calculated from the GWR model. It measures 
how far the fitted value deviates from the observed value. The positive standard residual means that the fitted value underestimates the observed value. The negative standard residual means that the fitted value overestimates the observed value. The standard residual histogram is shown in Figure 6-2. The figure shows that most of the standard residuals fall within the two standard deviation range. Two standard deviations correspond to approximately a $95 \%$ confidence interval. This means that the probability of standard residual falling within two standard deviations is about 0.95 , indicating that the GWR model is a better fit in terms of the observed values.

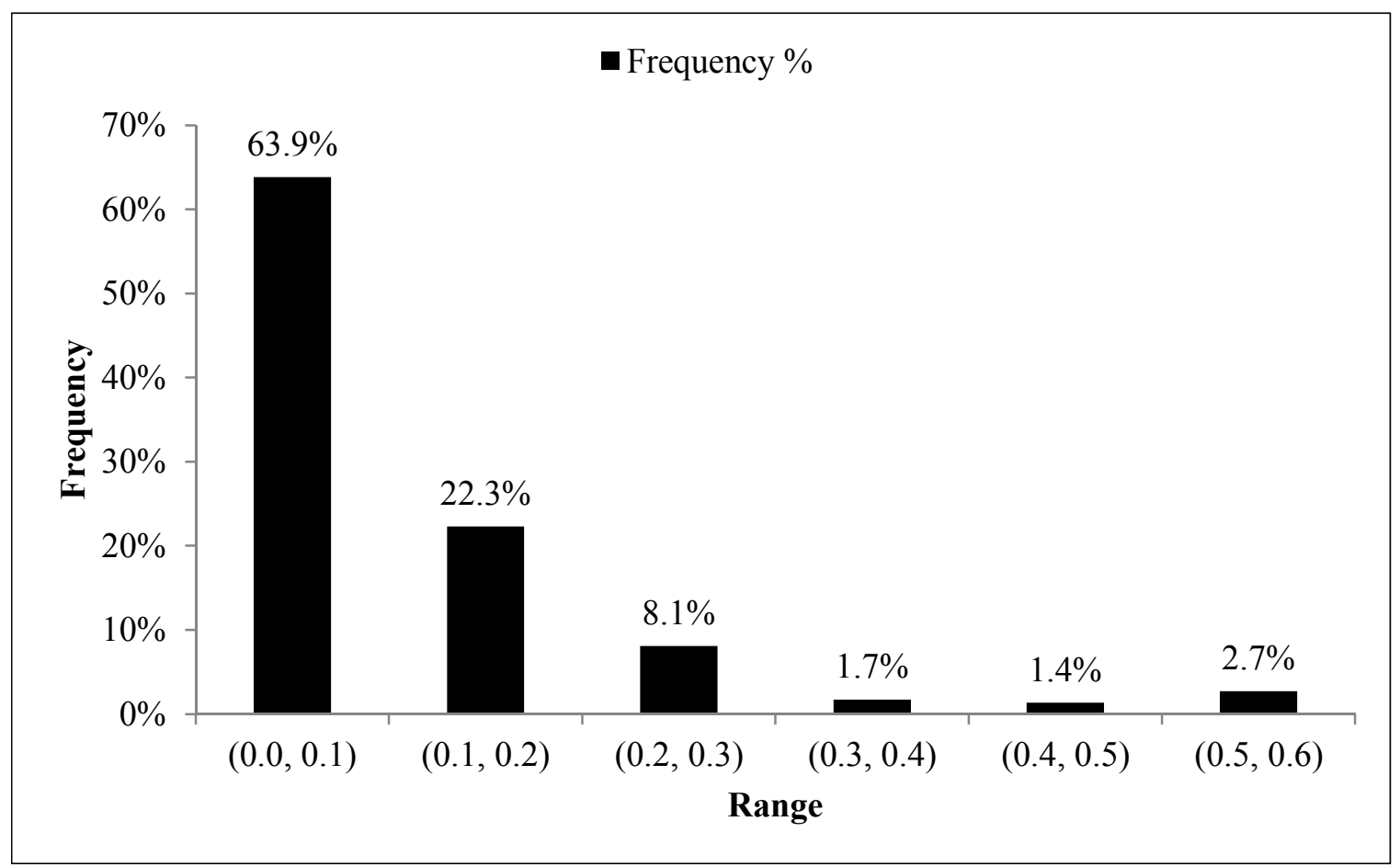

Figure 6-1: GWR Local R-Squared Histogram

The evaluation of the evacuation trip distance prediction model, based on the Hurricane Ivan evacuation survey data, the adjusted R-Squared, the local R-Squared, and the standard residual diagnostic results, shows a low to medium model performance. 
Therefore, the overall performance of the evacuation trip distance prediction model is low to moderate.

Since the GWR was used to develop the model, the model may also be affected by one of the parameters called bandwidth. The bandwidth is the key factor that determines the way in which the weighting schemes operate. This parameter may be defined manually or alternatively by some form of adaptive method. As a result, the evacuation trip distance prediction model performance may be impacted by the selection of bandwidth.

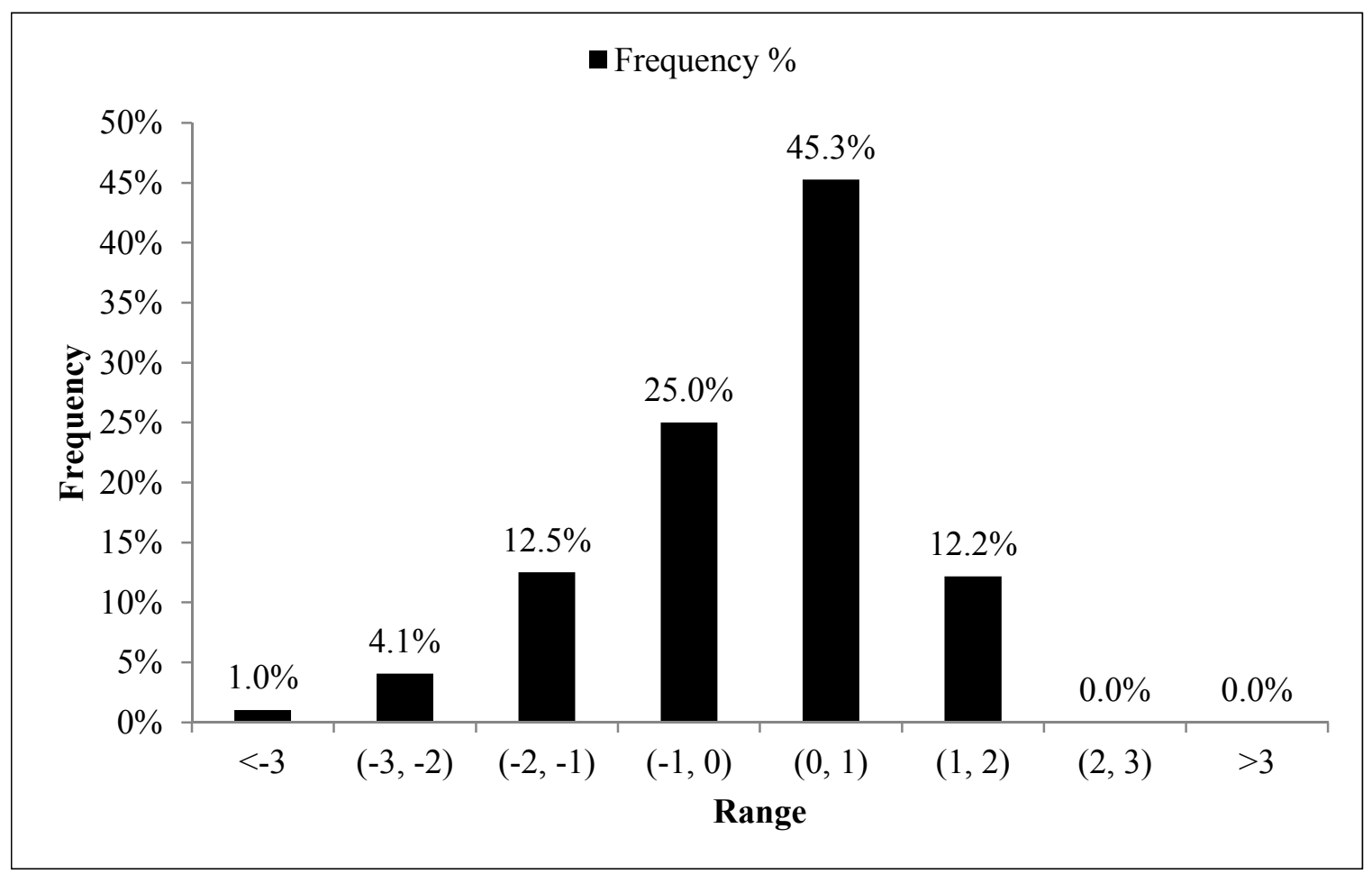

Figure 6-2: GWR Standard Residual Histogram

\subsection{Summary}

Three prediction models were evaluated by other hurricane evacuation survey data. The statistical diagnostic methods were also used to evaluate the models' 
performances. Each of the models was evaluated separately due to the different characteristics of each model. The evaluation results show that the percentages of the correct prediction average about $81.04 \%, 98.93 \%$, and $41.75 \%$ for the evacuation rate prediction model, evacuation trip prediction model, and evacuation trip distance prediction model, respectively. The statistical diagnostic results suggest that the evacuation rate prediction model and evacuation trip prediction model are significantly better than the corresponding empty model that only has the intercept, and the evacuation trip prediction model developed by the GWR is better than that developed by the OLS, where the spatial variations were identified. The statistical diagnostic results of the coefficients of the three models reveal that more than half of the coefficients are just or nearly statistically significant at the level of 0.05 , and the rest are not statistically significant. The p-values of the diagnostic statistics of the insignificant coefficients, however, are not far from 0.05 . The overall model performances are good for both the evacuation rate and trip prediction models, and low to moderate for the evacuation trip distance prediction model. 


\section{CHAPTER 7 CONCLUSIONS, LIMITATIONS AND RECOMMENDATIONS}

This dissertation has accomplished the following major research objectives: (1) performed a comprehensive literature search and review to investigate and assess hurricane evacuation practices in behavioral analysis, transportation planning, traffic operation, and applied technology; (2) studied the feasibility of the hurricane evacuation survey data as a potential source for developing the prediction models for predicting the daily trips for hurricane evacuation and the evacuation trip distance; (3) developed the prediction models to predict the number of trips generated on a given day during a hurricane evacuation by using logistic regression; and (4) developed a prediction model to predict the evacuation trip distance during a hurricane evacuation by using the Ordinary Least Square (OLS) and Geographically Weighted Regression (GWR).

The accomplished research tasks and major conclusions are stated in detail below. In addition, recommendations for future studies are also discussed.

\subsection{Summary and Conclusions}

The results and conclusions from each task described above are summarized as follows:

(1) Literature Review

A comprehensive literature search and review was performed to investigate and assess hurricane evacuation practices. The literature review showed that peoples' responses in a hurricane evacuation were affected by many factors, such as the socioeconomic status, demographic information, hurricane forecast information, etc. It 
was also found that transportation network planning was a critical part of the evacuation planning. The advancement of modeling technology helped improve the accuracy of hurricane evacuation models, and the emerging technology, like GWR, changed the way of regression analysis, compared to the traditional regression method.

\section{(2) Data Preparation}

The data used to develop the prediction models was extracted from the Hurricane Katrina evacuation survey. The original survey data contains a comprehensive list of items. For model evaluation, a second set of data that have similar items was extracted from the Hurricane Ivan evacuation survey. In addition, Hurricane forecast data were obtained from the National Hurricane Center.

In this dissertation, only the socio-economic and hurricane forecast data were used to develop the prediction models. The survey data were processed so that the new variables necessary were created and the invalid data were removed from the survey data. Two survey data sets were created since almost half of the variable "Education Level" are empty values. One data set has the education level data and the other does not.

\section{(3) Model Development}

Three prediction models were developed, as follows: the evacuation rate prediction model, evacuation trip prediction model, and evacuation trip distance prediction model. The evacuation rate prediction model and evacuation trip prediction model were used together to predict the number of evacuation daily trips. The methods used to develop the prediction models are binomial logistic regression, multinomial logistic regression, Ordinary Least Square (OLS), and Geographically Weighted Regression (GWR). 
The evacuation rate prediction model shows that the homeowners and the households with more people under age six are more likely to evacuate than the home renters and the households with less people under age six during a hurricane evacuation, respectively. The evacuation trip prediction model indicates that the probability of evacuation three days before hurricane landfall is in proportion to the number of people under age six in a household, the probability of evacuation one day before hurricane landfall is inverse proportion to the number of people under age six in a household, and the probability of evacuation two days before the hurricane landfall is not sensitive to the number of people under age six in the same household. The evacuation trip distance prediction model suggests that the evacuation distance of the households living along the forecasted hurricane track tends to be longer than that of the rest of the study area. The GWR was used to develop this model due to the existence of the spatial variations while modeling the evacuation distance.

The evacuation trip prediction model, along with the evacuation rate prediction model, can predict the number of trips generated three days, two days, and one day before hurricane landfall. The number of daily trips generated is important for transportation planners to plan the evacuation in a more efficient manner. The evacuation trip distance prediction model can predict the distance the evacuees travel during a hurricane evacuation. It can also model the spatial variations, for example, the varying influences of the predictor variables on the evacuation distance across the study area. This model can more accurately predict the evacuation distance. 


\section{(4) Model Evaluation}

The purpose of the model evaluation is to assess the validity and performance of the models developed. Three prediction models were evaluated by using other hurricane evacuation survey data and the statistical diagnostic methods. Each of the prediction models was evaluated separately since these models were developed by different statistical methods. The evaluation results show that the percentages of correct prediction are $81.04 \%, 98.93 \%$, and $41.75 \%$ for the evacuation rate prediction model, evacuation trip prediction model, and evacuation trip distance prediction model, respectively. The percentage of correct prediction of the evacuation rate prediction model is higher than the $65 \%$ from the logistic regression and neural network models (Wilmot and Mei, 2004) that were used to predict the participation rate during hurricane evacuation. The overall model performances are good for both the evacuation rate and trip prediction models, and low to moderate for the evacuation trip distance prediction model.

\subsection{Limitations and Recommendations}

The models discussed in this dissertation were developed by using the Hurricane Katrina Evacuation survey data. Hurricane Katrina made the landfall in southeast Louisiana. The City of New Orleans was pounded by Hurricane Katrina. The city is located in an area below sea level. It is protected by a levee. The households living in northern gulf coast can choose to evacuate inland. Those specific features could make

the models unique. Special care must be taken when applying the model to some other areas. For example, it may not be appropriate to apply the models developed to South Florida. The region is totally different from New Orleans in terms of elevations and 
choice of evacuation. Not only is South Florida above sea level, their residents have limited choices when evacuating from a hurricane since South Florida is located at the southern region of the Florida Peninsular. The whole Florida Peninsular may be within the potentially hurricane-impacted area.

There are limited hurricane evacuation survey data available for use in a hurricane evacuation analysis. In this dissertation, the Hurricane Ivan evacuation survey data was used to evaluate the prediction models that were developed. Since the path of Hurricane Ivan is east of the path of Hurricane Katrina, the two hurricanes are close to each other. The study areas for the two hurricanes are similar. If more hurricane evacuation survey data were available, it would be possible to use the survey data to either develop or evaluate the prediction models. More hurricane evacuation survey data would also improve the prediction models that were developed.

The Hurricane Katrina evacuation survey data contains the variable "Evacuation Day," which represents the day when households evacuated. In order to better understand when the evacuation starts on a certain day, it is recommended to introduce a variable called "Evacuation Time," which represents the time when evacuees left their homes. With the use of the variable "Evacuation Time," it may be possible to model the evacuation behaviors by the time of day. The time when the household evacuates varies on a certain day. Thus, the number of trips generated also varies during the time of day.

Regarding hurricane forecast data, it is recommended to include additional data into the hurricane evacuation survey data in order to identify how hurricane forecast data affects the households' behaviors in case of a hurricane strike. There are several types of hurricane forecast data that may be considered, such as wind speed and storm surge 
height. For example, storm surge height may mostly impact the residents living along the coast, while wind speed may impact residents living both along the coast and inland.

GWR was used to develop the evacuation trip distance prediction model to address the spatial variations found in the model developed OLS. It is recommended to incorporate the geographical weight to the evacuation rate and trip prediction models in order to address the potential spatial variations in these models for future studies. 


\section{REFERENCES}

Ali, K., M. D. Partridge, and M. R. Olfert. Can Geographically Weighted Regressions Improve Regional Analysis and Policy Making? International Regional Science Review, Vol. 30, No. 3, July 2007, pp. 300-329.

Arlikatti, S., M. K. Lindell, C. S. Prater, and Y. Zhang. Risk Area Accuracy and Hurricane Evacuation Expectations of Coastal Residents. Environment and Behavior, Vol. 38, No. 2, March 2006, pp. 226-247.

Atkinson, P. M., S. E. German, and D. A. Sear. Exploring the Relations Between Riverbank Erosion and Geomorphological Controls Using Geographically Weighted Logistic Regression, Geographical Analysis, Vol. 35, No. 1, January 2003, pp. 58-82

Baker, E. J. ,R. E. Deyle, S. C. Timothy, and J. Richardson. Are We Any Safer? Comprehensive Plan Impacts on Hurricane Evacuation and Shelter Demand in Florida. Coastal Management, Vol. 36, No. 3, 2008, pp. 294-317

Barrett, B., B. Ran, and R. Pillai. Developing a Dynamic Traffic Management Modeling Framework for Hurricane Evacuation. In Transportation Research Record: Journal of the Transportation Research Board, No. 1733, Transportation Research Board of the National Academies, Washington, DC, 2000, pp. 115-121.

Blake, E. S., E. A. Rappaport, ad C. W. Landsea. The Deadliest, Costliest, and Most Intense United States Tropical Cyclones from 1851 to 2006. NOAA Technical Memorandum NWS TPC-5, National Weather Service and National Hurricane Center, April 2007.

Boyd, E., ,B. Wolshon, and I. V. Hereden. Risk Communication and Public Response During Evacuations - The New Orleans Experience of Hurricane Katrina. Public Performance \& Management Review, Vol. 32, No. 3, March, 2009, pp. 437-462.

Brown, C., W. White, C. V. Slyke, and J. D. Benson. Development of a Strategic Hurricane Evacuation-Dynamic Traffic Assignment Model for the Houston, Texas, Region. In Transportation Research Record: Journal of the Transportation Research Board, No. 2137, Transportation Research Board of the National Academies, Washington, DC, 2009, pp. 46-53.

Brunsdon, C., A. S. Fotheringham, and M. Charlton. Geographically Weighted Regression as a Statistical Model. Proceedings of 40th Annual Meeting of the Western Regional Science Association, Palm Springs, California, 2001, pp. 25-28.

Brunsdon, C., A. S. Fotheringham, and M. Charlton. Geographically Weighted Regression-Modelling Spatial Non-Stationarity. The Statistician, Vol. 47, No. 3, 1998, pp. 431-443. 
Brunsdon, C., A. S. Fotheringham, and M. Charlton. Some Notes on Parametric Significance Tests for Geographically Weighted Regression. Journal of Regional Science, Vol. 39, No.3, 1999, pp. 497-524.

Burnside, R., D. S. Miller, and J. D. Rivera. The Impact of Information and Risk Perception on the Hurricane Evacuation Decision-Making of Greater New Orleans Residents. Sociological Spectrum, Vol. 27, No.6, November 2007, pp. 727-740.

Calvo , E. and M. Escolar. The Local Voter: A GeographicallyWeighted Approach to Ecological Inference. American Journal of Political Science, Vol. 47, No. 1, January 2003, pp. 189-204

Carpender S. K., P. H. Campbell, B. J. Quiram, J. Frances, and J. J. Artzberger. Urban Evacuations and Rural America: Lessons Learned from Hurricane Rita. Public Health Report, Vol. 121, No.6, 2006, pp. 775-779.

Chen, C. -C and C. -S. Chou. Modeling and Performance Assessment of a Transit-Based Evacuation Plan Within a Contraflow Simulation Environment. In Transportation Research Record: Journal of the Transportation Research Board, No. 2091, Transportation Research Board of the National Academies, Washington, DC, 2009, pp. 40-50.

Chen, X., J. W. Meaker and F. B. Zhan. Agent-Based Modeling and Analysis of Hurricane Evacuation Procedures for the Florida Keys. Natural Disater, Vol. 38, No. 3, January 2006, pp. 321-338

Chen, X.. Microsimulation of Hurricane Evacuation Strategies of Galveston. The Professional Geographer, Vol. 60, No. 2, January 2008, pp. 160-173

Cheng, G., C. G. Wilmot, and E. J. Baker. Destination Choice Model for Hurricane Evacuation. Presented at 87th Annual Meeting of the Transportation Research Board, Washington, D.C., 2008.

Chow, L. -F., F. Zhao, X. Liu, M. -T. Li, and I.. Ubaka. Transit Ridership Model Based on Geographically Weighted Regression. In Transportation Research Record: Journal of the Transportation Research Board, No. 1972, Transportation Research Board of the National Academies, Washington, DC, 2006, pp. 105-114.

Church, R. L. and R. M. Sexton. Modeling Small Area Evacuation: Can Existing Transportation Infrastructure Impede Public Safety? Final Report, Testbed Center for Interoperability Task Order 3021, California Department of Transportation, April, 2002. Clark, S. D. Estimating Car Ownership Using Geographically Weighted Regression. Journal of Traffic Engineering and Control, Vol. 45, No.11, January 2004, pp. 416-420. 
Corbley, K. P. Fleeing from Floyd - Internet GIS in the Eye of the Storm. Geo Info System, October 1999, pp. 28-35.

Corps of Engineers (COE). Alabama Hurricane Evacuation Study Technical Data Report: Behavioral Analysis. Final Report, 2001.

Corps of Engineers (COE). Hurricane Charley Behavioral Analysis. Final Report, 2005a.

Corps of Engineers (COE). Hurricane Frances Behavioral Analysis. Final Report, 2005 b. Corps of Engineers (COE). Hurricane Ivan Behavioral Analysis. Final Report, 2005c.

Corps of Engineers (COE). Hurricane Jeanne Behavioral Analysis. Final Report, 2005d.

Corps of Engineers (COE). Mississippi Hurricane Evacuation Study Technical Data Report: Behavioral Analysis. Final Report, 2002.

Dash, N. and H. Gladwin. Evacuation Decision Making and Behavioral Responses: Individual and Household. Natural Hazards Review, Vol. 8, No.3, August 2007, pp. 6977.

Dixit, V. V., A. Pande, E. Radwan, and M. Abdel-Aty. Understanding the Impact of a Recent Hurricane on Mobilization Time. In Transportation Research Record: Journal of the Transportation Research Board, No. 2041, Transportation Research Board of the National Academies, Washington, DC, 2008, pp. 49-57.

Dombroski, M. B. Fischhoff, and P. Fischbeck. Predicting Emergency Evacuation and Sheltering Behavior: A Structured Analytical Approach. Risk Analysis, Vol. 26, No. 6, December 2006, pp. 1675-1688

Dow, K., P. Burns, and S. L. Cutter To Stay or Leave: Residents' Evacuation of Hurricane Warnings. Proceedings of Applied Geography Conference, 1999, pp.107-114.

Dowab K. and S. L. Cutter. Crying Wolf: Repeat Responses to Hurricane Evacuation Orders. Coastal Management, Vol. 26, No. 4, 1998, pp. 237-252

$\mathrm{Du}, \mathrm{H}$. and C. Mulley, Transport accessibility and land value: a case study of Tyne and Wear, RICS Research Paper, Vol. 7, No. 3, London, United Kingdom, 2007.

Fotheringham, A. S., C. Brunsdon, and M. Charlton. Geographically Weighted Regression: The Analysis of Spatially Varying Relationships, Chichester: John Wiley \& Sons, Ltd., 2002.

Fu, H. and C. G. Wilmot. Sequential Logit Dynamic Travel Demand Model for Hurricane Evacuation. In Transportation Research Record: Journal of the Transportation Research 
Board, No. 1882, Transportation Research Board, Transportation Research Board of the National Academies, Washington, DC, 2004, pp.19-26.

Fu, H. and C. G. Wilmot. Survival Analysis-Based Dynamic Travel Demand Models for Hurricane Evacuation. In Transportation Research Record: Journal of the Transportation Research Board, No. 1974, Transportation Research Board of the National Academies, DC, 2006, pp. 211-218.

Fu, H. C. G. Wilmot, H. Zhang, and E. J. Baker. Modeling the Hurricane Evacuation Response Curve. In Transportation Research Record: Journal of the Transportation Research Board, No. 2022, Transportation Research Board, Transportation Research Board of the National Academies, Washington, DC, 2007, pp.94-102.

Hadayeghi, A., A. S. Shalaby, and B. N. Persaud. Macrolevel Accident Prediction Models for Evaluating Safety of Urban Transportation Systems. In Transportation Research Record: Journal of the Transportation Research Board, No. 1840, Transportation Research Board of the National Academies, Washington, DC, 2003, pp. $87-95$.

Hadayeghi, A., A. S. Shalaby, and B. N. Persaud. Development of Planning Level Transportation Safety Tools Using Geographically Weighted Poisson Regression. Accident Analysis and Prevention, Vol. 42, No. 2, 2010, pp. 676-688.

Hosmer, D. W. and S. Lemeshow. Applied Logistic Regression Second Edition. New York: John Wiley \& Sons, Inc., 2000.

Howell, S. E. and D. E. Bonner. Citizen Hurricane Evacuation Behavior in Southeastern Louisiana: A Twelve Parish Survey. Survey Research Center, University of New Orleans, July 2005.

Huang, Y. and Y. Leung. Analysing Regional Industrialisation in Jiangsu Province Using Geographically Weighted Regression. Journal of Geographical Systems, Vol. 4, No. 2, 2002, pp. 233-249.

Ibaugh, A. W. Hurricane Evacuation Analysis: A GIS-T Application. Proceedings of Urban and Regional Information Systems Association Conference, Salt Lake City, UT, 1996, pp. 133-141.

Kang, J. E., M. K. Lindell, and C. S. Prater. Hurricane Evacuation Expectations and Actual Behavior in Hurricane Lili. Journal of Applied Social Psychology, Vol. 37, No. 4, 2007, pp. 887-903.

Kar, B. and M. E. Hodgson. A GIS-Based Model to Determine Site Suitability of Emergency Evacuation Shelters. Transactions in GIS, Vol. 12, No. 2, 2008, pp. 227-248. 
Kiefer, J. J and R. S Montjoy. Incrementalism before the Storm: Network Performance for the Evacuation of New Orleans. Public Administration Review, Vol. 66, December, 2006, pp 122-130.

Lahmar, M., T. Assavapokee, and S. A. Ardekani. A Dynamic Transportation Planning Support System for Hurricane Evacuation. IEEE Intelligent Transportation System Conference, September 2006, pp. 612-617.

Legg, R. and T. Bowe. Applying Geographically Weighted Regression to a Real Estate Problem. ArcUser, Vol. 12, No.2, January 2009, pp.44-45.

Li, W. , C. A. Airriess, A. C. -C. Chen, K. J. Leong, and V. Keith Katrina and Migration: Evacuation and Return by African Americans and Vietnamese Americans in an Eastern New Orleans Suburb. The Professional Geographer, Vol. 62 No. 1, February 2010, pp. 103-118.

Lindell, M. K. and C. S. Prater. A Hurricane Evacuation Management Decision Support System (EMDSS). Natural Hazards, Vol. 40, No.3, March 2007, pp. 627-634.

Lindell, M. K., C. S. Prater, and W. G. Peacock. Organizational Communication and Decision Making for Hurricane Emergencies. Natural Hazards Review, Vol. 8, No.3, August, 2007, pp. 50-60.

Lindell, M. K., J. -C. Lu, and C. S. Prater. Household Decision Making and Evacuation in Response to Hurricane Lili. Natural Hazards Review, Vol. 6, No.4, November, 2005, pp. 171-179.

Litman, T. Lessons from Katrina and Rita: What Major Disasters Can Teach Transportation Planners. Journal of Transportation Engineering, Vol. 132, No.1, January 2006, pp. 11-18.

Liu, Y., N. Zou, and G. Chang. An Integrated Emergency Evacuation System for Realtime Operations - A Case Study of Ocean City, Maryland under Hurricane Attack. IEEE Intelligent Transportation System Conference, September 2005, pp. 281-285.

Massey, W. G. Modernized Hurricane Evacuation Studies - Taking the Traditional Hurricane Evacuation Study to a New Level. Proceedings of Solutions to Coastal Disasters 2008, 2008, pp. 860-866.

Morrow, R. B. Implementing ITS for Hurricane Evacuations in Florida. ITE Journal, Vol. 72, No. 4, April 2002, pp. 46-50.

Mountain, D.M., J. L. Y. Tsui, and J. F. Raper. Modelling Accessibility via Transportation Networks Based upon Previous Experience: A Geographically Weighted 
Regression Approach. Geocomputation 2007. National University of Ireland, Maynooth, Ireland, September 2007.

Mulley, C. and M. Tanner. The Vehicle Kilometres Travelled (VKT) by Private Car: A Spatial Analysis using Geographically Weighted Regression, Proceedings of the 32nd Australasian Transport Research Forum, Auckland, 2009.

National Hurricane Center (NHC). National Hurricane Center Forecast Verification. $<$ http://www.nhc.noaa.gov/verification/> Accessed March 18, 2008.

National Hurricane Study Program. Hurricane Preparedness Data. $<$ http://chps.sam.usace.army.mil/USHESdata/heshome.htm/> Accessed April 1, 2008.

Noh H., Y. -C. Chiu, H. Zheng, M. Hickman, and P. Mirchandani. Approach to Modeling Demand and Supply for a Short-Notice Evacuation. In Transportation Research Record: Journal of the Transportation Research Board, No. 2091, Transportation Research Board of the National Academies, Washington, DC, 2009, pp. 87-95.

Peacock, W. G. S. D. Brody, and W. Highfield. Hurricane Risk Perceptions Among Floridas Single Family Homeowners. Landscape and Urban Planning, Vol. 73, No. 2-3, October 2005, pp. 120-135

Petrolia, D. R. and S. Bhattacharjee. Why Don't Coastal Residents Choose to Evacuate for Hurricanes?. Coastal Management, Vol. 38, No. 2, February 2010, pp. 97-112

Post, Buckley, Schuh \& Jernigan, Inc. (PBS\&J). Hurricane Andrew Assessment - Florida Review of Hurricane Evacuation Studies Utilization and Information Dissemination, Florida Version, Tallahassee, FL, January 1993.

Post, Buckley, Schuh \& Jernigan, Inc. (PBS\&J). Hurricane Floyd Assessment Review of Hurricane Evacuation Studies Utilization and Information Dissemination, Tallahassee, FL, May 2000.

Renne, J. L. Evacuation and Equity: A Post-Katrina New Orleans Diary. Planning, Vol. 72, No.5, May. 2006, pp. 44-46.

Renne, J. L., T. W. Sanchez, and T. Litman. National Study on Carless and Special Needs Evacuation Planning: A Literature Review. Federal Transit Administration, October. 2008.

RMS. Hurricane Katrina Loss Estimate. $<$ http://www.rms.com/NewsPress/PR_090205_HUKatrina_insured_update.asp $>$ Accessed October 13, 2005. 
Rosenkoetter, M. M., E. K. Covan, B. K.Cobb, S. Bunting, and M. Weinrich. Perceptions of Older Adults Regarding Evacuation in the Event of a Natural Disaster. Public Health Nursing, No. 24, No.2, 2007, pp. 160-168.

Shekhar, S. and S. Kim. Contraflow Transportation Network Reconfiguration for Evacuation Route Planning. Final Report, Minnesota Department of Transportation Research Services Section, Minnesota, June 2006.

Smith, S. K. and C. McCarty. Fleeing the Storm(s): An Examination of Evacuation Behavior during Florida's 2004 Hurricane Season. Demography, Vol. 46, No. 1, February 2009, pp. 127-145.

Stein, R. M. L. Duenas-Osorio, and D. Subramanian. Who Evacuates When Hurricanes Approach? The Role of Risk, Information, and Location. Social Science Quarterly, Vol. 91, No. 3, September 2010, pp. 816-834.

Theodoulou, G. Contraflow Evacuation on The Westbound I-10 out of The City of New Orleans. Master Thesis, Department of Geography, Louisiana State University, 2001

Theodoulou, G. and B. Wolshon. Alternative Methods to Increase the effectiveness of Freeway Contraflow Evacuation. In Transportation Research Record: Journal of the Transportation Research Board, No. 1865, Transportation Research Board of the National Academies, Washington, DC, 2004, pp. 48-56.

Tuydes, H. and A. Ziliaskopoulos. Tabu-Based Heuristic Approach for Optimization of Network Evacuation Contraflow. In Transportation Research Record: Journal of the Transportation Research Board, No. 1964, Transportation Research Board of the National Academies, Washington, DC, 2006, pp. 157-168.

US Census Bureau. Census 2000 Public Use Microdata Area Maps. $<$ http://www.census.gov/geo/www/maps/puma5pct.htm> Accessed April 1, 2008.

Wegmann, S., and D. Fink. Mission Control: Houston Transtar Helps Execute an Orderly Evacuation from Hurricane Rita. Transportation Management + Engineering, April 2006, pp. 10-12.

Whitehead, J. C., B. Edwards, M. V. Willigen, J. R. Maiolo, and K. Wilson. Hurricane Evacuation Behavior: A Preliminary Comparison of Bonnie, Dennis, and Floyd. Department of Sociology and Department of Economics, East Carolina Univ., Greenville, $\mathrm{NC}$, May 2000a.

Whitehead, J. C., B. Edwards, M. V. Willigen, J. R. Maiolo, K. Wilson, and K. T. Smith. Heading for Higher Ground: Factors Affecting Real and Hypothetical Hurricane Evacuation Behavior. Environmental Hazards Vol. 2, No. 4, December 2000b, pp. 133142. 
Wilmot, C. G. and B. Mei. Comparison of Alternative Trip Generation Models for Hurricane Evacuation. Natural Hazard Review, Vol. 5, No. 4, November 2004, pp. 170178.

Wilmot, C. G. and N. Meduri. Methodology to Establish Hurricane Evacuation Zones. In Transportation Research Record: Journal of the Transportation Research Board, No. 1922, Transportation Research Board, Transportation Research Board of the National Academies, Washington, DC, 2005, pp.129-137.

Wolshon, B. Empirical Characterization of Mass Evacuation Traffic Flow. In Transportation Research Record: Journal of the Transportation Research Board, No. 2041, Transportation Research Board of the National Academies, Washington, DC, 2008, pp. $38-48$.

Wolshon, B. "Evacuation Planning and Engineering for Hurricane Katrina. The Bridge, Vol. 36, No. 1, March 2006, pp. 27-34.

Wolshon, B. "One-Way-Out": Contraflow Freeway Operation for Hurricane evacuation. Natural Hazards Review, Vol. 2, No. 3, August 2001, pp. 105-112.

Wolshon, B. Planning for the Evacuation of New Orleans. ITE Journal, Vol. 72, No. 2, February 2002, pp. 44-49.

Wolshon, B. NCHRP Synthesis of Highway Practice 392: Transportation's Role in Emergency Evacuation and Reentry. Transportation Research Board of the National Academies, Washington, D.C., 2009.

Wolshon, B., A. Catarella-Michel, and L. Lambert. Louisiana Highway Evacuation Plan for Hurricane Katrina: Proactive Management of a Regional Evacuation. Journal of Transportation Engineering, Vol. 132, No.1, January 2006, pp. 1-10.

Wolshon, B., E. Urbina, C. Wilmot, and M. Levitan. Review of Policies and Practices for Hurricane Evacuation I: Transportation Planning, Preparedness, and Response. Natural Hazards Review, Vol. 6, No.3, August 2005a, pp. 129-142.

Wolshon, B., E. Urbina, M. Levitan, and C. Wilmot. Review of Policies and Practices for Hurricane Evacuation II: Traffic Operations, Management, and Control. Natural Hazards Review, Vol. 6, No.3, August 2005b, pp. 143-161.

Wolshon, B. and L. Lambert NCHRP Synthesis of Highway Practice 340: Convertible Roadways and Lanes. Transportation Research Board of the National Academies, Washington, D.C., 2004.

Wolshon, B. and L. Lambert. Planning and Operational Practices for Reversible Roadways. ITE Journal, Vol. 76, No. 8, August 2006, pp. 38-43. 
Xie, F. and M. A. Turnquist. Integrated Evacuation Network Optimization and Emergency Vehicle Assignment. In Transportation Research Record: Journal of the Transportation Research Board, No. 2091, Transportation Research Board of the National Academies, Washington, DC, 2009, pp. 79-90.

Yamashita, K. Understanding Urban Fire: Modeling Fire Incidence Using Classical And Geographically Weighted Regression. Master Thesis, Department of Civil and Environmental Engineering, University of Colorado, 2008

Yu, D. Spatially Varying Development Mechanisms in the Greater Beijing Area: A Geographically Weighted Regression Investigation. Annals of Regional Science, Vol. 40, No. 1, 2006, pp. 173-190.

Yuan, F., L. D. Han, S. -M. Chin, and H. Hwang. Proposed Framework for Simultaneous Optimization of Evacuation Traffic Destination and Route Assignment. In Transportation Research Record: Journal of the Transportation Research Board, No. 1964, Transportation Research Board of the National Academies, Washington, DC, 2006, pp. $50-58$.

Zhao, F. and N. Park. Using Geographically Weighted Regression Models to Estimate Annual Average Daily Traffic. In Transportation Research Record: Journal of the Transportation Research Board, No. 1879, Transportation Research Board of the National Academies, Washington, DC, 2004, pp. 97-107.

Zhou, M., A. Korhonen, L. Malmi, I. Kosonen, and T. Luttinenand. Integration of Geographic Information System for Transportation with Real-Time Traffic Simulation System Application. In Transportation Research Record: Journal of the Transportation Research Board, No. 1972, Transportation Research Board of the National Academies, Washington, DC, 2006, pp. 78-84. 


\section{VITA}

\section{LIXIN HUANG}

June. 1968

Born, Beijing, China

EDUCATION

1987 - $1992 \quad$ B.S. in Civil Engineering

Beijing University of Technology,

Beijing, China

$1999-2000 \quad$ M.S. in Civil and Environmental Engineering

Florida International University

Miami, FL

$2002-2011$ Doctoral Candidate in Civil and Environmental Engineering

Florida International University

Miami, FL

\section{EMPLOYMENT}

$\begin{array}{ll}1992-1998 & \begin{array}{l}\text { Transportation Engineer } \\ \text { Research Institute of Highway Ministry of Transport } \\ \text { Beijing, China }\end{array} \\ 2000-2008 & \begin{array}{l}\text { Research Associate } \\ \text { International Hurricane Research Center } \\ \text { Florida International University } \\ \text { Miami, FL }\end{array} \\ 2008-2010 & \begin{array}{l}\text { GIS Professional/Transportation Engineering Analyst } \\ \text { Advanced Transportation Engineering Consultants } \\ \text { Miami, FL }\end{array} \\ & \begin{array}{l}\text { GIS Analyst III } \\ \text { Brevard County, Board of County Commissioners } \\ \text { Viera, FL }\end{array}\end{array}$

AFFILIATIONS

Member, Institute of Transportation Engineers (ITE), 2009 - 2010

Member, Urban and Regional Information Systems Association (URISA), 2009 - 2010 


\section{PUBLICATIONS AND PRESENTATIONS}

1. Huang, L. and Ma, L., "Using GIS to Identify High Crash Locations of Roadway Segments", Accepted for Publication at 2011 Esri China User Conference.

2. Huang, L., "Using GWR to Predict the Number of Crashes at Intersections", Accepted for Presentation at 2011 Esri International User Conference.

3. Huang, L., "Applying GIS in SR 5/Overseas Highway Right of Way Needs Assessment", Presented at 2010 Esri International User Conference, July 12-16, 2010 and Esri Survey and Engineering Summit, July 10-11, 2010.

4. Huang, L., "Using GIS to Analyze People's Behaviors in Hurricane Evacuation", Presented at 2009 Esri Southeast Regional User Group Conference, April 27-29, 2009. 